\title{
Malignant melanoma: genetics and therapeutics in the genomic era
}

\author{
Lynda Chin, ${ }^{1,2,3,6}$ Levi A. Garraway, ${ }^{1,3,4}$ and David E. Fisher ${ }^{1,4,5,7}$ \\ ${ }^{1}$ Melanoma Program, Dana-Farber Cancer Institute, Boston, Massachusetts 02115, USA; ${ }^{2}$ Department of Dermatology, \\ Harvard Medical School, Boston, Massachusetts 02115, USA; ${ }^{3}$ Department of Medical Oncology, Dana-Farber Cancer \\ Institute, Boston, Massachusetts 02115, USA; ${ }^{4}$ The Broad Institute of Harvard and Massachussetts Institute of Technology, \\ Cambridge, Massachusetts 02142, USA; ${ }^{5}$ Department of Pediatric Hematology/Oncology, Dana-Farber Cancer Institute and \\ Children's Hospital of Boston, Boston, Massachusetts 02115, USA
}

Cell for cell, probably no human cancer is as aggressive as melanoma. It is among a handful of cancers whose dimensions are reported in millimeters. Tumor thickness approaching $4 \mathrm{~mm}$ presents a high risk of metastasis, and a diagnosis of metastatic melanoma carries with it an abysmal median survival of 6-9 mo. What features of this malignancy account for such aggressive behavior? Is it the migratory history of its cell of origin or the programmed adaptation of its differentiated progeny to environmental stress, particularly ultraviolet radiation? While the answers to these questions are far from complete, major strides have been made in our understanding of the cellular, molecular, and genetic underpinnings of melanoma. More importantly, these discoveries carry profound implications for the development of therapies focused directly at the molecular engines driving melanoma, suggesting that we may have reached the brink of an unprecedented opportunity to translate basic science into clinical advances. In this review, we attempt to summarize our current understanding of the genetics and biology of this disease, drawing from expanding genomic information and lessons from development and genetically engineered mouse models. In addition, we look forward toward how these new insights will impact on therapeutic options for metastatic melanoma in the near future.

\section{The disease}

Melanomas most often arise within epidermal melanocytes of the skin, although they can also derive from noncutaneous melanocytes such as those lining the choroidal layer of the eye, GI and GU mucosal surfaces, or the meninges. Melanoma is also among the more common causes of "metastatic cancer of unknown primary," which may reflect either a propensity to arise in unex-

[Keywords: Development; genetics; genomics; melanoma; therapeutics] Corresponding authors.

${ }^{6}$ E-MAIL lynda chin@dfci.harvard.edu; FAX (617) 582-8169.

${ }^{7}$ E-MAIL david_fisher@dfci.harvard.edu; FAX (617) 632-2085.

Article is online at http://www.genesdev.org/cgi/doi/10.1101/gad.1437206. pected sites along the neural crest migratory route, or rapid growth of poorly differentiated lesions arising from indolent or unrecognized cutaneous primary lesions. Clinical staging for primary cutaneous melanoma employs measurements of thickness (in millimeters), presence of ulceration, penetration through cutaneous layers, mitotic rate, evidence of "in transit" metastasis, tumor spread to draining lymph nodes, and evidence of distant metastasis. Management issues in melanoma can be classified in terms of prevention, diagnosis, local disease management, and treatment of metastatic disease.

In view of the epidemiological and emerging experimental evidence linking melanoma incidence to UV exposure and skin phototype, prevention and screening strategies represent key areas for reduction of disease incidence and severity. For most cutaneous melanomas in the so-called radial growth phase (e.g., thin melanomas), surgical removal affords curative treatment. In contrast, a significant fraction of patients diagnosed with intermediate-thickness $(2-4 \mathrm{~mm})$ cutaneous melanoma eventually succumb to recurrence at regional or distant sites.

Critical biological questions facing the melanoma research community include: (1) What genetic and environmental factors contribute to and/or modulate risk of melanoma development in man? (2) What biological or molecular features (biomarkers) in early lesions can predict high risk of subsequent metastasis? (3) What genetic events underlie its propensity for metastasis and treatment resistance (phenotype)? (4) Which genetic alterations responsible for development and progression of melanoma are also essential for maintenance of established disease? (5) Finally, what maintenance-essential biological or molecular pathways/networks might prove amenable to preventive and/or therapeutic intervention in man?

The genetics of melanoma

Many studies conducted over several decades on benign and malignant melanocytic lesions as well as melanoma 
cell lines have implicated numerous genes in melanoma development and progression. In this review, we focus on validated genetic events, which include predisposing or somatic structural alterations in melanoma specimens on the DNA level, such as translocation, amplification/deletion, and point mutations (Futreal et al. 2004).

\section{CDKN2A, the familial melanoma locus}

Physical characteristics such as light complexion, an inability to tan, red hair, and blue eyes correlate with increased risk for melanoma development /Gilchrest et al. 1999|. Likewise, the presence of multiple pigmented lesions, including freckles and banal or clinically atypical moles, is associated with a quantitatively increased melanoma risk (Gandini et al. 2005a). However, one of the most significant risk factors for melanoma occurs in individuals with a strong family history of melanoma. Older case-control studies of patients with familial atypical mole-melanoma (FAMM) syndrome suggested an elevated risk of $\sim 434$ - to 1000 -fold over the general population (Greene et al. 1985). A more recent metaanalysis of family history found that the presence of at least one first-degree relative with melanoma increases the risk by 2.24-fold (Ford et al. 1995; Gandini et al. 2005b). Genetic studies of this heritable trait in large melanoma-prone families ultimately led to the initial identification of $C D K N 2 A$ as the familial melanoma gene. Located at chromosome $9 \mathrm{p} 21, \mathrm{LOH}$ or mutation at this locus cosegregated with melanoma susceptibility in familial melanoma kindred (Hussussian et al. 1994; Kamb et al. 1994b), and 9p21 homozygous deletions centered on CDKN2A were frequently observed in cancer cell lines of different types (Kamb et al. 1994a; Nobori et al. 1994). The CDKN2A story is one illustrative example of how rare inherited cancer syndromes can provide key insights into the genes and pathways relevant to malignant transformation of specific cell lineages in both familial and sporadic settings.

The genomic complexity of the 9p21 locus fueled considerable debate on the relative importance of the several overlapping proteins encoded therein. For example, a significant proportion of the $9 \mathrm{p} 21$ deletions also included the neighboring CDKN2B gene (for review, see Haluska and Hodi 1998; Ruas and Peters 1998). To confirm a causal role of CDKN2A loss in 9p21-mediated melanoma, a gene targeting approach was used to delete exons 2 and 3 of the Cdkn2a gene in the mouse germline (Serrano et al. 1996). These mice succumbed to fibrosarcomas and lymphomas with high frequency (Serrano et al. 1996) and became highly prone to cutaneous melanomas with short latency when combined with an activated $H$-RAS mutation in their melanocytes $\left(T y r-R A S^{+}\right)$ (Chin et al. 1997). Moreover, 100\% of melanomas that arose in Tyr-RAS $S^{+}$; Ink $4 a / A f^{+/-}$animals exhibited loss of heterozygosity ( $\mathrm{LOH}$ ) in the remaining wild-type allele (Chin et al. 1997). Specifically, exon 2 sequences were eliminated in all cases, the significance of which relates to the peculiar genomic organization of this gene that is unique in mammalian cells (human, mouse, opossum) (Sharpless et al. 2003; see below).

CDKN2A encodes two distinct proteins, INK4A and ARF, through utilization of alternative promoters and first exons ( $1 \alpha$ for INK4A and $1 \beta$ for $A R F$ ) (for review, see Chin 2003). The shared second exons of the two transcripts are translated in different reading frames, thus encoding two proteins with no amino acid homology yet each possessing potent anticancer activities. In particular, INK4A (also known as p16 ${ }^{\mathrm{INK} 4 \mathrm{a}}$ ) - the founding member of the INK4 (Inhibitor of cyclin-dependent kinase 4) family of proteins-inhibits the G1 cyclin-dependent kinases (CDKs) 4/6, which phosphorylate and inactivate the retinoblastoma protein $(\mathrm{RB})$, thereby allowing for S-phase entry (Serrano et al. 1993). Loss of INK4A function therefore promotes RB inactivation through hyperphosphorylation, resulting in unconstrained cell cycle progression. ARF-the alternative reading frame product of the locus (Quelle et al. 1995) (also known as p14 ${ }^{\mathrm{ARF}}$ in humans, or $\mathrm{p} 19^{\mathrm{ARF}}$ in mice)-inhibits MDM2mediated ubiquitination and subsequent degradation of p53 (Kamijo et al. 1998; Pomerantz et al. 1998; Stott et al. 1998; Zhang et al. 1998); thus, loss of ARF inactivates p53.

INK4A-CDK4/6-RB pathway In humans, germline intragenic mutations have been identified in familial melanoma kindred and melanoma-prone families that specifically inactivate INK4A while preserving ARF (e.g., exon $1 \alpha$ mutations) (Hussussian et al. 1994; Kamb et al. 1994b; FitzGerald et al. 1996). These findings provided the smoking gun fingering this protein as a bona fide melanoma suppressor (for review, see Chin 2003). In addition to the $25 \%-40 \%$ of melanoma-prone families and $0.2 \%-2 \%$ of sporadic melanoma patients harboring INK4A mutations in the coding region (Aitken et al. 1999; Tsao et al. 2000), polymorphism in both $5^{\prime}$ and $3^{\prime}$ untranslated regions (UTRs) that alter translation or possibly regulate message stability of INK4A as well as promoter and splicing mutations of INK4A have since been identified in association with 9p21-linked melanomaprone families (Liu et al. 1999; Kumar et al. 2001; for review, see Sharpless 2004). In line with this, mice with specific Ink4a inactivation did show increased susceptibility to carcinogen-induced and spontaneous melanoma (Krimpenfort et al. 2001; Sharpless et al. 2001); however, the phenotype observed was relatively weak. Consistent with this weak melanoma phenotype, it has recently been shown BRAF ${ }^{\mathrm{E} 600}$-induced senescence in nevus melanocytes is in part INK4A-independent, suggesting presence of another melanoma suppressor(s) that must be inactivated for unconstrained melanoma development (Michaloglou et al. 2005).

Germline mutations of CDK4, an Rb-kinase that is inhibited by INK4A, have also been identified in melanoma-prone kindreds (Wolfel et al. 1995; Zuo et al. 1996; Soufir et al. 1998; Tsao et al. 1998; Molven et al. 2005). These mutations, which are a rare cause of familial melanoma, target a conserved arginine residue (Arg24) and render the mutant protein insensitive to inhibition 
by the INK 4 class of cell cycle inhibitors. Melanomas from patients harboring these germline $C D K 4$ mutations do not demonstrate somatic INK4A inactivation, suggesting that INK4A inactivation and CDK4 activation are mutually exclusive. Accordingly, the mutant Cdk4 Arg24Cys (R24C) "knocked-in" mouse mirrored the human situation, in that it developed increased susceptibility to melanomas after carcinogen treatment, while lacking evidence of somatic Ink4a inactivation (Sotillo et al. 2001). Moreover, this R24C knockin mouse readily cooperates with activated HRAS in spontaneous and UVinduced melanoma genesis (Hacker et al. 2006). In line with these data in the mouse, somatic alteration of $C D K 4$, in form of focal amplification, is observed in sporadic melanomas in human (Muthusamy et al. 2006).

Finally, although less commonly associated with familial melanoma than with hereditary retinoblastoma, patients with germline inactivation of the retinoblastoma gene (RB1) are predisposed to melanoma (Draper et al. 1986; Sanders et al. 1989; Eng et al. 1993; Fletcher et al. 2004). In patients cured of bilateral retinoblastoma, the estimates of increased lifetime risk of melanoma range from fourfold to 80-fold (Eng et al. 1993; Fletcher et al. 2004). These melanomas do not necessarily occur in skin associated with radiotherapy treatment ports of the retinoblastoma, and likewise the excess incidence of melanoma in these cohorts has not been reduced by the practice of decreasing radiotherapy for retinoblastoma. In contrast, the lifetime risk of sarcoma in retinoblastoma survivors has markedly decreased in the setting of less primary treatment radiotherapy, suggesting that the bulk of sarcoma risk in these patients is treatment-related. Therefore, the increased risk of melanoma in patients who survive bilateral retinoblastoma appears to result from the stochastic loss of the remaining wildtype $R B 1$ allele in these patients. These data provide further evidence linking the entire $\mathrm{p} 16 / \mathrm{CDK} / \mathrm{RB}$ axis to melanoma suppression in human.

ARF-MDM2-P53 pathway Inactivation of the p53 pathway appears to be a rite of passage for virtually all tumor cells. While most human solid tumors inactivate this tumor suppression pathway at the level of p53 itself (e.g., within the TP53 coding region), melanoma provides a notable exception to this rule. Numerous surveys have found either rare or absent TP53 point mutations or allelic loss in surgical specimens from primary and metastatic melanomas (for review, see Chin 2003). Moreover, HMD2 amplification (encodes human ortholog of MDM2) occurs in only $3 \%-5 \%$ of human melanomas (Muthusamy et al. 2006), raising questions as to the pathogenetic relevance of the p53 pathway in melanoma. On the other hand, support for a role for p53 has been suggested by Mintz and colleagues, who showed that SV40 $\mathrm{T}$ antigen (which inactivates both RB and p53) generates a highly penetrant and aggressive melanoma phenotype (Bradl et al. 1991). More direct evidence for a role of p53 in melanoma suppression derived from Tyr-RAS $S^{+}$; Trp $53^{+/-}$mutant mice. These mice readily developed cutaneous melanomas characterized by $\mathrm{LOH}$ of the wild- type Trp53 allele and retention of Arf (Bardeesy et al. 2001), a mirror image to the molecular profile of the Tyr-RAS ; Ink4a/Arf ${ }^{-1}$ melanoma model, which retained wild-type p53 in all cases (Chin et al. 1997). These mouse genetic studies highlighted both the relevance of the p53 pathway in melanoma suppression and the reciprocal pattern of Arf-p53 inactivation, thereby suggesting their functional relatedness. Ultimately, elucidation of the role of ARF as a negative regulator of p53 (Kamijo et al. 1998; Pomerantz et al. 1998; Stott et al. 1998; Zhang et al. 1998) offered a mechanistic explanation for the patterns of genetic mutations in human disease, where the lack of p53 mutation in melanoma reflected preferred pathway inactivation at the level of ARF via 9p21 deletion.

A corollary to the above observation is that ARF represents an independent target of genetic inactivation at the $9 \mathrm{p} 21$ locus. Although insertions and deletions in $A R F$ exon $1 \beta$ without affecting INK4A or INK4B expression have been reported in melanoma cell lines (Kumar et al. 1998), the most convincing data on ARF as an independent melanoma suppressor came from two melanoma patients with germline ARF-specific mutations. One patient harbored a 14-kb deletion in exon $1 \beta$ sparing both INK4A and INK4B genes (Randerson-Moor et al. 2001), while the second patient had a 16-bp insertion in exon $1 \beta$ generating a frame-shifted ARF mutant defective in cell cycle arrest (Rizos et al. 2001). However, intact INK4A activity was not demonstrated in either case, precluding definitive assignment of INK4A-independent activity to ARF. In addition, in one case of a splice mutation of exon $1 \beta$ that was detected in a family of melanoma, inactivation of INK4A was acquired somatically in a melanoma from the family, pointing to the requirement for dual inactivation of these two genes (Hewitt et al. 2002). More recently, a cluster of five different germline mutations at the exon $1 \beta$ splice donor site was identified in melanoma pedigrees known to harbor no mutation in INK4A exons or in CDK4 exon 2 (INK4A-binding site) (Harland et al. 2005). These splice site variants were predicted to impair ARF activity, although their causal roles have not been functionally demonstrated. On the other hand, there is some evidence that point mutagenesis of shared exon 2 still preferentially targets the INK4A transcript. Previously, alterations in the shared exon 2 sequences were considered inactivating events for both INK4A and ARF, a notion that is being challenged by a recent survey, which examined reported exon 2 point mutations (both germline and somatic) and found a higher proportion of synonymous changes and a lower percentage of nonsense mutations in the $A R F$ reading frame when compared with the INK4A reading frame (Yang et al. 2005). In silico modeling of sequence variants that yield missense mutations in both reading frames further suggests that the impact of the codon change is more severe for INK4A than ARF (Yang et al. 2005).

Contrary to the equivocal situation in human, Arf is a potent tumor suppressor in vivo in the mouse. While Ink $4 a$ deficiency alone resulted in a modest tumor-prone phenotype (Krimpenfort et al. 2001; Sharpless et al. 2001, 
2002), this Ink4a-dependent susceptibility was significantly enhanced in the setting of Arf haploinsufficiency (Krimpenfort et al. 2001), arguing for an independent contribution from Arf in Ink4a/Arf-mediated melanoma suppression. Additionally, when crossed onto the melanoma-prone Tyr-RAS transgenic allele, either Ink $4 a$ or Arf deficiency facilitated enhanced melanoma formation, although Arf loss was more efficient than Ink4a (Sharpless et al. 2003). Moreover, the resultant melanomas showed reciprocal p53 or RB pathway inactivation. In other words, $\mathrm{Rb}$ pathway lesions were observed in melanomas from Tyr-RAS ${ }^{+}$; Arf ${ }^{-/-}$mice, and p53 pathway lesions were detected in Tyr- $R A S^{+}$; Ink $4 a^{-1-}$ melanomas (Sharpless et al. 2003). This profile provides unequivocal genetic evidence that both products of the Ink $4 a /$ Arf locus served prominent and synergistic/independent roles in melanoma suppression in vivo, which corroborated observation in humans (Hewitt et al. 2002). Moreover, this shared function may underlie the need for coordinated regulation imparted in part by their intimate and evolutionarily conserved genomic arrangement (Sharpless and DePinho 2004). This argument also explains another interesting feature of melanoma: the high frequency of 9p21 deletion as opposed to other mechanisms of INK4A loss such as promoter methylation or point mutation. These latter mechanisms only target INK4A, and are more common in tumors such as nonsmall-cell lung cancer, where direct p53 inactivation occurs. In summary, while INK4A is the preferred target of inactivation in the INK4A-CDK4-RB pathway, extensive biochemical and genetic data suggest an independent role for the ARF-p53 axis in melanoma suppression, with ARF as its preferred target via 9p21 deletion.

\section{Receptor tyrosine kinase (RTKs) activation}

A large body of evidence has implicated hyperactive RTK signaling in the development and progression of melanoma. Although most were based on expression alterations, several RTKs map to known regions of recurrent DNA copy number gain or amplification. Moreover, considering the example of c-Kit (see below), it is expected that systematic resequencing efforts will identify activating mutations in these and other RTKs in melanomas.

Late-stage melanomas often exhibit epidermal growth factor receptor (EGFR) overexpression in association with increased copies of chromosome 7 (Koprowski et al. 1985; Bastian et al. 1998; Udart et al. 2001). Enforced activation of EGFR has been associated in metastatic progression in cell-based study (de Wit et al. 1992; Huang et al. 1996b). However, unlike glioblastomas or lung adenocarcinoma (Maher et al. 2001; Sihto et al. 2005), focal amplification and/or mutation of EGFR has not been reported in melanoma. The nonfocal nature of chromosome 7 gains in melanoma renders it impossible to assign EGFR as a target of such genomic alterations. In an inducible HRAS-driven mouse melanoma model (Chin et al. 1999|, transcriptome analysis revealed the existence of a RAS-dependent EGFR signaling loop mediated through up-regulation of EGF family ligands (e.g., amphiregulin and epiregulin) (Bardeesy et al. 2005). This EGFR signaling pathway provides important survival signals involving PI3-K-dependent activation of AKT, as sustained EGFR activity is able to prolong viability of established melanoma upon inactivation of RAS. Conversely, inactivation by dominant-negative EGFR abolishes tumorigenicity of RAS-driven melanoma cells, consistent with observations in other cell systems (fibroblasts, keratinocytes, and intestinal epithelial cells) that autocrine EGFR signaling is required for transformation by activated RAS (Dlugosz et al. 1997; Gangarosa et al. 1997; Sibilia et al. 2000). Thus, in addition to providing experimental evidence that EGFR activation is biologically relevant, the abovementioned study in the inducible model also points out the possibility that EGFR or its ligands may constitute alternative point(s) of therapeutic intervention in RAS-activated melanoma. It should be mentioned that the contribution of EGFR signaling to melanoma development and possibly progression is evolutionarily conserved, as activating mutations in the EGFR homolog, Xmrk, increase melanoma susceptibility in Xiphophorus fish (Wittbrodt et al. 1992; Winnemoeller et al. 2005; Meierjohann et al. 2006; for review, see Bardeesy et al. 2000). It therefore remains possible that similar activating mutations exist in human melanoma, although systematic resequencing of large cohorts of melanomas from different ethnic and/or molecular subclasses will be required to uncover such examples.

The RTK c-MET is normally expressed on epithelial cells and melanocytes (Bottaro et al. 1991) and is activated by binding of its ligand, Hepatocyte growth factor/ scatter factor (HGF). Although MET is normally activated in a paracrine manner, autocrine activation of HGF-MET has been described in melanoma progression (Li et al. 2001; for review, see Vande Woude et al. 1997). Accordingly, increased c-MET expression has been observed in metastatic melanoma (Natali et al. 1993), and copy number gain of the c-MET locus at 7q33-qter seems to be a late event in melanoma progression (Wiltshire et al. 1995; Bastian et al. 1998). However, similar to EGFR above, neither focal MET amplifications nor activating MET point mutations have been detected in melanoma, although both have been observed in other human cancers (Jeffers et al. 1997; Schmidt et al. 1997; Kong-Beltran et al. 2006; Smolen et al. 2006). However, several lines of experimental and functional evidence support a causal role for MET signaling in human melanoma. For example, in explant models, it has been shown that elevated c-Met expression or Met RTK activity may correlate with metastasis (Rusciano et al. 1995). In genetically engineered models, constitutive and ubiquitous HGF expression establishes an autocrine loop with cMet, leading to stepwise development and progression of cutaneous and metastatic melanomas, which cooperates with UVB and Ink4a/Arf deficiency (Otsuka et al. 1998; Noonan et al. 2001; Recio et al. 2002). Correspondingly, while enforced expression of c-Met in melanocytes provides only weak cancer-initiating activity, this mutation 
drives the development of metastatic disease, and such tumor lesions show concomitant activation of HGF and establishment of HGF-Met signaling loop (L. Chin, unpubl.). Finally, c-MET was recently shown to be a direct transcriptional target of microphthalmia-associated transcription factor (MITF) (McGill et al. 2006), the melanocytic lineage transcription factor that can be activated by focal amplification in melanoma (see below).

The c-Kit gene encodes a RTK that serves as the receptor for Stem Cell Factor (SCF). Numerous immunohistochemical studies have linked progressive loss of cKIT expression with the transition from benign to primary and metastatic melanomas (Montone et al. 1997; Shen et al. 2003; Isabel Zhu and Fitzpatrick 2006). Reconstitution of c-Kit in metastatic melanoma cells apparently conferred sensitivity to SCF-induced apoptosis in vitro (Huang et al. 1996a). Thus, at first glance, Kit does not fit the profile of a RTK targeted for activation in melanoma. However, a recurrent L576P mutation in cKit has recently been reported in melanoma. Among 153 cases examined, Holden and colleagues identified four metastatic melanomas with robust expression of c-KIT on IHC. High-resolution amplicon melting analyses followed by direct DNA sequencing revealed that three of them harbored a L576P mutation with selective loss of the normal allele (Willmore-Payne et al. 2005, 2006). L576P is a known GIST-associated mutation that maps to the $5^{\prime}$ juxtamembrane domain where most activating KIT mutations cluster (Nakahara et al. 1998; Fukuda et al. 2001). Although likely representing an uncommon path to melanoma, the example of EGFR mutational status as a predictor for therapeutic responses in NSCLC (Lynch et al. 2004; Paez et al. 2004) suggests the possibility of identifying a melanoma patient subpopulation that will respond to imatinib based on c-Kit mutational status.

\section{RAS and RAF, activators of mitogen-activated protein (MAP) kinase signaling}

Considering the prominent roles of RTKs in transmitting extracellular signals to intracellular effectors, and the importance of homotypic and heterotypic cell-cell interactions in cancers, it is not surprising that almost all of the direct signaling components of RTKs have been implicated in human melanoma. One of the major signaling mediators of RTK is the MAP kinase pathway (ERK1/2), which has been most directly linked to its growth-promoting activities. Since self-sufficiency in growth signaling is a requisite capability acquired by all cancer cells (Hanahan and Weinberg 2000), hyperactive ERKs are common in many human cancers, including melanoma (Takata et al. 2005; Zhuang et al. 2005). Such a hyperactive state can theoretically be achieved by activating mutations of any signaling mediators upstream of ERKs, but there are clear tumor-type-specific patterns of mutational activation. RAS is perhaps the most frequently activated component of this signaling cascade in human cancer with a reported incidence of $15 \%-30 \%$ of all cases (Bos 1989), and in some cancer types, such as
KRAS in pancreas cancer, its mutation rate approaches $100 \%$ (Hezel et al. 2006). BRAF is also commonly targeted in human cancers with an overall occurrence of $7 \%$ (Davies et al. 2002), although it is notable that the mutation frequency approaches $70 \%$ in metastatic melanoma (Maldonado et al. 2003; Pollock et al. 2003; Uribe et al. 2003; Daniotti et al. 2004; Kumar et al. 2004; Shinozaki et al. 2004; Libra et al. 2005). However, while classically considered primarily mitogenic, ERK activation can also regulate differentiation, senescence, and survival. For instance, activated ERK protein kinases can phosphorylate enzymes that regulate metabolism, or cytoskeletal proteins that regulate cell shape and migration. In the nucleus, ERK can regulate gene expression by phosphorylating transcription factors such as ETS1/2 (Paumelle et al. 2002), or other protein kinases such as S6 Kinase (Crews et al. 1991). Therefore, genotype-phenotype correlation must take into account consequences other than growth promotion by activating mutations in components of ERK signaling.

The RAS family of proto-oncogenes: $H$-RAS, N-RAS, and $K-R A S$ In contrast to other solid tumors, activating mutations of $R A S$ proto-oncogenes are not detected with high frequency in melanoma, ranging from low to $10 \%-$ $15 \%$ incidence, with the highest frequencies detected in the amelanotic nodular subtype (for review, see Chin et al. 1998). N-RAS is the most frequent RAS family member targeted in the melanocyte lineage, with activating mutations in as many as $56 \%$ of congenital nevi (Papp et al. 1999 |, $33 \%$ of primary and $26 \%$ of metastatic melanoma samples (Demunter et al. 2001). Activating N-RAS mutations have been correlated with nodular lesions and sun exposure (Jafari et al. 1995; van Elsas et al. 1996). Interestingly, $N$-RAS mutations are rarely found in dysplastic nevi (Albino et al. 1989; Jafari et al. 1995; Papp et al. 1999), which may imply their distinct evolutionary path to melanoma. H-RAS activation has occasionally been detected in melanoma, albeit more commonly associated with Spitz nevi, based on amplification of its genomic locus on $11 \mathrm{p}$ and oncogenic point mutations (Bastian et al. 2000). K-RAS mutations have not been described in human melanocytic lesions. These mutation patterns point to distinct biological activities of the different RAS family members in melanocyte biology. The phenotypic impact of activated H-RAS versus N-RAS transgenic mice has reinforced this view. Specifically, an activated $H-R A S$ transgene, together with inactivating mutations in Ink4a, Arf, and/or p53 promotes development of nonmetastatic melanomas (Chin et al. 1997; Bardeesy et al. 2001; Sharpless et al. 2003). In contrast, when targeted to the melanocytic compartment, an activated $N$-RAS transgene and Ink4a/Arf deficiency drive cutaneous melanomas with high penetrance and short latency, as well as metastatic spread to lymph nodes and other distal sites (e.g., lung and liver) in a third of the cases (Ackermann et al. 2005).

$B R A F$, a potent activator of ERK protein kinases Activating BRAF mutations are the most prevalent somatic 
genetic event in human melanoma. Since its discovery through a genome-wide cancer resequencing effort (Davies et al. 2002), mutations in BRAF have been detected in a variety of tumor types, with the highest incidence in melanoma (ranging from $27 \%$ to $70 \%$ ) (Maldonado et al. 2003; Pollock et al. 2003; Uribe et al. 2003; Daniotti et al. 2004; Kumar et al. 2004; Shinozaki et al. 2004; Libra et al. 2005), followed by papillary thyroid tumors, colorectal cancers, and ovarian cancers (Ciampi and Nikiforov 2005; Young et al. 2005). These point mutations clustered in specific regions of biochemical importance, with the predominant melanoma mutation being a single phosphomimetic substitution in the kinase activation domain (V600E), which confers constitutive activation (Garnett and Marais 2004). The biology and detailed characterization of the RAF family in human cancers and in melanoma have been discussed in detail in several other reviews (Garnett and Marais 2004; Gray-Schopfer et al. 2005).

BRAF does not appear to be an inherited cancer predisposition gene (Laud et al. 2003; Casula et al. 2004; Jackson et al. 2005; Kelemen et al. 2005; Xing 2005), as individuals with germline mutations develop instead cardio-facio-cutaneous syndrome, which is not associated with increased cancer risk (Niihori et al. 2006; Rodriguez-Viciana et al. 2006). The high prevalence of BRAF mutations in cutaneous melanoma and the known epidemiological link between UV and melanoma has prompted speculation that the $\mathrm{BRAF}^{\mathrm{V} 600 \mathrm{E}}$ mutation is induced by UV damage. Arguing against this supposition is the fact that the $\mathrm{T} \rightarrow \mathrm{A}$ transversion that converts the valine to glutamic acid at amino acid 600 (V600E) is not classically associated with UV-induced damage (DayaGrosjean et al. 1995). However, the cutaneous distribution of melanomas harboring this $\mathrm{BRAF}^{\mathrm{V} 600 \mathrm{E}}$ mutation suggests a complex yet undefined relationship with UV exposure. Specifically, BRAF mutations are common $(59 \%)$ in melanomas arising in skin with intermittent sun exposure, such as trunk and arms, compared with only $23 \%$ of the acral melanomas and $11 \%$ of mucosal melanomas harboring BRAF mutations (Maldonado et al. 2003; Edwards et al. 2004; Curtin et al. 2005), but are absent in uveal melanoma (Cohen et al. 2003; Cruz et al. 2003; Edmunds et al. 2003; Rimoldi et al. 2003; Weber et al. 2003). A clear understanding of the UV-BRAF link is further complicated by the observation that melanomas from chronically sun-exposed areas (defined by histopathological evidence of chronic sun damage) possess only an $11 \%$ frequency of $\mathrm{BRAF}^{\mathrm{V} 600 \mathrm{E}}$ mutation (Maldonado et al. 2003; Edwards et al. 2004; Curtin et al. 2005). Together, these contrasting observations highlight the uncertainties surrounding the molecular factors driving BRAF mutation, in particular, the role of sun exposure.

$B-R A F$ mutations are also common in benign and dysplastic nevi (Pollock et al. 2003; Yazdi et al. 2003; Kumar et al. 2004; Saldanha et al. 2004), suggesting a role in the earliest stages of neoplasia. It is notable that nevi are considered growth-arrested and only rarely progress into melanoma, raising the possibility of $\mathrm{BRAF}^{\mathrm{V} 600 \mathrm{E}}$-induced checkpoint mechanisms operating to constrain malignant transformation. Indeed, a recent study showed that human congenital nevi are invariably positive for senescence-associated acidic $\beta$-galactosidase (SA- $\beta$-Gal), the classical senescence-associated marker (Michaloglou et al. 2005). In vitro, BRAF ${ }^{\mathrm{V} 600 \mathrm{E}}$ expression in human melanocytes has been shown to induce cell cycle arrest, with concomitant induction of both INK4A and SA- $\beta$ Gal, as well as methylation of Lys 9 of histone $\mathrm{H} 3$ on senescence-associated heterochromatic foci (SAHF). Thus, this study, along with others, provided evidence that oncogene-induced senescence (OIS) is an in vivo phenomenon functioning to constrain progression of early premalignant lesions (Sharpless and DePinho 2005). Intriguingly, expression of INK4A is not in $100 \%$ concordance with SA- $\beta$-Gal positivity, suggesting presence of a non-INK4A-dependent pathway in mediating BRAF-induced OIS (Michaloglou et al. 2005). It seems probable that the identification of this pathway would lead to the discovery of a tumor suppressor whose importance in melanoma rivals that of INK4A.

The notion that BRAF ${ }^{\mathrm{V} 600 \mathrm{E}}$ is not sufficient for transformation of melanocytes has also been demonstrated in other model systems. In zebrafish, it has been shown that BRAF activation leads only to development of benign nevi, while progression to frank melanoma requires cooperation of p53 deficiency (Patton et al. 2005). Similarly, BRAF ${ }^{\mathrm{V} 600 \mathrm{E}}$ mutation alone in TERT-immortalized RB-p53 mutant human melanocytes was found to produce only junctional nevi in the human/mouse skin graft, in contrast to activated NRAS or PI3K p110a mutants, which generated invasive melanoma lesions (Chudnovsky et al. 2005). While these biological outcomes indicate distinct roles for NRAS and BRAF activation in melanoma genesis, some functional overlap is suggested by the predominantly nonconcurrent occurrence of activated NRAS and $B-R A F$ alleles in melanoma and other tumor types (Davies et al. 2002; Rajagopalan et al. 2002; Goel et al. 2006). The single and compound mutant mouse models will prove useful in dissecting the common and distinct roles of activated NRAS and BRAF signaling in vivo in the melanocytic lineage.

\section{PTEN, negative regulator of phosphatidylinositol 3-kinase (PI3K)-AKT pathway}

The PI3 kinase-AKT pathway is often hyperactive in melanoma. Integrins and growth factors (such as HGF and IGF-1) promote melanoma cell growth and survival via PI3 kinase/AKT activation in vivo (Meier et al. 2005; Robertson 2005). In addition, elevated phospho-AKT levels appear to correlate adversely with patient survival (Dai et al. 2005). Taken together, these observations suggest the strong biological importance of PI3 kinase signaling in this disease. However, unlike the MAP kinase pathway, genetic alterations specifically targeting components of this signaling cascade do not occur at high frequency in melanoma. Of those that do occur, the best known culprit is the PTEN tumor suppressor.

PTEN encodes a lipid and protein phosphatase that 
resides on chromosome $10 \mathrm{q}$, a region known to sustain LOH in many human cancers, including melanoma (Bastian 2003; Wu et al. 2003). This protein regulates extracellular growth signals that use the lipid phosphatidylinositol phosphate $\left(\mathrm{PIP}_{3}\right)$ as an intracellular second messenger. In the presence of growth factor signaling, the intracellular level of $\mathrm{PIP}_{3}$ rises, leading to phosphorylation of AKT, which is known to promote cell cycle progression and inhibit apoptosis. PTEN regulates $\mathrm{PIP}_{3}$ levels, and its inactivation results in accumulation of $\mathrm{PIP}_{3}$, AKT hyperphosphorylation, and enhanced cell survival/ proliferation. In melanoma, allelic loss or altered expression of PTEN comprises $20 \%$ and $40 \%$ of melanoma tumors, respectively (Pollock et al. 2002; Mikhail et al. 2005; Slipicevic et al. 2005; Goel et al. 2006), although somatic point mutations and homozygous deletions are rarely observed. Functionally, ectopic expression of PTEN in PTEN-deficient melanoma cells can abolish phospho-AKT activity, induce apoptosis, and suppress growth, tumorigenicity, and metastasis (Robertson et al. 1998; Stewart et al. 2002; Stahl et al. 2003; for review, see Robertson 2005). Correspondingly, germline or somatic inactivation of Pten in the mouse strongly promotes tumor phenotypes in multiple cell lineages (Di Cristofano et al. 1998; Stambolic et al. 1998; Podsypanina et al. 1999; Ma et al. 2005), including melanoma (You et al. 2002).

In line with the experimental evidence supporting a melanoma-suppressive role of PTEN, constitutive activation of AKT has been shown to be a potent oncogenic lesion for melanocyte transformation (Chudnovsky et al. 2005). In addition, DNA copy gain involving the AKT3 locus has recently been described in melanoma, and selective AKT3 activation may characterize $40 \%-60 \%$ of sporadic tumors (Stahl et al. 2004). However, the complexity of this signaling cascade has not been fully understood. Recent data have suggested that activation of different AKT isotypes may elicit distinct effects on cell proliferation and survival. For example, one report found that AKT3 correlated most strongly with melanoma tumor progression among the three AKT isotypes, as described above; and that targeted AKT3 depletion triggered apoptotic signaling (Stahl et al. 2004). On the other hand, AKT1 activation was found to inhibit the migration and invasion of certain cancer cell lines (YoeliLerner et al. 2005), including MDA-MB435, a line previously believed to derive from breast cancer but subsequently shown through transcriptional and SNP array profiling studies to be a melanoma cell line (Ross et al. 2000; Garraway et al. 2005). Thus, although the PI3 kinase/AKT pathway clearly demonstrates enhanced activity in many melanomas, the extent to which this constitutes a critical melanoma dependency remains unresolved.

Lastly, although PTEN is a bona fide tumor suppressor of 10q24, the existence of additional melanoma suppressors has been inferred by the observation that many more human melanomas with $10 \mathrm{q} \mathrm{LOH}$ exist than do those with PTEN-specific homozygous/hemizygous loss or mutation, and that reintroduction of PTEN into such melanoma cells seems to have no growth-suppressive effect (Robertson et al. 1998). The Myc antagonist, MXI1, is a candidate for this, as $M y c$ is amplified or overexpressed in RAS-induced Trp53-deficient melanomas in mouse (Bardeesy et al. 2001); however, a role for Mxil in melanoma genesis in mice and humans has not been rigorously evaluated.

\section{The genomics of melanoma}

Beyond these characterized signature pathway alterations, genomic profiling of human melanoma has revealed a highly rearranged melanoma genome, attesting to underlying molecular heterogeneity of this disease. Mining of such heterogeneity represents an active area of investigation, as it is widely assumed that embedded within this complexity are clues to disease pathogenesis, clinical behavior, and possibly response to therapy. In addition, high-resolution characterization has revealed the existence of many recurrent nonrandom amplification and deletions with as yet no obvious or validated targets, potentially representing many yet-to-be-discovered melanoma-relevant genes. That these genomic events serve as productive entry points for discovery of melanoma genes is exemplified by discovery of MITF (see below). However, the high level of complexity inherent in the melanoma genome also brings into focus a critical need for biological systems capable of prioritizing in-depth validation efforts as illustrated in the case of NEDD9 (see below).

\section{Genomic heterogeneity of melanoma}

The underlying molecular heterogeneity of human melanoma has long been apparent on clinical grounds. For example, melanomas arising at different sites of the body may exhibit markedly distinct biological and clinical behaviors. Lentigo maligna melanomas are indolent tumors that develop over decades on chronically sun-exposed area such as the face. In contrast, acral lentigenous melanomas, which develop on sun-protected regions, tend to be more aggressive. "Thick" and "thin" primary melanomas provide additional examples: Although thick lesions have a much higher risk for metastasis than do their thinner counterparts, there is a subset of thin cutaneous melanoma that metastasizes early (Gimotty et al. 2005), suggesting inherent differences within this subset.

Recent advances in genome-wide technologies enable systematic documentation of tumor heterogeneity at high resolution, opening doors to better stratification and, ultimately, improved management of melanoma patients. Transcription profiling studies have provided evidence for distinct molecular subclasses of melanoma (Bittner et al. 2000; Segal et al. 2003; Tschentscher et al. 2003; Onken et al. 2004; Haqq et al. 2005). At the genomic DNA level, the nonrandom nature of the chromosomal alterations characteristic of melanoma likely also dictates disease behavior; thus, patterns of alterations 
detectable at either the DNA or RNA level may segregate melanoma tumors into subtypes with distinct clinical behaviors and possibly therapeutic responses. Indeed, a recent genome-wide CGH profiling and targeted resequencing study on 126 primary melanomas showed that distinctive patterns of genomic alterations, including $B R A F$ and NRAS mutation frequencies, can be identified in melanoma arising in different anatomic sites and with varying UV exposure histories (acral, mucosal, or with and without chronic sun damage) (Curtin et al. 2005). Similar genetic and biological heterogeneity characterized metastatic melanomas. High-resolution CGH studies of $>80$ metastatic melanomas found that metastatic tumors can be separated into three distinct classes by unsupervised classification. Such subdivision does not correlate with sites of metastasis; rather, these classes are determined primarily by patterns of chromosomal aberrations. When intersected with clinical outcome, one of the three classes showed a more significant survival advantage than the other two (L. Chin, unpubl.), suggesting that these DNA-based classes of metastatic melanomas may prove biologically pertinent.

\section{The melanoma gene atlas}

Beyond the characteristics described above, the melanoma genome also possesses numerous recurrent nonrandom chromosomal rearrangements indicative of the existence of many additional genetic elements governing disease genesis and progression. Whole-genome screening technologies such as spectral karyotype analysis and array-CGH have identified many recurrent nonrandom chromosomal structural alterations, particularly in chromosomes 1, 6, 7, 9, 10, and 11 (Bastian et al. 1998; Curtin et al. 2005; Garraway et al. 2005); however, in most cases, no known or validated targets have been linked to these alterations. Thus, there exists significant opportunity to discover novel melanoma genes and translate such discoveries into meaningful clinical endpoints.

In a systematic high-resolution genomic analysis of melanocytic genomes, array-CGH profiles of 120 melanocytic lesions, including 32 melanoma cell lines, 10 benign melanocytic nevi, and 78 melanomas (primary and metastatic) have revealed a level of genomic complexity not previously appreciated. In total, 435 distinct copy number aberrations (CNAs) were defined among the metastatic lesions, including 163 recurrent, high-amplitude events. These include all previously described large and focal events (e.g., 1q gain, 6p gain/6q loss, 7 gain, $9 \mathrm{p}$ loss, and 10 loss). Not surprisingly, compared with the metastatic tumors, the degree of genomic instability (as reflected by number of CNAs) evident in primary melanomas and benign nevi is significantly diminished (Fig. 1). These types of primary versus metastatic comparisons provide an effective biological filter for progression-related events, thereby enriching for genetic events that constitute likely drivers of metastasis. Such comparative approaches should provide robust future grounds for melanoma gene discovery, as primary melanomas are largely curable with surgical resection, while metastatic disease is near universally fatal.

\section{MITF, a melanoma oncogene targeted by amplification}

The promise of DNA-based structural alterations as the entry point for gene discovery has been illustrated by the recent identification of MITF as a melanoma oncogene. The discovery of MITF amplification in melanoma derived from an integrated analysis of genomic copy gains and losses, together with sample-matched mRNA expression data (Garraway et al. 2005). When clustering algorithms were applied to SNP array-derived chromosomal copy number data generated for the NCI-60 cancer cell line collection, some of these cell lines aggregated according to tissue of origin, including several melanoma cell lines. The bidimensionality of the hierarchical algorithm also enabled the identification of chromosomal alterations driving these lineage-restricted clustering patterns, and suggested that lineage-specific cancer genes might reside within the genomic regions implicated. For the melanoma cell lines, the common genomic alteration was a region of copy gain at chromosome 3p14-3p13. To facilitate the identification of an oncogene targeted by this amplification event, the NCI60 collection was partitioned based on the presence or absence of copy gain at the relevant chromosome $3 \mathrm{p}$ locus (Garraway et al. 2005). This partitioning served as a
Figure 1. The genomes of benign and malignant melanocytic lesions. Genome-wide profiles of representative benign nevus, primary, and metastatic melanoma showing increasing genomic complexity.

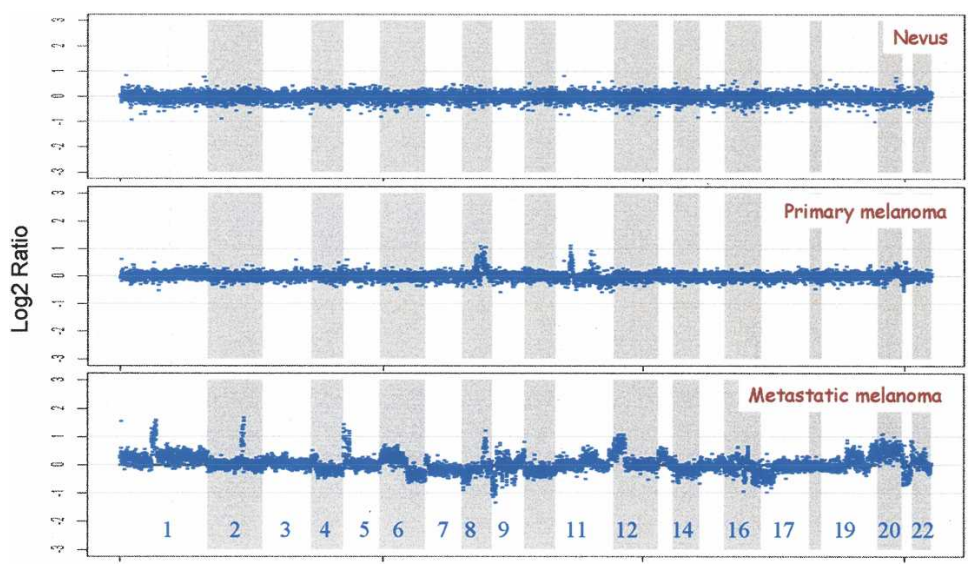


two-class distinction that drove a supervised analysis of sample-matched gene expression data. Although the gene expression signature that emerged was dominated by melanocyte lineage genes (as expected given that only melanoma cell lines comprised the 3 p-amplified class), $M I T F$ was the only gene showing significantly increased expression in association with the 3 p-amplified melanoma cell lines that also mapped to the common region of $3 \mathrm{p}$ copy gain.

MITF amplification was subsequently detected in $10 \%$ of primary cutaneous and $15 \%-20 \%$ of metastatic melanomas. Although the majority of amplifications were low level (e.g., four to six copies per cell), high-level amplicons were also observed, including one sample that exhibited $>100$ copies per diploid genome. A KaplanMeier analysis performed on metastatic melanomas suggested that MITF amplification in this setting correlated with adverse 5-yr patient survival. Finally, ectopic MITF overexpression complemented $\mathrm{BRAF}^{\mathrm{V} 600 \mathrm{E}}$ in conferring soft agar colony growth to immortalized melanocytes engineered to express TERT, and to lack the pRB and p53 pathways. These functional studies thereby suggested a genetic context that might characterize a subset of human melanomas whose survival is dependent on MITF (Garraway et al. 2005). MITF also exemplifies a newly recognized "lineage survival" oncogenic mechanism (Garraway and Sellers 2006a,b), wherein tumor genetic alterations may target survival functions also operant in the relevant cellular lineages during development and differentiation. Thus, while the discovery of MITF amplification began as a systematic genomics-based survey of many human cancer types, it provides a striking convergence of melanoma oncogene discovery and melanocyte development.

NEDD9, a melanoma metastasis gene identified by cross-species comparison The power of genetically engineered mouse (GEM) models as biological filters for human cancer gene discovery was illustrated in a recent study that identified NEDD9 as a novel melanoma metastasis gene (Kim et al. 2006). Since evolution preserves key molecular mechanisms governing biological processes, it is hypothesized that overlapping genomic al- terations in mouse and human tumors reflect selection driven by similar genetic pressure, and are thus more likely to represent critical events in tumorigenesis. Exploiting the experimental merits of an inducible mouse model of melanoma (Chin et al. 1999), Kim et al. (2006) compared nonmetastatic parental and metastatic variant melanomas in the mouse by genome-wide high-resolution array-CGH and identified a recurrent focal amplification associated with acquisition of metastatic potential. This amplification in mouse is syntenic to human 6 p24-25, a region that sustains copy number gain in $36 \%$ of human metastatic, but not primary, melanoma (Bastian et al. 1998; Namiki et al. 2005). Although the recurrence of this regional event speaks to its potential pathogenetic and/or prognostic importance, chromosome $6 \mathrm{p}$ gain in human tumors (including metastatic melanoma) typically involves an expansive region spanning $>35 \mathrm{Mb}$, rendering identification of target(s) difficult to impossible. The cross-species comparison quickly narrowed one region of interest on $6 \mathrm{p}$ to an $850-\mathrm{kb}$ region encompassing only eight annotated genes (Fig. 2). Further integration with expression data pointed to NEDD9 as the potential target. Accordingly, NEDD9 protein expression was shown to be up-regulated in a progression-correlated manner in human melanoma (Kim et al. 2006).

Biologically, NEDD9 amplification and overexpression in melanocytes and melanoma cells translated into enhanced invasion and metastasis as demonstrated in a series of loss-of-function and gain-of-function assays. Mechanistic studies further established that NEDD9 localizes to dynamic focal contacts at the cell periphery and physically and functionally interacts with focal adhesion kinase in mediating cell invasion. Here, the clear genotype (Nedd9 amplification and persistent HRAS expression)-phenotype (metastatic potential) link defined in the mouse highlighted another major advantage of gene discovery in the GEM model, as it logically guided the selection of functional assays (invasion and metastasis) and defined the genetic context (cooperation with activated HRAS or BRAF) upon which such assays should be conducted (Kim et al. 2006). Without such insight, oncogenic activity of NEDD9 would not have been apparent.
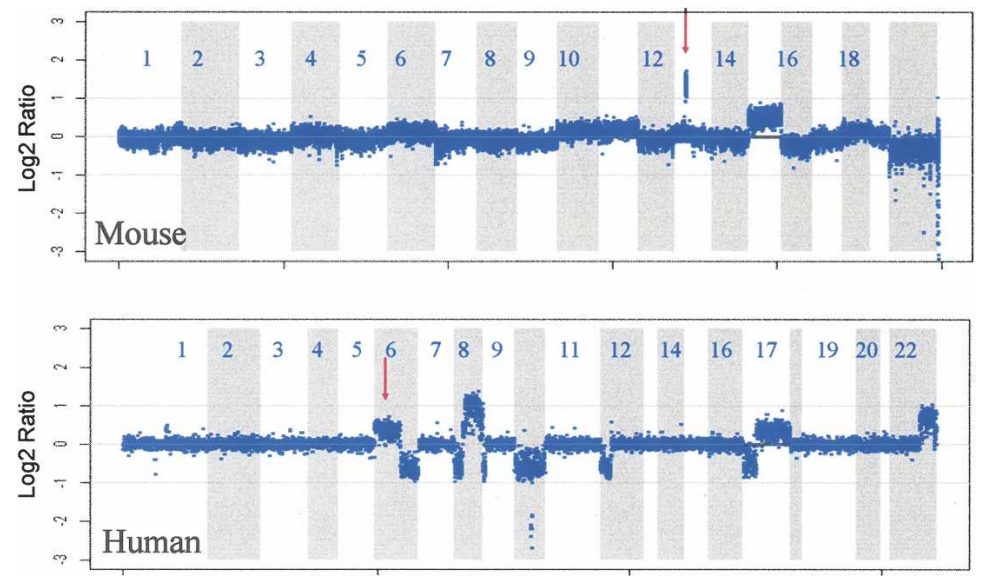

Figure 2. Nedd9 amplification in metastatic mouse melanoma maps to region of frequent gain in human metastatic melanoma. (Top) Genome-wide array-CGH profile of one mouse metastatic melanoma with Nedd9 amplification on chromosome 13. (Bottom) One metastatic human melanoma profile showing gain of chromosome 6p, spanning a large region. (Arrows) Mouse chromosome 13 amplicon maps by synteni to human chromosome 6p24-25. 
In addition to illustrating how comparative oncogenomics has enabled the identification and facilitated the validation of NEDD9 as a melanoma metastasis gene, this study also demonstrated evolutionarily conserved genomic activation of a component of the focal adhesion complex during melanoma metastasis (Kim et al. 2006), raising the possibility that inhibition of this signaling complex would halt progression of primary melanoma to metastatic disease. Along this line, it is interesting that NEDD9 expression appears to be positively selected for even at the primary melanoma stage, suggesting the potential predictive value of NEDD9 expression for future metastasis in primary melanoma.

\section{Melanoma maintenance genes as rational therapeutic targets}

The concept of tumor maintenance stems from the observation that cancer is the phenotypic end-point of numerous genetic and epigenetic alterations; moreover, the genomic complexity of human melanoma suggests that full malignant transformation of melanocytes requires the cooperating effects of multiple genetic lesions. This requirement has been well-demonstrated in genetically engineered models (GEMs), even when transformation has been driven by a potent initiating mutation (such as RAS). In the melanocyte lineage, even if one or more gain-of-function mutations are engineered into GEM models, transformed phenotypes only emerge (1) after a period of latency and (2) often with incomplete penetrance. Each of these characteristics implies a need for acquisition/selection of secondary cooperating events. Consistent with this, candidate or genome-wide molecular analyses of GEM melanoma have often identified spontaneous genetic alterations acquired de novo. For instance, in the HRAS-driven GEM model of melanoma on an Ink4a or Arf-deficient background, reciprocal p53 (e.g., p53 mutation or Arf loss) or Rb (e.g., Cdk6 amplification or Ink4a loss) pathway lesions, respectively, have been detected in the resultant melanomas, such that melanoma from either genetic backgrounds harbored concomitant inactivation of both $\mathrm{p} 53$ and $\mathrm{Rb}$ pathway (Kannan et al. 2003; O'Hagan et al. 2003; Sharpless et al. 2003). Along the same line, even on an In4a/Arf double-null or p53-deficient background, new and nonrandom genomic alterations can be detected by arrayCGH profiling in HRAS-driven melanoma (Bardeesy et al. 2001; Hochedlinger et al. 2004). In addition to the genetic lesions mentioned here, biological processes that maintain and sustain an established tumor likely involve epigenetic dysregulation and intimate tumor-stromal interactions, the molecular basis of which remains poorly understood. Clearly, efficacious therapeutic targets must play requisite roles in maintenance of established melanomas.

Inducible onco-transgene models have been developed to assess the tumor maintenance role of activated oncogenes in GEM (Chin and DePinho 2000). Using the tetracycline regulatory system, an inducible $H R A S$-driven melanoma model (Tyr-rtTA ${ }^{+}$Tet-RAS $S^{+}$Ink4a/Arf ${ }^{-/}$) has been generated whereby expression of the oncogenic RAS can be regulated in a tissue-specific and developmental stage-specific manner (Chin et al. 1999). In this system, despite the presence of irreversible genomic alterations in RAS-initiated melanomas, inactivation of RAS via doxycycline withdrawal in fully established melanomas led to clinical and histopathological regression, a remarkable finding that attests to the essential role of RAS activation in tumor maintenance. In addition to addressing the role of an oncogene in maintenance, inducible GEMs provide an in vivo system to examine the heterotypic interaction of tumor and stromal cells. For example, it has been shown that RAS-mediated melanoma regression is associated with dramatic activation of apoptosis in both tumor and host-derived endothelial cells, a phenotypic outcome not necessarily anticipated based on the intimate link of RAS activation to proliferation via MAP kinase activation in vitro (Chin et al. 1999). Real-time imaging during tumor regression by MR and bioluminescence provided additional evidence that loss of vascular function in regressing melanomas upon RAS inactivation represented an active response to loss of RAS activity upon doxycycline withdrawal, rather than a passive bystander effect of tumor cell deaths (Tang et al. 2005). Together, these experiments underscore the importance of GEMs to interrogate the tumor maintenance requirement of putative melanoma genes prior to their designation as a rational therapeutic target.

\section{The biology of melanoma-lessons from development}

It is a commonly accepted premise in cancer biology that signature phenotypic features of a malignancy may be traceable to the cell and developmental biological characteristics of its lineage origins. Melanoma is no exception. Multiple key tumor biological hallmarks mirror the distinctive features of the melanocytic lineage. Indeed, a defining aspect of melanoma is a strong propensity for metastasis, reflecting well the developmentally encoded dispersion of melanocytes from the neural crest to cutaneous sites. Thus, it stands to reason that valuable information may derive from the careful scrutiny of melanoma biology through the lens of melanocyte lineage development.

\section{Melanocyte stem cells}

Melanocyte progenitor cells migrate over considerable distances, along a predictable route upon their exit from the neural crest. They traverse discrete stages of differentiation recognizable in terms of marker expression, ultimately populating the basal epidermis as well as the hair follicle in human. In certain furry mammals such as the rodents, the epidermal population may be transient, a feature likely arising from a lack of SCF expression by basal keratinocytes since persistent epidermal melanocytes have been observed in transgenic mice, which ubiquitously express the cytokine HGF (Takayama et al. 
1996) or keratinocyte-targeted SCF (Kunisada et al. 1998). Within hair follicles, melanocytes reside in two locations: at the bulb (where they function as differentiated cells to provide pigment to the growing hair matrix) and as stem cells within the bulge region, located at the base of the permanent portion of the follicle (Nishimura et al. 2002).

As demonstrated by Nishimura et al. (2002), follicular bulge melanocytes satisfy the criteria of stemness, including properties of immaturity, slow cycling, selfmaintenance, and the capacity to repopulate the hair follicle at the anagen phase. At the beginning of anagen, signals within the stem cell niche trigger an emergence from quiescence that results in two distinct melanocytic progeny. The differentiated population migrates to the base of the follicle (hair bulb), where melanin synthesis and transport to adjacent keratinocytes occur, resulting in melanization of newly formed hairs. Later in the hair follicle cycle, the deep (transient) portion of the follicle undergoes a regressive (catagen) phase characterized by apoptosis of the deep structures. Following a resting (telogen) phase of variable duration, a new anagen phase is triggered.

The existence of melanoma stem cells has also been investigated recently. Herlyn and colleagues identified a CD20-enriched subpopulation of cells from melanoma lines or metastases that grew as nonadherent spheroids when cultured in human ES-like medium. Moreover, these CD20-enriched cells could be induced to differentiate toward multiple lineages, including melanocyte, adipocyte, osteoblast, and chondrocyte, suggesting the presence of such a subpopulation with a stem cell phenotype (Fang et al. 2005). Separately, Frank and colleagues identified a subpopulation of melanoma cells with expression of a drug efflux transporter ABCB5 and showed that this subpopulation was enriched for the CD133+ (stem cell marker-enhanced) fraction (Frank et al. 2005). Interestingly, ABCB5 expression was associated with resistance to adriamycin treatment, and correspondingly, ABCB5 blockade resulted in adriamycin accumulation and enhanced drug sensitivity. While it remains unclear how melanoma stem cells might be related to melanocyte stem cells, these studies suggest novel strategies for identification and targeting of clinically critical tumor subpopulations that exhibit stemlike features in melanoma.

\section{Pigmentation}

Considerable information on genetic and signaling pathways important for melanocyte biology has come from analysis of hair pigmentation dynamics. These studies are aided by the accumulation of easily recognizable coat color mutations in multiple animal species, as well as the generally benign nature of altered melanocyte function and therefore survival for the host organism. Examination of hair graying represents a good example of such analysis. The geographic separation between follicular melanocyte stem cells (bulge region) relative to their differentiated progeny (hair bulb) permitted relatively simple quantitative analysis of each population. Using transgenic mice in which the melanocyte lineage was tagged by LacZ (Mackenzie et al. 1997), it was observed that senile graying is associated with progressive depletion of the stem cell pool (Nishimura et al. 2005). Melanocyte stem cell depletion was preceded by the stochastic appearance of pigmented melanocytes within the bulge region-a population that was not maintained, suggesting that it may represent a dead-end route away from the stem cell pool. Similar observations were made in aging human hair follicles (Nishimura et al. 2005). In addition, several murine models of accelerated graying have been analyzed, and demonstrate either an accelerated version of the age-related process (Mitf $f^{v i t / v i t}$ ) or abrupt and selective stem cell loss $\left(\mathrm{Bcl}^{-/-}\right)$. Interestingly, graying in the Bcl2-deficient background is dramatically rescued by simultaneous deficiency of the proapoptotic family member BIM (Bouillet et al. 2001).

The cellular and molecular events regulating apoptosis of the melanocyte population during the regressive (catagen) phase of the hair follicle cycle are being revealed by systematic analyses (Sharov et al. 2005) that may identify critical steps in homeostatic regulation of this lineage. Collectively these studies are beginning to define not only the genes that play essential roles in melanocyte survival, but also the molecular contexts for the further characterization of signaling and transcriptional pathways that interact with those genes. Moreover, it is plausible that lineage-specific survival pathways and factors may emerge as mechanistically important players in the genesis of melanoma, as exemplified by MITF discussed above.

Due to the combination of obvious phenotype, germline heritability, and modest (if any) effects on organismal survival, analyses of pigmentation mutants have led to the discovery of numerous melanocyte viability genes. One of the best characterized human conditions of syndromic pigmentation is the autosomal dominant condition Waardenburg Syndrome, named for the Dutch ophthalmologist who characterized patients exhibiting "core" pigmentation and deafness defects (Type 2) or others exhibiting the core defects plus other recurring phenotypic abnormalities (Types 1, 3, and 4). Unique features of each subtype, and their associated genes, are outlined in Table 1 . The core phenotype of melanocyte deficiency is characterized by a combination of ventral spotting (typically the belly in mice, the forlock in man) and variable degrees of deafness. Hearing deficiency stems from a requirement for melanocytes within the stria vascularis of the cochlea (inner ear)-a requirement whose role appears to involve maintenance of endolymphatic potassium required for the auditory nerve action potential (Steel 1995). Genetic causes of Waardenburg Syndrome are now well characterized (for review, see Price and Fisher 2001). The gene whose mutation is associated with the "core" pigmentation/deafness phenotype is the MITF transcription factor /although MITF mutation occurs in only a minority of Waardenburg Syndrome Type 2 patients, termed Type 2A). The Waardenburg-associated mutations represent a striking epistatic 
Chin et al.

Table 1. Human syndromic pigmentation/deafness genes

\begin{tabular}{llll}
\hline Syndrome & \multicolumn{1}{c}{ Gene(s) } & \multicolumn{1}{c}{ Affected lineage(s) } & \multicolumn{1}{c}{ Symptoms } \\
\hline Waardenburg Type 1 & Pax3 & Melanocyte, musculoskeletal & White hairlock, deafness, craniofacial defects \\
Waardenburg Type 2a & MITF & Melanocyte & White hairlock, deafness \\
Other 2 & Slug & Melanocyte & White hairlock, deafness \\
Waardenburg Type 3 & Pax3 & Melanocyte, musculoskeletal & White hairlock, deafness, limb deformities \\
Waardenburg Type 4 & Sox10 ET1, EdnrB & Melanocyte, enteric ganglia & White hairlock, deafness, Hirschshprung's \\
& & & syndrome (megacolon) \\
\hline
\end{tabular}

series in which essentially every culprit gene is mechanistically linked to regulation of MITF expression or activity. These genes, Pax3, Slug, Sox10, endothelin 1, and endothelin receptor $B$ are transcriptional regulators of MITF expression (Pax3 and Sox10), transcriptional targets of MITF (Slug), or activators of MAPK that directly phosphorylate MITF (ET1 and EdnrB) (Hemesath et al. 1998; Watanabe et al. 1998; Bondurand et al. 2000; Lee et al. 2000; Potterf et al. 2000; Verastegui et al. 2000; Sanchez-Martin et al. 2003).

\section{MITF, the master regulator}

As an essential factor for melanocyte development, analysis of the mechanistic role(s) of MITF is likely to shed light on the wiring of critical signaling pathways within the lineage. Mutation of MITF was originally described in the microphthalmia mouse $\left(M_{i t} f^{m i / m i}\right)$, which arose $>50$ yr ago (Silvers 1979). These mice exhibit complete absence of neural-crest-derived melanocytes, hyperproliferative/dysfunctional retinal pigment epithelium (RPE), deficient mast cells, and osteopetrosis (due to osteoclast defects). Whereas the RPE and mast cell defects are beyond the scope of this review, the melanocyte and osteoclast defects are pertinent to both melanoma and other human malignancies based on clues from related transcription factors. The melanocyte defect arises very early in development, with recognizable progenitor cells $($ Dct +$)$ disappearing very shortly after their emergence from the neural crest (Hodgkinson et al. 1993). Heterozygous mutant mice or humans with a single mutant Mitf allele typically display ventral white spotting due to diminished melanocytes within this watershed zone, which requires the greatest migration from the (dorsal) neural crest. It is uncertain at present why ventral spotting in humans is selective for hair follicles (rather than epidermal melanocytes), although the phenotype suggests a greater migratory or survival "strain" on the lineage. Regardless, complete deficiency of Mitf results in complete absence of melanocytes, suggesting that Mitf is essential for lineage survival, or proliferation, or to prevent transdifferentiation toward other neural crest lineages (such as glia or neurons). The identification of signaling pathways residing upstream and downstream of Mitf has helped to illuminate the context in which it functions.

Pigmentation versus survival Although Mitf plays a central role in the pigmentation pathway, it is notewor- thy that the phenotypic consequence of Mitf deficiency primarily involves lineage survival, rather than pigmentation/differentiation. While there is at least one Mitf mutant allele that displays altered pigmentation (Mitfbrownish $^{r}$ ) (Steingrimsson et al. 1996), the others (including the founder allele Mitf ${ }^{m i}$ ) are devoid of melanocytes, rather than failing to make pigment within viable melanocytes. The latter situation occurs in albinos, which are unpigmented due to mutations within genes essential for pigmentation, without affecting melanocyte viability. It is also a potential possibility that Mitf's role in lineage survival could be a fleeting role during a transient developmental stage (with only a pigmentation role in adulthood). However, this is unlikely, given the phenotype of the Mitf ${ }^{v i t}$ allele. Mitf $f^{v i t}$ encodes a mutation mapping to the helix-loop-helix (HLH) domain that produces a mild hypomorphic biochemical behavior in DNA-binding activity (Hemesath et al. 1994; Steingrimsson et al. 1994). Mitf $f^{v i t / v i t}$ mice are born with nearly normal coat color (occasional white spot), but undergo accelerated graying (with melanocyte loss) within 3-12 mo, demonstrating a post-developmental requirement for Mitf in continued survival of the melanocyte lineage.

Mitf is certainly not the only gene implicated in melanocyte survival. Some, such as Sox10 and Pax3, are transcription factors epistatically linked to Mitf (for review, see Price and Fisher 2001). Another group includes growth factor or receptor genes, such as endothelin 3, endothelin receptorB, stem cell factor, and c-Kit. The list of all cytokine/receptor genes essential for melanocyte survival is undoubtedly underestimated by the likelihood that other melanocyte survival genes may also be essential for overall survival of the organism, thus precluding the recognition of their role in pigment cell defects in humans (or other species). Nonetheless, these known mutations clearly provide vital survival signals, possibly mediated by the PI3Kinase and/or MAPK pathways. In fact, one melanocyte-specific target downstream of c-Kit/MAPK signaling is MITF, which has been shown to be directly phosphorylated by Erk kinase in a manner that measurably enhanced affinity for the p300 transcriptional coactivator (Hemesath et al. 1998; Price et al. 1998a). In addition, the identical phosphorylation (plus an additional one mediated by Rsk kinase) triggered ubiquitylation and degradation of Mitf (Wu et al. 2000; Xu et al. 2000), suggesting a post-translational regulatory event that is under tight homeostatic control. It is incompletely understood whether the net conse- 
quence of this MITF phosphorylation is enhanced transcriptional activity, diminished activity (associated with decreased protein stability), or a combination thereofperhaps segregating among specific transcriptional target genes. Furthermore, as already mentioned, nearly all human melanomas harbor MAPK activation, the majority of which occur through BRAF or NRAS activating mutations. One biochemical consequence among the myriad of MAPK targets is robust and constitutive Erkmediated phosphorylation of Mitf. Indeed, mutant BRAF has been shown to down-regulate MITF levels (Wellbrock and Marais 2005), and correspondingly, MITF overexpression (in a specific context) could inhibit growth-stimulatory effects of mutant BRAF. MITF has also been shown to undergo a variety of additional posttranslational modifications, including phosphorylation by p38 kinase (Mansky et al. 2002), GSK3 $\beta$ (Takeda et al. 2000a), and sumoylation (Miller et al. 2005; Murakami and Arnheiter 2005), each of which has been linked biochemically to modulate MITF transcriptional activity.

The MITF locus is complex, with multiple distinct promoter/exon units residing within an $\sim 200$-kb locus (Hershey and Fisher 2005). Alternative splicing links the various initial exons to the common downstream coding exons. The most $3^{\prime}$ of these promoters appears to direct melanocyte-specific expression of an MITF isoform whose expression is specific to the melanocyte lineage (whereas the others are not) (Fuse et al. 1996). This promoter is the best studied, and contains regulatory elements that respond to cAMP and Wnt signaling as well as Sox10, Pax3, and other transcription factors of importance in neural crest lineage development.

MITF as an oncogene Additional evidence in support of MITF's functionally important role in melanocyte growth/survival came from studies identifying genomic amplification of its genetic locus in $10 \%-20 \%$ of human clinical melanoma specimens (see above). Is MITF a plausible human oncogene? After all, its biochemical activities in mediating melanocytic pigmentation/differentiation are well established, and these are hardly activities associated with oncogenesis. Aside from the direct evidence for MITF's amplified state in a fraction of melanomas, other studies have strongly linked MITF to several nonmelanocytic neoplasms that arise through genomic alterations in close relatives of MITF.

Early biochemical characterization of MITF revealed that its basic/HLH/leucine-zipper (bHLHzip) DNA-binding/dimerization domain placed it as a relative of the MYC oncoprotein family (Hemesath et al. 1994). However, MITF was not found to form functional heterodimers with members of the MYC subfamily of bHLHzip factors. Instead, a different set of three closely related transcription factors, TFE3, TFEB, and TFEC, were found to even more closely resemble MITF, with the capacity to homo- or heterodimerize and bind DNA together with MITF. This MITF-containing subfamily of bHLHzip transcription factors was termed the MiT family (Hemesath et al. 1994). In addition, elegant genetic studies by Steingrimsson et al. (2002) revealed an ability of TFE3 to functionally replace MITF activity in osteoclast development, suggesting biochemical redundancy in the activities of these closely related family members.

TFE3 was the first family member to be identified as a fusion oncogene (Sidhar et al. 1996; Weterman et al. 1996; Clark et al. 1997). A significant fraction of pediatric papillary renal cell carcinomas (now termed "translocation-associated" renal cell carcinomas) was seen to harbor translocations that fused the TFE3 to a variety of alternative 5' partner genes. In each case, the bHLHzip of TFE3 was preserved. Other fusions of TFE3 were seen to occur in alveolar soft parts sarcoma (Ladanyi et al. 2001), where a recurring $5^{\prime}$ fusion to the ASPS gene was identified. Although there was ambiguity over which portion (or portions) of the fusion oncoproteins conferred oncogenic activity, the situation was considerably clarified with the identification of TFEB translocated papillary renal carcinomas (Davis et al. 2003; Kuiper et al. 2003). Interestingly, these tumors were identified, in part, by their unexpected expression of several melanocytic markers in combination with an isolated, recurring translocation localizing to 6p21 (Argani et al. 2001). The fusion gene was informative because the $5^{\prime}$ partner gene (from chromosome 11) fused upstream of TFEB's translation initiation codon and did not apparently contribute open reading frame sequences, but rather promoter-swap mechanism to the fusion gene. This mode of translocation oncogenesis was reminiscent of Myc-immunoglobulin translocations in lymphoid malignancies, and suggested that transcriptional dysregulation of TFE3 or TFEB expression is likely to represent an oncogenic event. It is thus highly plausible that gene amplification, another mode of Myc family dysregulation in cancer, would represent an oncogenic event through which MITF contributes to melanomagenesis. Another recently identified MiT tumor is Clear Cell Sarcoma (also called Melanoma of Soft Parts). This sarcoma is occasionally pigmented and expresses a variety of melanocytic markers (Granter et al. 2001) as well as a recurring translocation that fuses the EWS and ATF1 genes (Fujimura et al. 1996). Recent data have suggested that EWSATF1 functions by oncogenically activating MITF expression (via EWS-ATF1's role in mimicking melanocyte-stimulating hormone [MSH] signaling), since MITF is essential for viability of Clear Cell Sarcoma (Davis et al. 2006).

Transcriptional targets of Mitf Numerous technical approaches have been used to identify genes whose expression is modulated by Mitf in melanocytes. Using candidate approaches, multiple pigmentation-associated factors have been thus recognized, although it is noteworthy that factors other than MITF are undoubtedly important in their regulation as well, because the endogenous genes are not always predictably up- or down-regulated by modulation of Mitf expression alone (Gaggioli et al. 2003). Other transcription factors of importance in the regulation of potential Mitf targets include CREB/ATF1, SOX10 (Jiao et al. 2004; Ludwig et al. 2004), Pax3 (as a negative regulator and potential media- 
tor of melanocyte stem cell maintenance) (Lang et al. 2005), OTX2 in retinal pigment epithelium (MartinezMorales et al. 2003), CBP and MAZR (in mast cells) (Ogihara et al. 1999; Morii et al. 2002), Pu.1 in osteoclast target genes (Sato et al. 1999; Luchin et al. 2001; Cassady et al. 2003; So et al. 2003; Partington et al. 2004), Wnt/ LEF (Yasumoto et al. 2002), and probably others as well.

Although the list of identified transcriptional targets of Mitf is growing rapidly, one plausible classification of these genes is through the broad groups of differentiation/pigmentation-associated factors versus proliferation/survival-associated genes. These designations undoubtedly represent some degree of oversimplification, yet may be helpful in linking Mitf biochemistry to major pathways with which it is associated. Two interesting reported transcriptional targets are the cyCDK inhibitors (CDKi) INK4A (Loercher et al. 2005) and p21 (Carreira et al. 2005). Both potentially provide links to melanocytic differentiation although neither alone is apparently essential for melanocyte differentiation/pigmentation, since knockouts of both appear normally pigmented. Still, $\mathrm{p} 16^{\text {In } 4 \mathrm{a}}$ is an unequivocally important melanoma genetic locus in man (see above), and these studies suggest a means through which loss of CDKi activity could permit (or reveal) an oncogenic activity of Mitf that is otherwise constrained by the CDKi (Merlino 2005).

Pigmentation and differentiation targets. Pigmentation-associated transcriptional targets of MITF include the pigment enzyme genes tyrosinase, TRP1, TRP2/Dct, which were recognized to contain an evolutionarily conserved consensus promoter/enhancer element that matches the MITF recognition sequence (Bentley et al. 1994; Hemesath et al. 1994; Yasumoto et al. 1994). Additional differentiation-associated genes include Pmel17/silver/gp100 /which encodes the melanoma diagnostic epitope HMB45) (Halaban et al. 1996; Baxter and Pavan 2003; Du et al. 2003), MelanA/Mart1(Du et al. 2003), Melastatin (TRPM1) (Miller et al. 2004; Zhiqi et al. 2004), AIM1 (ocular albinism 4 gene) (Du and Fisher 2002), Ocular albinism 1 gene (OA1) (Vetrini et al. 2004), VMD2 (Esumi et al. 2004), HIF1 $\alpha$ (Busca et al. 2005), Plasminogen activator inhibitor-1 (Murakami et al. 2006), numerous mast cell targets of MITF including Prostaglandin D2, multiple mast cell genes including proteases, various adhesion molecules and others (see Ito et al. 2004; Morii et al. 2004; Takeda et al. 2006 and references therein), and melanocortin 1 receptor (MC1R) in mast cells and possibly in melanocytes (Adachi et al. 2000; Smith et al. 2001; Aoki and Moro 2002). Numerous additional genes are being identified through expression microarrays, and are liable to reflect the multiple steps involved between signaling, expressing, packaging, and exporting pigment.

Proliferation and survival targets. Significantly fewer genes have been identified to date as potential mediators of the MITF-dependent survival or proliferation. $\mathrm{Bcl} 2$ is one such gene, which was also notable for the melanocytic viability phenotype associated with its knockout in the mouse (McGill et al. 2002; Nishimura et al. 2005). CDK2 is another example of a MITF target selectively in the melanocyte lineage (Du et al. 2004). This finding stemmed from analysis of the pmel17/ gp100 locus, which virtually overlaps the CDK2 gene and appeared to use a common enhancer element to regulate expression of both genes /whereas the MITFbinding site was dispensable for CDK2 expression in nonmelanocytes). For uncertain reasons, melanoma cells were also seen to selectively require CDK2 expression, because knockdown of CDK2 affected their cell cycle and viability, but not the viability of a variety of nonmelanocytic cancer cell types (Du et al. 2004) as had previously been observed by others (Tetsu and McCormick 2003). Importantly, neither Bcl2 nor CDK2 appears to explain MITF's requirement for melanocyte viability during development, because the phenotype of MITF homozygous deficiency is profoundly worse than either alone, and expression of neither gene in MITF-knockeddown melanoma cells is capable of rescuing viability. Evidence has also been obtained that suggests that Slug may be a direct transcriptional target of Mitf (SanchezMartin et al. 2002). This finding is of note because of the same authors' discovery of several Waardenburg Syndrome Type 2 patients with (germline or somatic) deletion of Slug, thereby implying an epistatic relationship between Mitf and Slug. The potential importance of Slug in lineage survival is highlighted by its recent discovery as a transcriptional target of p53 and a transcriptional repressor of the apoptotic factor PUMA (Wu et al. 2005). Furthermore, relevance of Slug to melanocyte biology is reinforced by the demonstration that Slug contributes to invasive behavior of human melanocytes transformed with defined genetic events (Gupta et al. 2005). The cytokine receptor c-Met has also recently emerged as a direct transcriptional target of Mitf (McGill et al. 2006). Additional targets of MITF are likely to mediate its survival/proliferation effects, and it remains to be seen whether some of these genes might serve as surrogate drug targets for the MITF oncogenic pathway.

\section{Wnt signaling}

Wnt signaling has long been linked to major developmental decisions in neural crest derivatives. Among the various lineages derived from neural crest progenitors, Wnt pathway overactivation has been shown to bias differentiation toward the melanocytic lineage (Dorsky et al. 1998), consistent with the possibility that it regulates the lineage commitment decision. Indeed, zebrafish studies by Raible, Moon, and colleagues demonstrated that canonical Wnt pathway activation resulted in upregulated Mitf expression via discrete TCF/LEF sequence elements within proximal melanocyte-specific promoter of the Mitf gene (Dorsky et al. 2000). Importantly, the investigators found that enforced Mitf expression was able to measurably rescue melanoblast survival in Wntdeficient embryos, providing functional evidence that Mitf is a developmentally essential Wnt target. Additional studies identified similar biochemical relationships between Wnt effectors ( $\beta$-catenin, TCF/LEF) and Mitf expression in murine and human melanocytes and 
melanoma cells (Takeda et al. 2000b; Widlund et al. 2002). Interactions have also been observed between LEF-1 and MITF, suggesting that MITF may function as an alternative coactivator of certain Wnt-signaling targets (independent of $\beta$-catenin) (Yasumoto et al. 2002).

Although a relatively high incidence of stabilizing $\beta$-catenin mutations has been observed in melanoma cell lines (Rubinfeld et al. 1997), a much lower incidence of such mutations has been detected in primary clinical melanoma specimens. However, a significant fraction of clinical melanoma lesions do exhibit immunohistochemical evidence of nuclear $\beta$-catenin localization (Rimm et al. 1999), signifying activation of the canonical Wnt pathway, thus an activity (albeit biochemically incompletely defined as yet) through which this upstream regulator of Mitf may be contributing to melanoma survival/proliferation. While it is likely that $\beta$-catenin acts on other genes, Mitf is an important downstream target, as cell line studies showed that lethality caused by Wnt pathway suppression (by dominant-negative TCF) could be rescued by enforced expression of Mitf (Widlund et al. 2002). Collectively, these observations are consistent with the view that Mitf plays an essential role in at least certain melanoma cell lines.

Distinct from the effects of the canonical Wnt pathway's regulation of Mitf, gene expression studies of human melanoma have identified the Wnt5a signaling pathway as a participant in melanoma progression (Weeraratna et al. 2002). Wnt5a expression correlated with invasive behavior in vitro, as well as with increased tumor grade in clinical specimens. Overexpression of Wnt5a appears to enhance the invasion capability of melanoma cells, while blockade of Frizzled 5 (the Wnt5a receptor) can suppress invasiveness. The Wnt5a pathway in melanoma cells was found to be associated with PKC activation, rather than $\beta$-catenin targeting (Weeraratna et al. 2002).

\section{MSH signaling}

The signaling pathway triggered by MSH is thought to represent one of the most important regulators of pigmentation (Fig. 3), although other pathways clearly exist (Barsh 1996; Fitch et al. 2003; Van Raamsdonk et al. 2004; Lamason et al. 2005), and will likely provide valuable insights to the pigmentation process. MSH binds to its receptor, $\mathrm{Mc} 1 \mathrm{R}$, in a manner that is directly competed by the agouti protein in nonhuman mammalian species (the role of agouti in man is less clear). Successful competition by agouti results in fur/hair bands with characteristic yellow stripe patterns, whereas the nonagouti phenotype (due to deficient agouti protein) produces uniform black pigmentation associated with unimpeded access to Mc1R by MSH and is responsible for the "black" color of the commonly studied C57bl/6 mouse strain.

MC1R is a seven-transmembrane G-protein-coupled receptor (GPCR) expressed on epidermal melanocytes. It is highly polymorphic in human populations, and its allelic variation is the principle determinant of pigment phenotypes and skin phototypes in humans (Valverde et

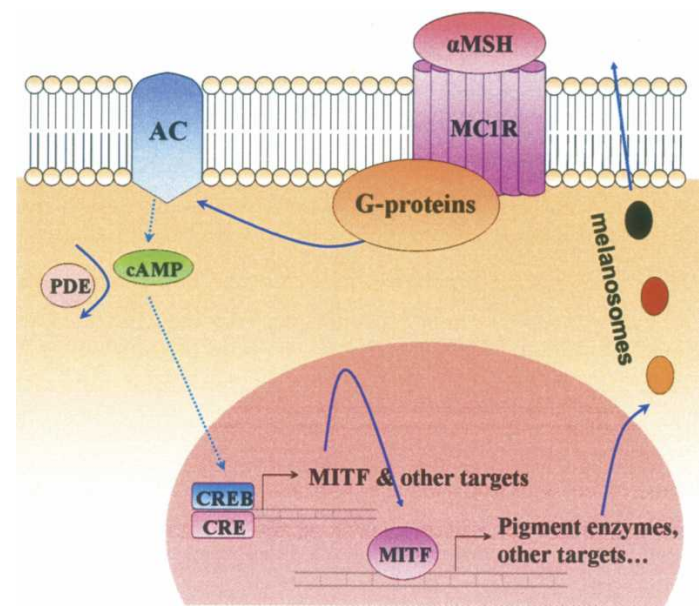

Figure 3. Melanocortin signaling $\alpha-\mathrm{MSH}$ stimulates the cAMP pathway via MC1R, a seven-transmembrane GPCR on melanocytes. Heterotrimeric G-protein complexes downstream of MC1R stimulate adenylyl cyclase (AC), which catalyzes the production of cyclic AMP (cAMP). Elevated cAMP triggers (via intermediates) the phosphorylation/activation of the CREB (cAMP-responsive element binding) family of transcription factors, triggering recruitment of the $\mathrm{CBP} / \mathrm{p} 300$ coactivators and transcriptional activation of multiple target genes. In melanocytes, one critical CREB target is MITF, a bHLHzip protein that transactivates genes important for pigmentation/differentiation as well as other cellular processes (see text for details). Among these are genes that produce synthesis and maturation of melanosomes, specialized melanin-containing vesicles that are exported to neighboring keratinocytes in the epidermis.

al. 1995; Sturm 2002). Three common variants of MC1R (R151C, R160W, and D294H) have been associated with the so-called Red Hair Color (RHC) phenotype (Box et al. 1997, 2001; Smith et al. 1998; Flanagan et al. 2000; Palmer et al. 2000; Bastiaens et al. 2001a,b), characteristic of individuals with red hair, fair complexion, an inability to tan, and a tendency to freckle. Carrying a single RHC MC1R variant is associated with a significantly diminished ability of the epidermis to respond to damage by UV (Flanagan et al. 2000; Box et al. 2001; Healy et al. 2001), presumably contributing to increased melanoma risk (Palmer et al. 2000; Healy et al. 2001). However, the observation that RHC MC1R variants are associated with increased melanoma risk even in individuals with dark/olive complexions (Palmer et al. 2000; Healy et al. 2001; Kennedy et al. 2001) suggests that MC1R have additional pigment-independent effect(s) on melanoma risk.

In general, those MC1R variants that robustly transduce MSH signals to activate adenylate cyclase, result in dark pigmentation phenotypes. In contrast, those Mc1R variants that produce weak or absent cAMP responses to MSH stimulation are associated with red/fair skin pigmentation and phototype (Kadekaro et al. 2003). Downstream from cAMP activation, multiple events occur, including phosphorylation/activation of CREB/ATF1 transcription factors that, in turn, activate expression of the Mitf promoter in melanocytes (Bertolotto et al. 1998; 
Price et al. 1998b). The precise kinase(s) responsible for CREB/ATF1 phosphorylation are likely to include Rsk kinase (Bohm et al. 1995) and/or Protein Kinase A. Other consequences of cAMP stimulation have also been suggested, including activation of RAF/MAPK (Busca and Ballotti 2000) and inhibition of the PI3K pathways (Khaled et al. 2003), in addition to activation of the canonical PKA response. While CREB and ATF1 likely contribute directly to transcriptional regulation of certain components of the pigmentation machinery, it is probable that their activation of Mitf plays an important role as well, with Mitf likely imposing tissue-specific expression of these genes. The pheomelanin (red pigment) to eumelanin (brown/black pigment) switch occurring at the level of $\mathrm{MSH} / \mathrm{Mc1R}$ signaling likely represents alternatively low- versus high-level Mitf expression, with correspondingly low versus high tyrosinase (and tyrosinase-related-protein) enzymatic metabolism of tyrosine to either thiol-reduced red-blond pigments or non-thiol-reduced brown-black pigments.

One potential challenge to the simple MSH signaling schema is the fact that cAMP and CREB/ATF1 activation is highly ubiquitous, yet Mitf activation (and pigmentation) is highly tissue restricted. One clue to how this restriction occurs came from the observation that the melanocyte-specific Mitf promoter is nonresponsive to cAMP in nonmelanocytes (Bertolotto et al. 1998; Price et al. 1998b), and also lost responsiveness to cAMP within the melanocyte lineage in the absence of an upstream promoter region (Huber et al. 2003). The cooperating site was mapped to a Sox10 consensus element, and enforced Sox10 expression was seen to permit cAMP responsiveness of endogenous Mitf gene expression within nonmelanocytes (Huber et al. 2003). Collectively these studies linked regulation of pigmentation, cAMP signaling, and Mitf expression to the Sox10 (Waardenburg Syndrome Type 4) gene.

\section{Emerging paradigms for melanoma therapeutics}

The treatment of advanced melanoma has witnessed numerous clinical innovations and recurrent frustrations over the past several decades. While primary cutaneous melanoma often can be effectively treated with surgical resection alone, the 5-yr survival of patients with regional lymph node spread hovers just above $50 \%$, and disseminated melanoma represents one of the most treatment-resistant of all human malignancies, with a median survival of 6-9 mo (Balch et al. 2001). At the same time, this disease has consistently provided tantalizing glimpses into possible therapeutic avenues that, if actualized, might prove broadly transforming to cancer medicine. Rare but profound clinical responses to immune modulation (for review, see Wolchok and Livingston 2001) and frequent genetic lesions affecting the hotly targeted MAP kinase pathway (Davies et al. 2002) represent two prominent examples in this regard. Although both immunotherapy and targeted therapy have encountered many more failures than successes thus far, recent advances in both arenas suggest that melanoma may offer a proving ground for emerging therapies capable of altering the natural history of molecularly defined tumor subtypes.

Dacarbazine (DTIC) and hydroxylurea remain the only FDA-approved chemotherapeutic agents in common use for metastatic melanoma. Between $10 \%$ and $20 \%$ of patients will experience a clinical response to DTIC; however, the response duration is short (4-6 mo), and no randomized, controlled trial has ever compared patient survival following DTIC treatment to that achieved with either best supportive care or placebo (Eigentler et al. 2003). The additional combination of chemotherapy agents with antimelanoma activity (e.g., platinum compounds, taxanes, or other alkylating agents) may improve the patient response rate, but these strategies also increase the toxicity of therapy and have not enhanced overall survival. Temozolomide, which shares the same active metabolite as DTIC, can cross the blood-brain barrier; thus, this agent has garnered attention as a possible systemic agent for the treatment of metastatic melanoma involving the brain and central nervous system. However, this agent has not demonstrated enhanced efficacy relative to DTIC alone in randomized trials (Middleton et al. 2000). For this reason, temozolomide failed to receive FDA approval for use in metastatic melanoma. Together, these grim realities underscore an urgent need for improved systemic treatment of this highly resistant malignancy.

\section{Targeted therapy in melanoma}

The MAP kinase pathway The prevalence of activating BRAF and NRAS mutations and consistent downstream activation of ERK suggests that activation of the MAP kinase signaling cascade may constitute an obligatory rite of passage in the transformation of melanocytes. Such dependency may present a therapeutically vulnerable point of attack (Fig. 4). Several lines of experimental evidence affirm this notion, particularly in melanomas harboring the BRAF ${ }^{\mathrm{V} 600 \mathrm{E}}$ mutation. First, the MAP kinase pathway exhibits constitutive activation in BRAF $^{\mathrm{V} 600 E}$ melanoma cells (as measured by ERK activation), which is required for melanoma proliferation in this context (Hingorani et al. 2003; Karasarides et al. 2004; Wellbrock et al. 2004). Second, depletion of BRAF, but not A-RAF or C-RAF, by small interfering RNA (siRNA)-mediated knockdown inhibits both ERK activation and cell growth while also triggering apoptosis in $\mathrm{BRAF}^{\mathrm{V} 600 \mathrm{E}}$ melanoma cells (Hingorani et al. 2003; Wellbrock et al. 2004). Consistent with these effects, BRAF depletion also abrogates both colony formation in soft agar and tumor xenograft formation by BRAF ${ }^{\mathrm{V} 600 \mathrm{E}}$ melanoma cells. Moreover, inducible RNAi experiments have shown that knockdown of BRAF attenuates growth of BRAF $^{\mathrm{V} 600 E}$ melanoma xenografts in an ERK-dependent manner (Hoeflich et al. 2006). Silencing of activated NRAS by siRNA knockdown also decreases phosphoERK levels and triggers apoptosis in NRAS-mutant melanoma cells (Eskandarpour et al. 2005). Together, these 


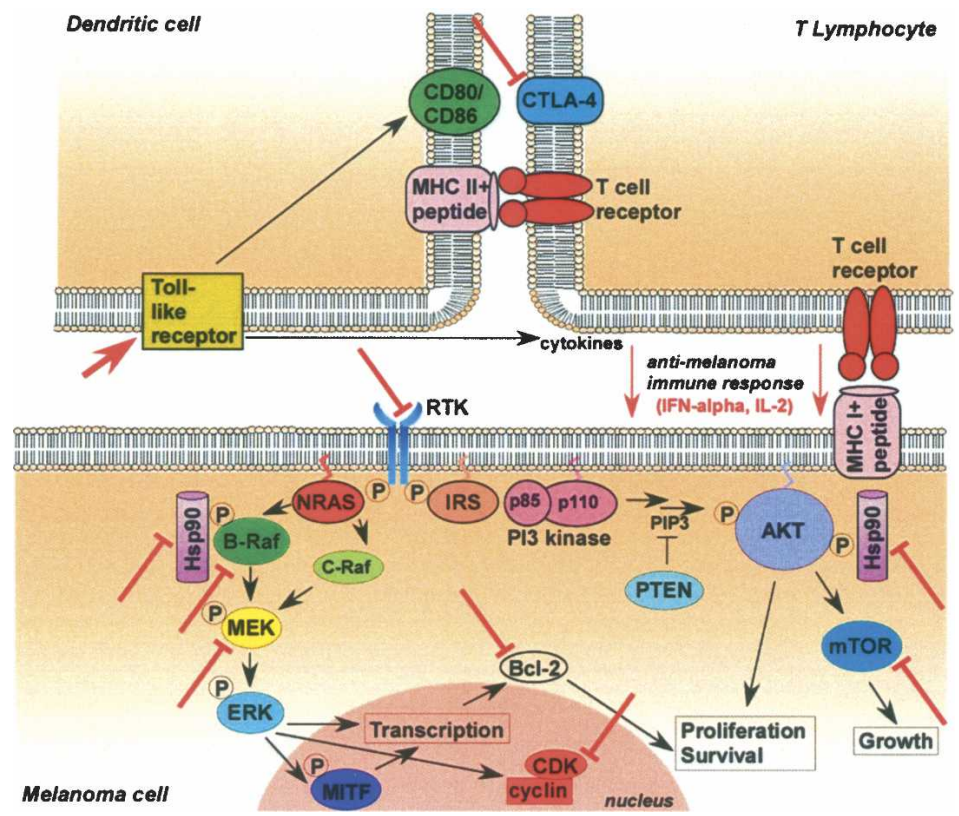

Figure 4. Melanoma pathways and targeted therapeutics. Several investigational agents designed to inhibit cell-autonomous melanoma pathways or augment antimelanoma immune mechanisms have entered clinical development. Proteins that have been targeted in melanoma clinical trials are indicated (red bars and bold arrow). The MAP kinase pathway (bottom left) has been targeted by RAF and MEK inhibitors, the PI3 kinase/ AKT pathway (bottom right) by TOR inhibitors, and the cell cycle by CDK inhibitors (bottom middle). Drugs inhibiting the Hsp90 chaperone protein may lead to degradation of several activated oncogenes (see text for details). The Bcl-2 antiapoptotic oncoprotein has been targeted by an antisense agent (see text). Aside from IFN- $\alpha$ and IL-2, recent attempts to enhance melanoma immunotherapy include toll-like receptor agonists (top left) and CTLA-4 antibody blockade (top middle). These are predicted to generate a more effective T-cell-mediated immunotoxicity to melanoma cells. Strategies to interdict RTK such as c-kit may prove fruitful in the future against defined melanoma subtypes. data suggest that melanomas carrying activating BRAF or NRAS mutations may exhibit an "oncogene addiction" phenotype involving the MAP kinase pathway.

Despite these intriguing observations, the MAP kinase pathway has not yet been fully credentialed as a melanoma target for several reasons. First, the MAP kinase dependency operant in cultured $\mathrm{BRAF}^{\mathrm{V} 600 \mathrm{E}}$ melanoma cell lines and xenografts may become attenuated in vivo because of the well-characterized redundancies in ERK activation by numerous autocrine and paracrine factors (Lazar-Molnar et al. 2000). Second, although BRAF mutations occur early in melanoma genesis, they are clearly insufficient for melanocyte transformation; thus continued BRAF ${ }^{\mathrm{V} 600 \mathrm{E}}$ activity in the context of all other cooperating events may not be essential for melanoma maintenance in situ. Moreover, although ectopic BRAF ${ }^{\mathrm{V} 600 \mathrm{E}}$ expression transforms certain murine melanocytes, it is incapable of transforming immortalized human melanocytes by itself (Chudnovsky et al. 2005); rather, it requires the cooperative actions of additional genes, such as MITF (Garraway et al. 2005). BRAF ${ }^{\mathrm{V} 600 \mathrm{E}}$ therefore seems a much weaker melanoma oncogene than are the RAS family members. Furthermore, siRNA-mediated interdiction of the MAP kinase pathway in NRAS-mutant melanoma cells yields only limited effects on ERK activation and cell proliferation (Wellbrock et al. 2004). These data raise the possibility that BRAF ${ }^{\mathrm{V} 600 \mathrm{E}}$ mutations and, by extension, aberrant MAP kinase activation may influence tumor establishment but prove insufficient for maintenance in human melanomas.

Given the prominence of MAP kinase signaling in many tumor types, several small molecules that target this pathway have entered clinical development. Sorafenib (BAY 43-9006) was one of the first such compounds to be evaluated in clinical trials; this bi-aryl urea exhibits in vitro inhibition of both wild-type and mutant BRAF kinase activities in the 20-40 nM range (Ahmad and Eisen 2004). Sorafenib also inhibits C-RAF and VEGFR-3 at low to subnanomolar concentrations, while exhibiting higher nanomolar activity in vitro against PDGFR, VEGFR-2, c-KIT, and FLT3. Despite its robust anti-RAF activity in vitro, the potency of sorafenib against MAP kinase activity in whole cells has proved more variable. $\mathrm{IC}_{50}$ values for this compound against BRAF $^{\mathrm{V} 600 \mathrm{E}}$ melanoma cells are 5-6 $\mu \mathrm{M}$ (50- to 100-fold higher than that required for in vitro kinase inhibition) (Karasarides et al. 2004); concentrations as high as 10-20 $\mu \mathrm{M}$ are required for full phospho-ERK inhibition (Panka et al. 2006). In xenografts, daily administration of $50 \mathrm{mg} /$ kg sorafenib partially inhibited phospho-MEK activity, and attenuated (but did not abrogate) tumor growth. Despite its promising preclinical properties, the preliminary efficacy data for sorafenib in melanoma patients appears more modest. In a recent phase I/II clinical trial involving 22 melanoma patients, only one partial responder was observed, while 12 patients had stable disease with a median duration of only 4 mo (the BRAF and NRAS mutation status of these patients is not yet available) (Flaherty et al. 2005). Sorafenib received FDA approval for the treatment of metastatic renal cancer, a malignancy whose pathophysiology involves angiogenesis, but where BRAF mutations have not heretofore been observed. Thus, the clinical efficacy of sorafenib may derive more from its anti-VEGFR activity than from BRAF blockade.

Nonetheless, cautious optimism persists for the development of targeted therapeutics against the MAP kinase pathway in melanoma. Several second-generation small molecule inhibitors of RAF and MEK exhibit in vitro potencies exceeding that of sorafenib. For example, the recently described RAF inhibitor RAF-265, previously known as CHIR-265 (Novartis, Inc.), shows pharmacologic $\mathrm{IC}_{50}$ values of $<100 \mathrm{nM}$ against BRAF-mutant melanoma cell lines (e.g., 50- to 100 -fold more potent 
than sorafenib in the same genetic context) (Jallal 2006). RAF-265 dosed daily at $100 \mathrm{mg} / \mathrm{kg}$ achieved tumor regression in $\mathrm{BRAF}^{\mathrm{V} 600 \mathrm{E}}$ melanoma xenografts, which correlated with phospho-MEK and cyclin D1 inhibition, as well as p27 up-regulation. In addition, a series of small molecules has been purported to selectively target the V600E variant of BRAF, resulting in submicromolar $\mathrm{IC}_{50}$ values against BRAF ${ }^{\mathrm{V} 600 \mathrm{E}}$ melanoma cells (http://www. plexxikon.com). Presumably, these and other emerging RAF inhibitors with enhanced potency and selectivity may afford more robust MAP kinase pathway interdiction in clinical trials.

Since MEK1 and MEK2 serine-threonine kinases constitute the critical downstream effectors of BRAF in the MAP kinase cascade (Fig. 4), MEK inhibition also offers an attractive means of targeting tumors with this dependency. Toward this end, several small molecule MEK inhibitors are also in development. Although clinical trials of the first-generation MEK inhibitor CI-1040 (Pfizer, Inc.) were confounded by its suboptimal pharmacokinetic and pharmacodynamic parameters (Rinehart et al. 2004), the second-generation oral inhibitor PD0325901 blocks MEK1/2 at much higher potency (Sebolt-Leopold and Herrera 2004). Recently, an unbiased pharmacologic analysis of NCI-60 cell lines stratified based on the presence or absence of $\mathrm{BRAF}^{\mathrm{V} 600 \mathrm{E}}$ mutation revealed that compounds targeting MEK kinase were among the most potent of $>40,000$ compounds examined against $\mathrm{BRAF}^{\mathrm{V} 600 \mathrm{E}}$ cells (Solit et al. 2006). Interestingly, this selective MEK sensitivity was not observed when the same cell lines were classified based on RAS mutation status. Testing of CI-1040 and PD0325901 against a largely independent panel of BRAF ${ }^{\mathrm{V} 600 E}$ and NRAS ${ }^{\mathrm{Q} 61 \mathrm{R}}$ melanoma cell lines and xenografts yielded similar results. These data suggest that clinical trials of melanoma patients stratified according to $\mathrm{BRAF}^{\mathrm{V} 600 \mathrm{E}}$ mutation may enrich for patients most likely to benefit from secondgeneration RAF and MEK inhibitors. In a recent phase I/II trial of PD0325901 that enrolled 41 patients (27 melanoma patients), melanoma was the only tumor type in which partial disease responses were observed, and such responses were associated with strong phosphoERK inhibition (Lorusso et al. 2005). Although genotype (BRAF and NRAS status) correlation for the responders is not yet available from this trial, these results raise the possibility that RAF and MEK inhibitors dosed to complete target inhibition may prove effective against a defined subset of human melanomas.

The PI3 kinase/AKT pathway A large body of evidence suggests that the TOR pathway acts as a major effector of the AKT oncogenic signal downstream of PI3 kinase activation (described above) (Fig. 4). Pathway components associated with increased cell growth, such as phosphorylation of p70S6 kinase, are sensitive to the TOR inhibitor rapamycin (for a recent review, see Wullschleger et al. 2006). The premise that TOR may mediate downstream tumorigenic functions of activated AKT has generated intense enthusiasm around the idea that TOR inhibitors might prove efficacious in melanoma and other malignancies characterized by frequent PTEN deficiencies. However, the predicted efficacy of TOR inhibitors in melanoma was questioned a priori by a tissue microarray study that examined TOR pathway profiles across a spectrum of human tumors (Xu et al. 2004). Here, none of the 10 melanomas examined expressed the triad of low PTEN, high phospho-S6 kinase, and high phospho-AKT predicted based on in vitro cell line studies to confer rapamycin sensitivity. Consistent with this observation, a phase II trial of the TOR inhibitor temsirolimus (CCI-779) by Wyeth that enrolled 33 melanoma patients resulted in only one partial response (Margolin et al. 2004). These data suggest that single-agent TOR inhibition has limited efficacy in melanoma, and that future trials must either combine other agents with TOR inhibitors or develop robust molecular diagnostic methods to predict TOR dependency in appropriate cancer patients.

Cyclin-dependent kinases The observation that CDKN2A is frequently deleted in melanoma /Chin 2003), combined with the role of cyclin-dependent kinases such as CDK2 in melanoma proliferation (Du et al. 2004), implicates the $\mathrm{p} 16 / \mathrm{CDK} / \mathrm{pRb}$ pathway as an additional melanoma dependency with possible therapeutic implications. Indeed, unopposed activation of CDK2 as well as CDK4/6 mediates hyperphosphorylation of all Rb pocket proteins in melanoma (Halaban 1999). CDK2 inhibition, in particular, may offer a theoretical therapeutic index in melanoma, because melanoma cell lines appeared to exhibit particular dependence on this kinase, whereas normal tissues (and nonmelanoma cancers) appeared to tolerate CDK2 inhibition (Tetsu and McCormick 2003; Du et al. 2004). These findings have prompted the clinical development of several agents capable of inhibiting CDKs. Flavopiridol, which inhibits CDK1, CDK2, CDK4, and CDK7, represents the best characterized CDK inhibitor. This compound promotes cell cycle arrest and apoptosis in many cancer cell lines; however, flavopiridol has thus far been ineffective as an anticancer agent in several clinical trials (Shapiro 2004). Several additional CDK inhibitors currently at various stages of development (e.g., UCN-01, CYC202, and BMS387032) may provide greater selectivity among these kinases; their efficacies against melanoma and other solid tumors remain to be determined.

Global regulators of protein homeostasis The ubiquitous chaperone protein Hsp90 mediates proper folding and activation of many cell signaling proteins and transcriptional activators (Fig. 4). Known Hsp90 client proteins include several well-known oncogenes, such as the EGF, HER-2, and MET RTKs, AKT family members; and the CDK4/6 cell cycle regulators (for review, see Workman 2004). Of particular relevance to melanoma, Hsp90 appears to bind and stabilize the activated protein conformations of BRAF, as well as other oncogenes that result from gain-of-function mutations (da Rocha Dias et al. 2005; Grbovic et al. 2006). These observations may in part explain the often substantial increases in Hsp90 activity 
observed in tumor cells as compared with normal cells. In principle, pharmacologic blockade of Hsp90 might simultaneously interdict multiple cellular mechanisms operant in advanced melanoma as well as other solid tumors. If so, Hsp90 small molecule inhibitors may approximate combinatorial actions against multiple hallmark tumor mechanisms. Toward this end, the ansamycin antibiotic geldanamycin and its less toxic derivative 17-allylaminogeldanamycin (17-AAG) have been shown to effect potent inhibition of Hsp90 in vitro, resulting in degradation of oncoproteins such as RAF, CDK4, and HER-2, and efficient tumor growth inhibition in several tumor model systems (for review, see Kamal et al. 2004). Accordingly, several phase I clinical trials using varying 17-AAG dosing schedules have been conducted (Banerji et al. 2005; Goetz et al. 2005; Grem et al. 2005; Ramanathan et al. 2005). At high doses (ca. $450 \mathrm{mg} / \mathrm{m}^{2}$ per week), evidence of clinical efficacy has occasionally been achieved; two melanoma patients have been reported whose disease stabilized for as long as $2 \mathrm{yr}$ in response to 17-AAG treatment (for review, see Workman 2004). However, development of this agent has been stunted by limited drug solubility and potency in the setting of frequent and diverse toxicities. Therefore, recent efforts in this arena have shifted toward clinical trials using lower 17-AAG doses in combination with conventional chemotherapeutic agents, or to the identification of novel Hsp90 inhibitors with improved potency and therapeutic indices (Llauger et al. 2005). For example, IPI-504 is a novel, water-soluble Hsp90 inhibitor in clinical development that is converted to $17-\mathrm{AAG}$ in vivo; this may enable targeted delivery of higher doses into tumor tissue (http://www.ipi.com).

Targeting apoptosis in melanoma: inhibiting Bcl2 In recent years it has become clear that resistance to apoptosis promotes both tumor survival and refractoriness to cytotoxic chemotherapy (Johnstone et al. 2002). Normal melanocytes appear to elaborate several intrinsic and extrinsic anti-apoptotic mechanisms that may be exploited in melanoma; these include the expression of melanin and other factors that protect against phototoxic DNA damage, as well as prosurvival signals from the autocrine and paracrine factors mentioned above (for review, see Soengas and Lowe 2003). Aggressive melanoma tumors and cell lines often manifest low apoptotic indices (Glinsky et al. 1997). Moreover, signaling pathways such as the MAP kinase and PI3 kinase/AKT cascades that undergo aberrant activation in melanoma produce well-characterized tumor survival effects (for recent reviews, see Wada and Penninger 2004; Kharas and Fruman 2005). In melanoma, MAP kinase signaling prevents apoptosis through several mechanisms, including the inhibition of mitochondrial Smac/DIABLO release in response to TRAIL (Zhang et al. 2003), up-regulation of Bcl2 expression via MITF (McGill et al. 2002), and inactivation of the Bad proapoptotic protein (Eisenmann et al. 2003). These observations have fueled a heightened interest in anti-apoptotic melanoma therapeutic strategies.
Melanoma oncogenic growth factors such as NGF and SCF induce the expression of the Bcl-2 oncoprotein (Zhai et al. 1996), as does MITF (McGill et al. 2002), which is also deregulated in some melanomas, as described above. Similarly, the "classic" melanoma growth factor bFGF subverts inhibitory signals from TGF- $\beta$ that reduce Bcl-2 levels (von Willebrand et al. 2005). Expression of activated NRAS in melanoma cell lines can also up-regulate Bcl-2 (Borner et al. 1999). Both normal melanocytes and melanoma cells express Bcl-2 (Plettenberg et al. 1995), and several studies have correlated elevated Bcl-2 with adverse clinical and pathological factors such as tumor ulceration and patient survival, particularly in thicker primary melanomas (Leiter et al. 2000; Ilmonen et al. 2005). Moreover, germline knockout of Bcl-2 results in death of melanocyte stem cells within the hair follicle at a discrete developmental state (Nishimura et al. 2005), demonstrating a critical role for Bcl-2 in the melanocyte lineage. Additional BCL anti-apoptotic proteins such as Mcl-1 and Bcl-XL are also expressed at various stages of melanoma and may influence both tumor progression and chemoresistance (Tron et al. 1995; Selzer et al. 1998; Skvara et al. 2005). Thus, targeting BCL family members either alone or in combination with conventional cytotoxic agents has been predicted to offer therapeutic benefit in this malignancy.

Extensive clinical experience now exists with Genasense (G3139; Genta, Inc.), an antisense therapeutic directed against Bcl-2 (Badros et al. 2005; Marcucci et al. 2005; O'Brien et al. 2005; Tolcher et al. 2005). Encouraging phase II trial results, including evidence of target modulation, have been reported in hormone-refractory prostate cancer and relapsed multiple myeloma (Badros et al. 2005; Tolcher et al. 2005). Genasense has also been tested in a large phase III study that randomized 771 metastatic melanoma patients to receive DTIC plus either Genasense or placebo. Here, the addition of Genasense to DTIC failed to increase patient survival relative to DTIC alone (median survival $9.0 \mathrm{mo}$ vs. $7.8 \mathrm{mo}$; $p=0.18$ ). Thus, like Temozolomide (described above), Genasense failed to receive FDA approval for use in metastatic melanoma (a summary report from the Genasense FDA review team is available at http://www. fda.gov/ohrms/dockets/ac/04/slides/4037S1_02_FDA-KaneYang\%20.ppt).

A retrospective view of the preclinical and clinical data surrounding Bcl-2 inhibition presents several important considerations that should influence future targeted therapeutic attempts in melanoma and other cancers. One issue pertains to rigorous target validation: In the case of Bcl-2, the scientific literature projects marked discordance concerning the extent to which Bcl-2 levels correlate with melanoma progression (Bush and Li 2003). In fact, some reports have suggested that melanoma progression is associated with loss of Bcl-2 expression (van den Oord et al. 1994; Vlaykova et al. 2002). A large study of anti-apoptotic gene expression levels from melanoma sentinel lymph nodes suggested that only survivin expression correlated significantly with clinical outcome, with Bcl-2 showing no association /Gradilone et al. 
2003). In one sense, these data might imply that Bcl-2 constitutes a suboptimal melanoma target. However, given the known oncogenic function of Bcl-2 in many human cancers, an alternative explanation is that its anti-apoptotic mechanism may operate primarily within a restricted melanoma subset; for example, those tumors characterized by strong Bcl-2 immunostaining, or other predictive molecular alterations. Thus, lessons from the Bcl-2 experience support future patient selection based on key cellular dependency metrics, where possible.

The above notion underscores an emerging premise relevant to targeted therapeutics across all human tumors: In general, biomarker panels capable of predicting drug sensitivity need to be developed in parallel to the relevant investigational agents. In some cases, a critical somatic genetic alteration by itself may serve as the informative biomarker; the available data for RAF and MEK inhibitor studies in $\mathrm{BRAF}^{\mathrm{V} 600 \mathrm{E}}$ melanomas endorse this idea. More commonly, biomarkers will likely require empiric determination and iterative validation based on unbiased omics-derived correlates from large clinical trials. Such predictive biomarker signatures will pave the way for rational clinical trial designs that stratify patients a priori based on the likelihood that their tumors will respond to the agent in question. Finally, the Bcl-2 experience offers a reminder that clinical trials of targeted agents increasingly require concomitant pharmacodynamic studies that link tumor response to effective target interdiction. Such analyses have proved informative in MEK inhibitor trial (described above), where the suboptimal performance of CI-1040 was attributable to incomplete target inhibition. Toward this end, melanoma provides a favorable setting for in situ pharmacodynamic testing; often, patients with advanced disease contain numerous dermal metastases that can be biopsied with minimal risk.

\section{Melanoma immunotherapy}

The longstanding recognition that primary melanoma lesions may exhibit regions of spontaneous regression, combined with histologic evidence that T-cell infiltration of melanoma tumors correlates with better prognosis (Clemente et al. 1996), places this malignancy at the forefront of immunotherapeutic approaches in human solid tumors. The idea of harnessing the immune system against solid tumors offers conceptual appeal because of the unparalleled target specificity achievable in principle through immune recognition of tumor antigens. Unfortunately, several decades of translational science in cancer immunotherapy have not yet succeeded in altering the natural history of advanced melanoma. Instead, these efforts have unwittingly demonstrated the diverse and sophisticated avenues by which melanoma cells can resist immune destruction. Protective tumor mechanisms include immunoediting, lack of expression of "danger signals" recognized by the immune system, induction of tolerance and/or a refractory inflammatory environment, and elaboration of immunosuppressive factors. Despite these challenges, immunomodulatory agents have consistently triggered rare but profound melanoma tumor responses, suggesting that some patients with metastatic disease may be cured by these regimens. This observation stands in marked contradistinction to the experience with conventional chemotherapy described above. Moreover, recent advances in biological understanding of immune regulatory mechanisms justify a guarded optimism that future immunotherapeutic strategies might enjoy an even larger measure of success in defined melanoma subtypes.

Interferon- $\alpha$ (IFN- $\alpha)$ and interleukin-2 (IL-2) anchor the existing immunotherapeutic repertoire for melanoma treatment. IFN- $\alpha$ is given as adjuvant therapy for patients whose primary lesion poses a high risk for relapse (either because of adverse histologic features or spread to regional lymph nodes); in this setting, it improves both relapse-free and overall survival (Kirkwood et al. 1996, 2001). The response rate to IFN- $\alpha$ in metastatic melanoma is $\sim 16 \%$; up to one-third of these may be prolonged (Agarwala 2003). IL-2 therapy also yields response rates ranging from $15 \%$ to $20 \%$ in advanced melanoma; complete remissions (which are often durable) may occur in $\sim 4 \%-6 \%$ of patients (Atkins et al. 1999). Despite these encouraging results, both IFN- $\alpha$ and IL-2 regimens are hampered by substantial and frequently dose-limiting toxicities, which have curbed their widespread use in metastatic disease.

The toxicity associated with systemic IL-2 and IFN- $\alpha$ treatment has led to dose modifications and a series of combinatorial regimens collectively termed biochemotherapy or chemoimmunotherapy (Richards et al. 1992; Atkins et al. 1994). Several of these regimens have yielded encouraging tumor response rates (Legha et al. 1998; Eton et al. 2002); however, no large randomized trial has yet demonstrated a survival benefit. These ambiguous results have thus far precluded widespread application of biochemotherapy in advanced melanoma.

Melanoma vaccines The toxicities and limited efficacy of existing immunotherapeutic approaches provides a rationale for less toxic alternatives to harnessing the immune system against melanoma. Robust methods to identify melanoma-specific antigens recognized by $\mathrm{CD}^{+}$ and $\mathrm{CD}^{+} \mathrm{T}$-lymphocytes have fueled a diverse array of melanoma vaccine efforts in recent years, including some that exploit enforced expression of the immunostimulatory cytokine GM-CSF. While a comprehensive discussion of their design and underlying immunologic principles lies beyond the scope of this review (and has been discussed in several recent reviews, Dranoff 2002; Sondak and Sosman 2003; Speiser et al. 2003; Talebi and Weber 2003), three broad melanoma vaccine categories may be recognized: (1) those that use lymphocyte-derived tumor antigens; (2) vaccines derived from whole tumor cells; and (3) the use of dendritic cells pulsed with melanoma antigens. These strategies have been tested both alone and in combination with novel adjuvants aimed at boosting the resulting anti-tumor immune response. Induction of a specific immune response is frequently demonstrable in melanoma patients following 
vaccination; however, meaningful clinical responses are much less common. Efforts are ongoing to test systemic immunotherapeutic agents after vaccination to see if the vaccine-primed immune system can garner a more effective tumor regression in this context.

Toll-like receptor agonists Dendritic cells, monocytes, and other innate immune cell types express Toll-like receptors (TLRs), a family of transmembrane proteins that direct initiation of innate immune responses and enhance subsequent adaptive responses to a variety of insults (Pasare and Medzhitov 2003). TLR activation augments the host immune response in several ways (Fig. 4), including cytokine/chemokine activation, induction of phagocytosis by host cells, and increasing expression of costimulatory molecules (e.g., CD80 and CD86) on dendritic cells, thereby effecting more efficient T-cell activation. Many of these same immune activities should be beneficial in anti-tumor immunity, particularly in the case of melanoma, since TLR actions appear critical in the dermal immune environment. Thus, several groups have begun to investigate pharmacologic approaches toward TLR activation in melanoma immunotherapy.

The imidazoquinolones, which include imiquimod and resiquimod (R-848), are well-known immune-modifying compounds that possess TLR agonistic activity, particularly against the TLR7 isoform. TLR7 agonists can eradicate tumor cells both in cell culture and in vivo (Schon et al. 2003). Imiquimod, which is used clinically to treat anogenital human papillomavirus (HPV) infections, also demonstrates anti-tumor activity against numerous benign and malignant human skin neoplasms. Administration of imiquimod as a topical cream has achieved partial or complete regressions in dysplastic nevi, lentigo maligna, basal cell cancers, and melanoma skin metastases (Ahmed and Berth-Jones 2000; Naylor et al. 2003; Schon et al. 2004; Noel and Kunzle 2005; Zeitouni et al. 2005; Dusza et al. 2006). Moreover, preliminary evidence suggests that this agent may enhance the potency of anti-melanoma vaccines (Craft et al. 2005). Direct application of imiquimod to these cutaneous lesions is associated with natural killer (NK) cell infiltration within days, followed by tumor cell lysis and macrophage infiltration; this response is consistent with immune-mediated killing. Decreased BCL-2 expression within neoplastic cells appears to precede tumor cell death. Whether imiquimod or other TLR agonists can safely be administered as systemic agents is uncertain; however, these findings suggest that this form of immune modulation might prove useful as palliative management within the subset of melanoma patients whose metastatic disease is confined to the skin.

CTLA-4 antibody blockade An essential component of tumor immunotherapy involves T-cell activation in response to tumor-specific antigens. However, effective Tcell stimulation also requires a costimulatory signal; the absence of such costimulation results in anergy or death of the T cell. CD28, the major costimulatory receptor for $\mathrm{T}$ cells, binds to CD80 or CD86 ligands expressed on antigen-presenting cells, as shown in Figure 4. CTLA-4 is a member of the CD28 family and is expressed only on activated $\mathrm{T}$ cells; this protein binds CD80 and CD86 with high affinity. However, in contrast to CD28, CTLA-4 appears to attenuate T-cell function. Consistent with this observation, altered CTLA-4 activity contributes to pathogenesis in several mouse models of autoimmune disease. Genetic studies in humans link specific variant CTLA-4 alleles to autoimmune thyroid disease and insulin-dependent diabetes, among others (for review, see Kristiansen et al. 2000). Moreover, CTLA-4 appears to contribute significantly to maintenance of $\mathrm{T}$ cell tolerance to self antigens present on both normal and tumor cells (Takahashi et al. 2000).

Anti-CTLA-4 monoclonal antibodies have recently entered clinical development. Blockade of CTLA-4 function by these antibodies can trigger or exacerbate autoimmunity, but also enhances immune-mediated tumor rejection in mouse models (Leach et al. 1996; van Elsas et al. 1999; Egen et al. 2002). A phase I study of this strategy was reported by Hodi et al. (2003) and demonstrated significant biologic activity in subsets of previously immunized patients with advanced disease. MDX-010 (Mederex, Inc.), a fully humanized anti-CTLA-4 antibody, yielded an encouraging tumor response rate in a phase II trial that enrolled 56 metastatic melanoma patients (Attia et al. 2005), including several patients whose responses persisted for $>2$ yr. Systemic autoimmunity constitutes the major toxicity associated with CTLA-4 blockade; this can be severe or even lethal if not identified promptly. In the future, administration of antiCTLA-4 after a trial of a melanoma vaccine may augment a more specific anti-melanoma immune response while allowing patients to receive a less toxic dose (Sanderson et al. 2005; Hodi et al. 2006). Overall, the CTLA-4 experience highlights both the promise of melanoma immunotherapy and the challenges of uncoupling a robust anti-tumor response from the predictable and often dangerous immune-mediated side effects (Dranoff 2005).

\section{Future directions in melanoma therapy}

Expanding knowledge of melanoma somatic genetics and advances in anti-tumor immunity provide a rich ground for targeted small-molecule and immunotherapeutic deployment. Anti-angiogenesis therapy may also offer promise in melanoma; indeed, advanced melanomas often become highly vascular and bleed easily, particularly when metastatic to brain. Recent work suggests that many metastatic melanomas exhibit down-regulation of the AP-2 transcription factor; this leads to increased MCAM/MUC18 and thrombin receptor expression, which, in turn, activates angiogenic factors such as IL-8 (for review, see Bar-Eli 1999). Fully humanized monoclonal antibodies directed against MCAM/MUC18 and IL-8 inhibit melanoma growth and angiogenesis in mouse xenografts (Huang et al. 2002; Mills et al. 2002). These intriguing findings merit additional study, particu- 
larly in light of the recent successes of anti-angiogenic monoclonal antibody therapy in other solid tumors.

At the same time, use of the above regimens as single agents may at best benefit subsets of melanoma patients and prove unlikely to achieve long-term remissions; therefore, combinations of targeted and/or immunotherapeutic options may expand their cumulative clinical benefit. On the other hand, the toxic side effects of even "targeted" therapies remain considerable. Thus, a major priority for future clinical trials will be the concordant development of genetic or molecular markers that may be used by clinical pathologists and medical oncologists to allow prospective selection of patients most likely to benefit from emerging therapeutic regimens. Biomarker-based patient stratification will therefore improve the chances of therapeutic success while minimizing unnecessary patient exposure to drug toxicities.

BRAF mutation currently represents the leading candidate for a genetic biomarker; presumably, this variant will predict responders to RAF or MEK inhibition, as described above. The demonstration of c-Kit mutation in $1 \%-2 \%$ of melanoma patients justifies efforts to evaluate the therapeutic efficacy of imatinib in this patient subpopulation. Identification of predictive biomarkers for response to immunotherapies (e.g., IL-2, INF- $\alpha$, and anti-CTLA-4) is equally important and remains an area of active investigation. Recently, a nested study of 200 patients from an ongoing randomized trial found that the presence of either vitiligo or autoantibodies in the serum of metastatic melanoma patients 1 mo after initiation of IFN- $\alpha$ treatment was strongly correlated with increased patient survival (Gogas et al. 2006). These findings raise the possibility that biomarkers indicative of the presence of sensitive melanoma antigens or an effective antitumor immune response might similarly prove to be predictive of future responders to other systemic immunotherapeutic regimens.

While traditionally considered nondrugable, the increasing recognition that transcription factors (e.g., MITF) may play oncogenic roles in melanoma has driven efforts to devise alternative approaches to target this protein class. One such approach involves the use of peptide to block transcription factor activities. In melanoma, ATF2 has been targeted in this fashion with impressive preclinical results (Bhoumik et al. 2002, 2004). These observations are particularly intriguing given evidence that ATF2 nuclear localization correlates with prognosis in human melanoma specimens (Berger et al. 2003). An additional strategy involves elucidating the critical downstream target(s) of oncogenic transcription factors, some of which may prove to be more amenable to smallmolecule compound inhibition. Finally, elucidation of these pathways stands to offer novel targeted strategies at prevention (D'Orazio et al. 2006).

The unprecedented propagation of melanoma genetics, genomics, and biological understanding justifies an optimistic view of its future therapeutic outlook. Undoubtedly, the road ahead will remain stunted with challenges and occasional setbacks; however, salient tumor depen- dencies that underlie definable melanoma subtypes have begun to emerge. In partnership with versatile in vitro and in vivo model systems, increasingly rigorous target validation and rational drug development efforts, and judicious use of correlative omics studies for robust biomarkers, melanoma promises to provide an instructive framework for progress against even the most brittle of human malignancies.

\section{Acknowledgments}

We extend our sincere apology to those colleagues whose studies were not cited in this review due to space constraints. We thank Drs. C. Goding, M. Atkins, and H. Tsao for critical comments and discussion on the manuscript. This work is supported by grants to L.C. (NIH RO1 CA93947; UO1 CA84313; and P50 CA93683), L.A.G. (NIH K08 CA115927-01), and D.E.F. (NIH AR045662; AR43369; CA102309). D.E.F. is a Doris Duke Distinguished Clinical Investigator and the Jan and Charles Nirenberg Fellow at the Dana-Farber Cancer Institute.

\section{References}

Ackermann, J., Frutschi, M., Kaloulis, K., McKee, T., Trumpp, A., and Beermann, F. 2005. Metastasizing melanoma formation caused by expression of activated N-RasQ61K on an INK4a-deficient background. Cancer Res. 65: 4005-4011.

Adachi, S., Morii, E., Kim, D., Ogihara, H., Jippo, T., Ito, A., Lee, Y.M., and Kitamura, Y. 2000. Involvement of mi-transcription factor in expression of $\alpha$-melanocyte-stimulating hormone receptor in cultured mast cells of mice. J. Immunol. 164: $855-860$.

Agarwala, S. 2003. Improving survival in patients with high-risk and metastatic melanoma: Immunotherapy leads the way. Am. J. Clin. Dermatol. 4: 333-346.

Ahmad, T. and Eisen, T. 2004. Kinase inhibition with BAY 439006 in renal cell carcinoma. Clin. Cancer Res. 10: 6388S6392S.

Ahmed, I. and Berth-Jones, J. 2000. Imiquimod: A novel treatment for lentigo maligna. Br. J. Dermatol. 143: 843-845.

Aitken, J., Welch, J., Duffy, D., Milligan, A., Green, A., Martin, N., and Hayward, N.K. 1999. CDKN2A variants in a population-based sample of Queensland families with melanoma. J. Natl. Cancer Inst. 91: 446-452.

Albino, A.P., Nanus, D.M., Mentle, I.R., Cordon-Cardo, C., McNutt, N.S., Bressler, J., and Andreeff, M. 1989. Analysis of ras oncogenes in malignant melanoma and precursor lesions: Correlation of point mutations with differentiation phenotype. Oncogene 4: 1363-1374.

Aoki, H. and Moro, O. 2002. Involvement of microphthalmiaassociated transcription factor (MITF) in expression of human melanocortin-1 receptor (MC1R). Life Sci. 71: 21712179.

Argani, P., Hawkins, A., Griffin, C.A., Goldstein, J.D., Haas, M., Beckwith, J.B., Mankinen, C.B., and Perlman, E.J. 2001. A distinctive pediatric renal neoplasm characterized by epithelioid morphology, basement membrane production, focal HMB45 immunoreactivity, and $\mathrm{t}(6 ; 11)(\mathrm{p} 21.1 ; \mathrm{q} 12)$ chromosome translocation. Am. J. Pathol. 158: 2089-2096.

Atkins, M.B., O'Boyle, K.R., Sosman, J.A., Weiss, G.R., Margolin, K.A., Ernest, M.L., Kappler, K., Mier, J.W., Sparano, J.A., Fisher, R.I., et al. 1994. Multiinstitutional phase II trial of intensive combination chemoimmunotherapy for metastatic melanoma. J. Clin. Oncol. 12: 1553-1560. 
Atkins, M.B., Lotze, M.T., Dutcher, J.P., Fisher, R.I., Weiss, G., Margolin, K., Abrams, J., Sznol, M., Parkinson, D., Hawkins, M., et al. 1999. High-dose recombinant interleukin 2 therapy for patients with metastatic melanoma: Analysis of 270 patients treated between 1985 and 1993. J. Clin. Oncol. 17: 2105-2116.

Attia, P., Phan, G.Q., Maker, A.V., Robinson, M.R., Quezado, M.M., Yang, J.C., Sherry, R.M., Topalian, S.L., Kammula, U.S., Royal, R.E., et al. 2005. Autoimmunity correlates with tumor regression in patients with metastatic melanoma treated with anti-cytotoxic T-lymphocyte antigen-4. J. Clin. Oncol. 23: 6043-6053.

Badros, A.Z., Goloubeva, O., Rapoport, A.P., Ratterree, B., Gahres, N., Meisenberg, B., Takebe, N., Heyman, M., Zwiebel, J., Streicher, H., et al. 2005. Phase II study of G3139, a Bcl-2 antisense oligonucleotide, in combination with dexamethasone and thalidomide in relapsed multiple myeloma patients. J. Clin. Oncol. 23: 4089-4099.

Balch, C.M., Soong, S.J., Gershenwald, J.E., Thompson, J.F., Reintgen, D.S., Cascinelli, N., Urist, M., McMasters, K.M., Ross, M.I., Kirkwood, J.M., et al. 2001. Prognostic factors analysis of 17,600 melanoma patients: Validation of the American Joint Committee on Cancer melanoma staging system. J. Clin. Oncol. 19: 3622-3634.

Banerji, U., Walton, M., Raynaud, F., Grimshaw, R., Kelland, L., Valenti, M., Judson, I., and Workman, P. 2005. Pharmacokinetic-pharmacodynamic relationships for the heat shock protein 90 molecular chaperone inhibitor 17-allylamino, 17demethoxygeldanamycin in human ovarian cancer xenograft models. Clin. Cancer Res. 11: 7023-7032.

Bardeesy, N., Wong, K.K., DePinho, R.A., and Chin, L. 2000. Animal models of melanoma: Recent advances and future prospects. Adv. Cancer Res. 79: 123-156.

Bardeesy, N., Bastian, B.C., Hezel, A., Pinkel, D., DePinho, R.A., and Chin, L. 2001. Dual inactivation of RB and p53 pathways in RAS-induced melanomas. Mol. Cell. Biol. 21: 2144-2153.

Bardeesy, N., Kim, M., Xu, J., Kim, R.S., Shen, Q., Bosenberg, M.W., Wong, W.H., and Chin, L. 2005. Role of epidermal growth factor receptor signaling in RAS-driven melanoma. Mol. Cell. Biol. 25: 4176-4188.

Bar-Eli, M. 1999. Role of AP-2 in tumor growth and metastasis of human melanoma. Cancer Metastasis Rev. 18: 377-385.

Barsh, G.S. 1996. The genetics of pigmentation: From fancy genes to complex traits. Trends Genet. 12: 299-305.

Bastiaens, M., ter Huurne, J., Gruis, N., Bergman, W., Westendorp, R., Vermeer, B.J., and Bouwes Bavinck, J.N. 2001a. The melanocortin-1-receptor gene is the major freckle gene. Hum. Mol. Genet. 10: 1701-1708.

Bastiaens, M.T., ter Huurne, J.A., Kielich, C., Gruis, N.A., Westendorp, R.G., Vermeer, B.J., and Bavinck, J.N. 2001b. Melanocortin-1 receptor gene variants determine the risk of nonmelanoma skin cancer independently of fair skin and red hair. Am. J. Hum. Genet. 68: 884-894.

Bastian, B.C. 2003. Understanding the progression of melanocytic neoplasia using genomic analysis: From fields to cancer. Oncogene 22: 3081-3086.

Bastian, B.C., LeBoit, P.E., Hamm, H., Brocker, E.B., and Pinkel, D. 1998. Chromosomal gains and losses in primary cutaneous melanomas detected by comparative genomic hybridization. Cancer Res. 58: 2170-2175.

Bastian, B.C., LeBoit, P.E., and Pinkel, D. 2000. Mutations and copy number increase of HRAS in Spitz nevi with distinctive histopathological features. Am. J. Pathol. 157: 967-972.

Baxter, L.L. and Pavan, W.J. 2003. Pmel17 expression is Mitfdependent and reveals cranial melanoblast migration during murine development. Gene Expr. Patterns 3: 703-707.
Bentley, N.J., Eisen, T., and Goding, C.R. 1994. Melanocytespecific expression of the human tyrosinase promoter: Activation by the microphthalmia gene product and role of the initiator. Mol. Cell. Biol. 14: 7996-8006.

Berger, A.J., Kluger, H.M., Li, N., Kielhorn, E., Halaban, R., Ronai, Z., and Rimm, D.L. 2003. Subcellular localization of activating transcription factor 2 in melanoma specimens predicts patient survival. Cancer Res. 63: 8103-8107.

Bertolotto, C., Abbe, P., Hemesath, T.J., Bille, K., Fisher, D.E., Ortonne, J.P., and Ballotti, R. 1998. Microphthalmia gene product as a signal transducer in cAMP-induced differentiation of melanocytes. J. Cell Biol. 142: 827-835.

Bhoumik, A., Huang, T.G., Ivanov, V., Gangi, L., Qiao, R.F., Woo, S.L., Chen, S.H., and Ronai, Z. 2002. An ATF2-derived peptide sensitizes melanomas to apoptosis and inhibits their growth and metastasis. J. Clin. Invest. 110: 643-650.

Bhoumik, A., Gangi, L., and Ronai, Z. 2004. Inhibition of melanoma growth and metastasis by ATF2-derived peptides. Cancer Res. 64: 8222-8230.

Bittner, M., Meltzer, P., Chen, Y., Jiang, Y., Seftor, E., Hendrix, M., Radmacher, M., Simon, R., Yakhini, Z., Ben-Dor, A., et al. 2000. Molecular classification of cutaneous malignant melanoma by gene expression profiling. Nature 406: 536540.

Bohm, M., Moellmann, G., Cheng, E., Alvarez-Franco, M., Wagner, S., Sassone-Corsi, P., and Halaban, R. 1995. Identification of p90RSK as the probable CREB-Ser133 kinase in human melanocytes. Cell Growth Differ. 6: 291-302.

Bondurand, N., Pingault, V., Goerich, D.E., Lemort, N., Sock, E., Caignec, C.L., Wegner, M., and Goossens, M. 2000. Interaction among SOX10, PAX3 and MITF, three genes altered in Waardenburg syndrome. Hum. Mol. Genet. 9: 1907-1917.

Borner, C., Schlagbauer Wadl, H., Fellay, I., Selzer, E., Polterauer, P., and Jansen, B. 1999. Mutated N-ras upregulates Bcl-2 in human melanoma in vitro and in SCID mice. Melanoma Res. 9: 347-350.

Bos, J.L. 1989. ras oncogenes in human cancer: A review. Cancer Res. 49: 4682-4689.

Bottaro, D.P., Rubin, J.S., Faletto, D.L., Chan, A.M., Kmiecik, T.E., Vande Woude, G.F., and Aaronson, S.A. 1991. Identification of the hepatocyte growth factor receptor as the c- met proto-oncogene product. Science 251: 802-804.

Bouillet, P., Cory, S., Zhang, L.C., Strasser, A., and Adams, J.M. 2001. Degenerative disorders caused by Bcl-2 deficiency prevented by loss of its BH3-only antagonist Bim. Dev. Cell 1: 645-653.

Box, N.F., Wyeth, J.R., O'Gorman, L.E., Martin, N.G., and Sturm, R.A. 1997. Characterization of melanocyte stimulating hormone receptor variant alleles in twins with red hair. Hum. Mol. Genet. 6: 1891-1897.

Box, N.F., Duffy, D.L., Chen, W., Stark, M., Martin, N.G., Sturm, R.A., and Hayward, N.K. 2001. MC1R genotype modifies risk of melanoma in families segregating CDKN2A mutations. Am. J. Hum. Genet. 69: 765-773.

Bradl, M., Klein-Szanto, A., Porter, S., and Mintz, B. 1991. Malignant melanoma in transgenic mice. Proc. Natl. Acad. Sci. 88: $164-168$.

Busca, R. and Ballotti, R. 2000. Cyclic AMP a key messenger in the regulation of skin pigmentation. Pigment Cell Res. 13: 60-69.

Busca, R., Berra, E., Gaggioli, C., Khaled, M., Bille, K., Marchetti, B., Thyss, R., Fitsialos, G., Larribere, L., Bertolotto, C., et al. 2005. Hypoxia-inducible factor $1 \alpha$ is a new target of microphthalmia-associated transcription factor (MITF) in melanoma cells. J. Cell Biol. 170: 49-59.

Bush, J.A. and Li, G. 2003. The role of Bcl-2 family members in 
the progression of cutaneous melanoma. Clin. Exp. Metastasis 20: 531-539.

Carreira, S., Goodall, J., Aksan, I., La Rocca, S.A., Galibert, M.D., Denat, L., Larue, L., and Goding, C.R. 2005. Mitf cooperates with Rb1 and activates p21Cip1 expression to regulate cell cycle progression. Nature 433: 764-769.

Cassady, A.I., Luchin, A., Ostrowski, M.C., and Hume, D.A. 2003. Regulation of the murine TRACP gene promoter. $J$. Bone Miner. Res. 18: 1901-1904.

Casula, M., Colombino, M., Satta, M.P., Cossu, A., Ascierto, P.A., Bianchi-Scarra, G., Castiglia, D., Budroni, M., Rozzo, C., Manca, A., et al. 2004. BRAF gene is somatically mutated but does not make a major contribution to malignant melanoma susceptibility: The Italian Melanoma Intergroup Study. J. Clin. Oncol. 22: 286-292.

Chin, L. 2003. The genetics of malignant melanoma: Lessons from mouse and man. Nat. Rev. Cancer 3: 559-570.

Chin, L. and DePinho, R.A. 2000. Flipping the oncogene switch: Illumination of tumor maintenance and regression. Trends Genet. 16: 147-150.

Chin, L., Pomerantz, J., Polsky, D., Jacobson, M., Cohen, C., Cordon-Cardo, C., Horner II, J.W., and DePinho, R.A. 1997. Cooperative effects of INK4a and ras in melanoma susceptibility in vivo. Genes \& Dev. 11: 2822-2834.

Chin, L., Merlino, G., and DePinho, R.A. 1998. Malignant melanoma: Modern black plague and genetic black box. Genes \& Dev. 12: 3467-3481.

Chin, L., Tam, A., Pomerantz, J., Wong, M., Holash, J., Bardeesy, N., Shen, Q., O'Hagan, R., Pantginis, J., Zhou, H., et al. 1999. Essential role for oncogenic Ras in tumour maintenance. Nature 400: 468-472.

Chudnovsky, Y., Adams, A.E., Robbins, P.B., Lin, Q., and Khavari, P.A. 2005. Use of human tissue to assess the oncogenic activity of melanoma-associated mutations. Nat. Genet. 37: 745-749.

Ciampi, R. and Nikiforov, Y.E. 2005. Alterations of the BRAF gene in thyroid tumors. Endocr. Pathol. 16: 163-172.

Clark, J., Lu, Y.J., Sidhar, S.K., Parker, C., Gill, S., Smedley, D., Hamoudi, R., Linehan, W.M., Shipley, J., and Cooper, C.S. 1997. Fusion of splicing factor genes PSF and NonO (p54nrb) to the TFE3 gene in papillary renal cell carcinoma. Oncogene 15: 2233-2239.

Clemente, C.G., Mihm Jr., M.C., Bufalino, R., Zurrida, S., Collini, P., and Cascinelli, N. 1996. Prognostic value of tumor infiltrating lymphocytes in the vertical growth phase of primary cutaneous melanoma. Cancer 77: 1303-1310.

Cohen, Y., Goldenberg-Cohen, N., Parrella, P., Chowers, I., Merbs, S.L., Pe'er, J., and Sidransky, D. 2003. Lack of BRAF mutation in primary uveal melanoma. Invest. Ophthalmol. Vis. Sci. 44: 2876-2878.

Craft, N., Bruhn, K.W., Nguyen, B.D., Prins, R., Lin, J.W., Liau, L.M., and Miller, J.F. 2005. The TLR7 agonist imiquimod enhances the anti-melanoma effects of a recombinant Listeria monocytogenes vaccine. J. Immunol. 175: 1983-1990.

Crews, C.M., Alessandrini, A.A., and Erikson, R.L. 1991. Mouse Erk-1 gene product is a serine/threonine protein kinase that has the potential to phosphorylate tyrosine. Proc. Natl. Acad. Sci. 88: 8845-8849.

Cruz III, F., Rubin, B.P., Wilson, D., Town, A., Schroeder, A., Haley, A., Bainbridge, T., Heinrich, M.C., and Corless, C.L. 2003. Absence of BRAF and NRAS mutations in uveal melanoma. Cancer Res. 63: 5761-5766.

Curtin, J.A., Fridlyand, J., Kageshita, T., Patel, H.N., Busam, K.J., Kutzner, H., Cho, K.H., Aiba, S., Brocker, E.B., LeBoit, P.E., et al. 2005. Distinct sets of genetic alterations in melanoma. N. Engl. J. Med. 353: 2135-2147.
Dai, D.L., Martinka, M., and Li, G. 2005. Prognostic significance of activated Akt expression in melanoma: A clinicopathologic study of 292 cases. J. Clin. Oncol. 23: 1473-1482.

Daniotti, M., Oggionni, M., Ranzani, T., Vallacchi, V., Campi, V., Di Stasi, D., Torre, G.D., Perrone, F., Luoni, C., Suardi, S., et al. 2004. BRAF alterations are associated with complex mutational profiles in malignant melanoma. Oncogene 23: 5968-5977.

da Rocha Dias, S., Friedlos, F., Light, Y., Springer, C., Workman, P., and Marais, R. 2005. Activated B-RAF is an Hsp90 client protein that is targeted by the anticancer drug 17-allylamino17-demethoxygeldanamycin. Cancer Res. 65: 10686-10691.

Davies, H., Bignell, G.R., Cox, C., Stephens, P., Edkins, S., Clegg, S., Teague, J., Woffendin, H., Garnett, M.J., Bottomley, W., et al. 2002. Mutations of the BRAF gene in human cancer. Nature 417: 949-954.

Davis, I.J., Hsi, B.L., Arroyo, J.D., Vargas, S.O., Yeh, Y.A., Motyckova, G., Valencia, P., Perez-Atayde, A.R., Argani, P., Ladanyi, M., et al. 2003. Cloning of an $\alpha$-TFEB fusion in renal tumors harboring the $\mathrm{t}(6 ; 11)(\mathrm{p} 21 ; \mathrm{q} 13)$ chromosome translocation. Proc. Nat1. Acad. Sci. 100: 6051-6056.

Davis, I.J., Kim, J.J., Ozsolak, F., Widlund, H.R., RozenblattRosen, O., Granter, S.R., Du, J., Fletcher, J.A., Denny, C.T., Lessnick, S.L., et al. 2006. Oncogenic MITF dysregulation in clear cell sarcoma: Defining the MiT family of human cancers. Cancer Cell 9: 473-484.

Daya-Grosjean, L., Dumaz, N., and Sarasin, A. 1995. The specificity of p53 mutation spectra in sunlight induced human cancers. J. Photochem. Photobiol. B 28: 115-124.

Demunter, A., Stas, M., Degreef, H., De Wolf-Peeters, C., and van den Oord, J.J. 2001. Analysis of N- and K-ras mutations in the distinctive tumor progression phases of melanoma. $J$. Invest. Dermatol. 117: 1483-1489.

de Wit, P.E., Moretti, S., Koenders, P.G., Weterman, M.A., van Muijen, G.N., Gianotti, B., and Ruiter, D.J. 1992. Increasing epidermal growth factor receptor expression in human melanocytic tumor progression. J. Invest. Dermatol. 99: 168173.

Di Cristofano, A., Pesce, B., Cordon-Cardo, C., and Pandolfi, P.P. 1998. Pten is essential for embryonic development and tumour suppression. Nat. Genet. 19: 348-355.

Dlugosz, A.A., Hansen, L., Cheng, C., Alexander, N., Denning, M.F., Threadgill, D.W., Magnuson, T., Coffey Jr., R.J., and Yuspa, S.H. 1997. Targeted disruption of the epidermal growth factor receptor impairs growth of squamous papillomas expressing the v-ras(Ha) oncogene but does not block in vitro keratinocyte responses to oncogenic ras. Cancer Res. 57: $3180-3188$

D’Orazio, J.A., Nobuhisa, T., Cui, R., Arya, M., Spry, M., Wakamatsu, K., Igras, V., Kunisada, T., Granter, S.R., Nishimura, E.K., et al. 2006. Rescue of MC1R-dependent UV signaling triggers sunless tanning and skin cancer problems. Nature (in press).

Dorsky, R.I., Moon, R.T., and Raible, D.W. 1998. Control of neural crest cell fate by the Wnt signalling pathway. Nature 396: $370-373$.

Dorsky, R.I., Raible, D.W., and Moon, R.T. 2000. Direct regulation of nacre, a zebrafish MITF homolog required for pigment cell formation, by the Wnt pathway. Genes \& Dev. 14: $158-162$

Dranoff, G. 2002. GM-CSF-based cancer vaccines. Immunol. Rev. 188: 147-154.

- 2005. CTLA-4 blockade: Unveiling immune regulation. J. Clin. Oncol. 23: 662-664.

Draper, G.J., Sanders, B.M., and Kingston, J.E. 1986. Second primary neoplasms in patients with retinoblastoma. Br. J. Can- 
cer 53: 661-671.

Du, J. and Fisher, D.E. 2002. Identification of Aim-1 as the underwhite mouse mutant and its transcriptional regulation by MITF. J. Biol. Chem. 277: 402-406.

Du, J., Miller, A.J., Widlund, H.R., Horstmann, M.A., Ramaswamy, S., and Fisher, D.E. 2003. MLANA/MART1 and SILV/PMEL17/GP100 are transcriptionally regulated by MITF in melanocytes and melanoma. Am. J. Pathol. 163: 333-343.

Du, J., Widlund, H.R., Horstmann, M.A., Ramaswamy, S., Ross, K., Huber, W.E., Nishimura, E.K., Golub, T.R., and Fisher, D.E. 2004. Critical role of CDK2 for melanoma growth linked to its melanocyte-specific transcriptional regulation by MITF. Cancer Cell 6: 565-576.

Dusza, S.W., Delgado, R., Busam, K.J., Marghoob, A.A., and Halpern, A.C. 2006. Treatment of dysplastic nevi with 5\% imiquimod cream, a pilot study. J. Drugs Dermatol. 5: 56-62.

Edmunds, S.C., Cree, I.A., Di Nicolantonio, F., Hungerford, J.L., Hurren, J.S., and Kelsell, D.P. 2003. Absence of BRAF gene mutations in uveal melanomas in contrast to cutaneous melanomas. Br. J. Cancer 88: 1403-1405.

Edwards, R.H., Ward, M.R., Wu, H., Medina, C.A., Brose, M.S., Volpe, P., Nussen-Lee, S., Haupt, H.M., Martin, A.M., Herlyn, M., et al. 2004. Absence of BRAF mutations in UVprotected mucosal melanomas. J. Med. Genet. 41: 270-272.

Egen, J.G., Kuhns, M.S., and Allison, J.P. 2002. CTLA-4: New insights into its biological function and use in tumor immunotherapy. Nat. Immunol. 3: 611-618.

Eigentler, T.K., Caroli, U.M., Radny, P., and Garbe, C. 2003. Palliative therapy of disseminated malignant melanoma: A systematic review of 41 randomised clinical trials. Lancet Oncol. 4: 748-759.

Eisenmann, K.M., VanBrocklin, M.W., Staffend, N.A., Kitchen, S.M., and Koo, H.M. 2003. Mitogen-activated protein kinase pathway-dependent tumor-specific survival signaling in melanoma cells through inactivation of the proapoptotic protein bad. Cancer Res. 63: 8330-8337.

Eng, C., Li, F.P., Abramson, D.H., Ellsworth, R.M., Wong, F.L., Goldman, M.B., Seddon, J., Tarbell, N., and Boice Jr., J.D. 1993. Mortality from second tumors among long-term survivors of retinoblastoma. J. Natl. Cancer Inst. 85: 1121-1128.

Eskandarpour, M., Kiaii, S., Zhu, C., Castro, J., Sakko, A.J., and Hansson, J. 2005. Suppression of oncogenic NRAS by RNA interference induces apoptosis of human melanoma cells. Int. J. Cancer 115: 65-73.

Esumi, N., Oshima, Y., Li, Y., Campochiaro, P.A., and Zack, D.J. 2004. Analysis of the VMD2 promoter and implication of E-box binding factors in its regulation. J. Biol. Chem. 279: 19064-19073.

Eton, O., Legha, S.S., Bedikian, A.Y., Lee, J.J., Buzaid, A.C., Hodges, C., Ring, S.E., Papadopoulos, N.E., Plager, C., East, M.J., et al. 2002. Sequential biochemotherapy versus chemotherapy for metastatic melanoma: Results from a phase III randomized trial. J. Clin. Oncol. 20: 2045-2052.

Fang, D., Nguyen, T.K., Leishear, K., Finko, R., Kulp, A.N., Hotz, S., Van Belle, P.A., Xu, X., Elder, D.E., and Herlyn, M. 2005. A tumorigenic subpopulation with stem cell properties in melanomas. Cancer Res. 65: 9328-9337.

Fitch, K.R., McGowan, K.A., van Raamsdonk, C.D., Fuchs, H., Lee, D., Puech, A., Herault, Y., Threadgill, D.W., Hrabe de Angelis, M., and Barsh, G.S. 2003. Genetics of dark skin in mice. Genes \& Dev. 17: 214-228.

FitzGerald, M.G., Harkin, D.P., Silva-Arrieta, S., MacDonald, D.J., Lucchina, L.C., Unsal, H., O'Neill, E., Koh, J., Finkelstein, D.M., Isselbacher, K.J., et al. 1996. Prevalence of germ- line mutations in p16, p19ARF, and CDK4 in familial melanoma: Analysis of a clinic-based population. Proc. Nat1. Acad. Sci. 93: 8541-8545.

Flaherty, K.T., Redlinger, M., Shchucter, L.M., Lathia, C.D., Weber, B.L., and O'Dwyer, P.J. 2005. Phase I/II, pharmacokinetic and pharmacodynamic trial of BAY 43-9006 alone in patients with metastatic melanoma. ASCO Annual Meeting, Abstract No. 3037.

Flanagan, N., Healy, E., Ray, A., Philips, S., Todd, C., Jackson, I.J., Birch-Machin, M.A., and Rees, J.L. 2000. Pleiotropic effects of the melanocortin 1 receptor (MC1R) gene on human pigmentation. Hum. Mol. Genet. 9: 2531-2537.

Fletcher, O., Easton, D., Anderson, K., Gilham, C., Jay, M., and Peto, J. 2004. Lifetime risks of common cancers among retinoblastoma survivors. J. Nat1. Cancer Inst. 96: 357-363.

Ford, D., Bliss, J.M., Swerdlow, A.J., Armstrong, B.K., Franceschi, S., Green, A., Holly, E.A., Mack, T., MacKie, R.M., Osterlind, A., et al. 1995. Risk of cutaneous melanoma associated with a family history of the disease. The International Melanoma Analysis Group (IMAGE). Int. J. Cancer 62: 377381.

Frank, N.Y., Margaryan, A., Huang, Y., Schatton, T., WaagaGasser, A.M., Gasser, M., Sayegh, M.H., Sadee, W., and Frank, M.H. 2005. ABCB5-mediated doxorubicin transport and chemoresistance in human malignant melanoma. Cancer Res. 65: 4320-4333.

Fujimura, Y., Ohno, T., Siddique, H., Lee, L., Rao, V.N., and Reddy, E.S. 1996. The EWS-ATF-1 gene involved in malignant melanoma of soft parts with $\mathrm{t}(12 ; 22)$ chromosome translocation, encodes a constitutive transcriptional activator. Oncogene 12: 159-167.

Fukuda, R., Hamamoto, N., Uchida, Y., Furuta, K., Katsube, T., Kazumori, H., Ishihara, S., Amano, K., Adachi, K., Watanabe, M., et al. 2001. Gastrointestinal stromal tumor with a novel mutation of KIT proto-oncogene. Intern. Med. 40: 301-303.

Fuse, N., Yasumoto, K., Suzuki, H., Takahashi, K., and Shibahara, S. 1996. Identification of a melanocyte-type promoter of the microphthalmia-associated transcription factor gene. Biochem. Biophys. Res. Commun. 219: 702-707.

Futreal, P.A., Coin, L., Marshall, M., Down, T., Hubbard, T., Wooster, R., Rahman, N., and Stratton, M.R. 2004. A census of human cancer genes. Nat. Rev. Cancer 4: 177-183.

Gaggioli, C., Busca, R., Abbe, P., Ortonne, J.P., and Ballotti, R. 2003. Microphthalmia-associated transcription factor (MITF) is required but is not sufficient to induce the expression of melanogenic genes. Pigment Cell Res. 16: 374-382.

Gandini, S., Sera, F., Cattaruzza, M.S., Pasquini, P., Abeni, D., Boyle, P., and Melchi, C.F. 2005a. Meta-analysis of risk factors for cutaneous melanoma: I. Common and atypical naevi. Eur. J. Cancer 41: 28-44.

Gandini, S., Sera, F., Cattaruzza, M.S., Pasquini, P., Zanetti, R., Masini, C., Boyle, P., and Melchi, C.F. 2005b. Meta-analysis of risk factors for cutaneous melanoma: III. Family history, actinic damage and phenotypic factors. Eur. J. Cancer 41: 2040-2059.

Gangarosa, L.M., Sizemore, N., Graves-Deal, R., Oldham, S.M., Der, C.J., and Coffey, R.J. 1997. A raf-independent epidermal growth factor receptor autocrine loop is necessary for Ras transformation of rat intestinal epithelial cells. I. Biol. Chem. 272: 18926-18931.

Garnett, M.J. and Marais, R. 2004. Guilty as charged: B-RAF is a human oncogene. Cancer Cell 6: 313-319.

Garraway, L.A. and Sellers, W.R. 2006a. From integrated genomics to tumor lineage dependency. Cancer Res. 66: 25062508 .

2006b. Lineage dependency and lineage-survival onco- 
genes in human cancer. Nat. Rev. Cancer 6: 593-602.

Garraway, L.A., Widlund, H.R., Rubin, M.A., Getz, G., Berger, A.J., Ramaswamy, S., Beroukhim, R., Milner, D.A., Granter, S.R., Du, J., et al. 2005. Integrative genomic analyses identify MITF as a lineage survival oncogene amplified in malignant melanoma. Nature 436: 117-122.

Gilchrest, B.A., Eller, M.S., Geller, A.C., and Yaar, M. 1999. The pathogenesis of melanoma induced by ultraviolet radiation. N. Engl. J. Med. 340: 1341-1348.

Gimotty, P.A., Van Belle, P., Elder, D.E., Murry, T., Montone, K.T., Xu, X., Hotz, S., Raines, S., Ming, M.E., Wahl, P., et al. 2005. Biologic and prognostic significance of dermal Ki67 expression, mitoses, and tumorigenicity in thin invasive cutaneous melanoma. J. Clin. Oncol. 23: 8048-8056.

Glinsky, G.V., Glinsky, V.V., Ivanova, A.B., and Hueser, C.J. 1997. Apoptosis and metastasis: Increased apoptosis resistance of metastatic cancer cells is associated with the profound deficiency of apoptosis execution mechanisms. Cancer Lett. 115: 185-193.

Goel, V.K., Lazar, A.J., Warneke, C.L., Redston, M.S., and Haluska, F.G. 2006. Examination of mutations in BRAF, NRAS, and PTEN in primary cutaneous melanoma. J. Invest. Dermatol. 126: 154-160.

Goetz, M.P., Toft, D., Reid, J., Ames, M., Stensgard, B., Safgren, S., Adjei, A.A., Sloan, J., Atherton, P., Vasile, V., et al. 2005. Phase I trial of 17-allylamino-17-demethoxygeldanamycin in patients with advanced cancer. J. Clin. Oncol. 23: $1078-1087$.

Gogas, H., Ioannovich, J., Dafni, U., Stavropoulou-Giokas, C., Frangia, K., Tsoutsos, D., Panagiotou, P., Polyzos, A., Papadopoulos, O., Stratigos, A., et al. 2006. Prognostic significance of autoimmunity during treatment of melanoma with interferon. N. Engl. I. Med. 354: 709-718.

Gradilone, A., Gazzaniga, P., Ribuffo, D., Scarpa, S., Cigna, E., Vasaturo, F., Bottoni, U., Innocenzi, D., Calvieri, S., Scuderi, N., et al. 2003. Survivin, bcl-2, bax, and bcl-X gene expression in sentinel lymph nodes from melanoma patients. $I$. Clin. Oncol. 21: 306-312.

Granter, S.R., Weilbaecher, K.N., Quigley, C., Fletcher, C.D., and Fisher, D.E. 2001. Clear cell sarcoma shows immunoreactivity for microphthalmia transcription factor: Further evidence for melanocytic differentiation. Mod. Pathol. 14: 6-9.

Gray-Schopfer, V.C., da Rocha Dias, S., and Marais, R. 2005 The role of B-RAF in melanoma. Cancer Metastasis Rev. 24: $165-183$.

Grbovic, O.M., Basso, A.D., Sawai, A., Ye, Q., Friedlander, P., Solit, D., and Rosen, N. 2006. V600E B-Raf requires the Hsp90 chaperone for stability and is degraded in response to Hsp90 inhibitors. Proc. Nat1. Acad. Sci. 103: 57-62.

Greene, M.H., Clark Jr., W.H., Tucker, M.A., Kraemer, K.H., Elder, D.E., and Fraser, M.C. 1985. High risk of malignant melanoma in melanoma-prone families with dysplastic nevi. Ann. Intern. Med. 102: 458-465.

Grem, J.L., Morrison, G., Guo, X.D., Agnew, E., Takimoto, C.H., Thomas, R., Szabo, E., Grochow, L., Grollman, F., Hamilton, J.M., et al. 2005. Phase I and pharmacologic study of 17-(allylamino)-17-demethoxygeldanamycin in adult patients with solid tumors. J. Clin. Oncol. 23: 1885-1893.

Gupta, P.B., Kuperwasser, C., Brunet, J.P., Ramaswamy, S., Kuo, W.L., Gray, J.W., Naber, S.P., and Weinberg, R.A. 2005. The melanocyte differentiation program predisposes to metastasis after neoplastic transformation. Nat. Genet. 37: 10471054.

Hacker, E., Muller, H.K., Irwin, N., Gabrielli, B., Lincoln, D., Pavey, S., Powell, M.B., Malumbres, M., Barbacid, M., Hay- ward, N., et al. 2006. Spontaneous and UV radiation-induced multiple metastatic melanomas in Cdk4R24C/R24C/TPras mice. Cancer Res. 66: 2946-2952.

Halaban, R. 1999. Melanoma cell autonomous growth: The Rb/ E2F pathway. Cancer Metastasis Rev. 18: 333-343.

Halaban, R., Bohm, M., Dotto, P., Moellmann, G., Cheng, E., and Zhang, Y. 1996. Growth regulatory proteins that repress differentiation markers in melanocytes also downregulate the transcription factor microphthalmia. J. Invest. Dermatol. 106: 1266-1272.

Haluska, F.G. and Hodi, F.S. 1998. Molecular genetics of familial cutaneous melanoma. J. Clin. Oncol. 16: 670-682.

Hanahan, D. and Weinberg, R.A. 2000. The hallmarks of cancer. Cell 100: 57-70.

Haqq, C., Nosrati, M., Sudilovsky, D., Crothers, J., Khodabakhsh, D., Pulliam, B.L., Federman, S., Miller III, J.R., Allen, R.E., Singer, M.I., et al. 2005. The gene expression signatures of melanoma progression. Proc. Natl. Acad. Sci. 102: 60926097.

Harland, M., Taylor, C.F., Chambers, P.A., Kukalizch, K., Randerson-Moor, J.A., Gruis, N.A., de Snoo, F.A., ter Huurne, J.A., Goldstein, A.M., Tucker, M.A., et al. 2005. A mutation hotspot at the p14ARF splice site. Oncogene 24: 4604-4608.

Healy, E., Jordan, S.A., Budd, P.S., Suffolk, R., Rees, J.L., and Jackson, I.J. 2001. Functional variation of MC1R alleles from red-haired individuals. Hum. Mol. Genet. 10: 2397-2402.

Hemesath, T.J., Steingrimsson, E., McGill, G., Hansen, M.J., Vaught, J., Hodgkinson, C.A., Arnheiter, H., Copeland, N.G., Jenkins, N.A., and Fisher, D.E. 1994. Microphthalmia, a critical factor in melanocyte development, defines a discrete transcription factor family. Genes \& Dev. 8: 2770-2780.

Hemesath, T.J., Price, E.R., Takemoto, C., Badalian, T., and Fisher, D.E. 1998. MAP kinase links the transcription factor Microphthalmia to c-Kit signalling in melanocytes. Nature 391: 298-301.

Hershey, C.L. and Fisher, D.E. 2005. Genomic analysis of the Microphthalmia locus and identification of the MITF-J/ Mitf-J isoform. Gene 347: 73-82.

Hewitt, C., Lee Wu, C., Evans, G., Howell, A., Elles, R.G., Jordan, R., Sloan, P., Read, A.P., and Thakker, N. 2002. Germline mutation of ARF in a melanoma kindred. Hum. Mol. Genet. 11: 1273-1279.

Hezel, A.F., Kimmelman, A.C., Stanger, B.Z., Bardeesy, N., and DePinho, R.A. 2006. Genetics and biology of pancreatic ductal adenocarcinoma. Genes \& Dev. 20: 1218-1249.

Hingorani, S.R., Jacobetz, M.A., Robertson, G.P., Herlyn, M., and Tuveson, D.A. 2003. Suppression of BRAF(V599E) in human melanoma abrogates transformation. Cancer Res. 63: 5198-5202.

Hochedlinger, K., Blelloch, R., Brennan, C., Yamada, Y., Kim, M., Chin, L., and Jaenisch, R. 2004. Reprogramming of a melanoma genome by nuclear transplantation. Genes \& Dev. 18: 1875-1885.

Hodgkinson, C.A., Moore, K.J., Nakayama, A., Steingrimsson, E., Copeland, N.G., Jenkins, N.A., and Arnheiter, H. 1993. Mutations at the mouse microphthalmia locus are associated with defects in a gene encoding a novel basic-helixloop-helix-zipper protein. Cell 74: 395-404.

Hodi, F.S., Mihm, M.C., Soiffer, R.J., Haluska, F.G., Butler, M., Seiden, M.V., Davis, T., Henry-Spires, R., MacRae, S., Willman, A., et al. 2003. Biologic activity of cytotoxic T lymphocyte-associated antigen 4 antibody blockade in previously vaccinated metastatic melanoma and ovarian carcinoma patients. Proc. Nat1. Acad. Sci. 100: 4712-4717.

Hodi, F.S., Seiden, M., Butler, M., Haluska, F.G., Kruse, A., Mac 
Rae, S., Nelson, M., Mihm, M., Lowy, I., Allison, J.P., et al. 2006. Cytotoxic T lymphocyte-associated antigen 4 (CTLA4) antibody blockade in previously vaccinated melanoma and ovarian cancer patients. Keystone symoposia. Advances in the understanding and treatment of melanoma. Abstract no. 109: 42.

Hoeflich, K.P., Gray, D.C., Eby, M.T., Tien, J.Y., Wong, L., Bower, J., Gogineni, A., Zha, J., Cole, M.J., Stern, H.M., et al. 2006. Oncogenic BRAF is required for tumor growth and maintenance in melanoma models. Cancer Res. 66: 9991006.

Huang, S., Luca, M., Gutman, M., McConkey, D.J., Langley, K.E., Lyman, S.D., and Bar-Eli, M. 1996a. Enforced c-KIT expression renders highly metastatic human melanoma cells susceptible to stem cell factor-induced apoptosis and inhibits their tumorigenic and metastatic potential. Oncogene 13: 2339-2347.

Huang, T.S., Rauth, S., and Das Gupta, T.K. 1996b. Overexpression of EGF receptor is associated with spontaneous metastases of a human melanoma cell line in nude mice. Anticancer Res. 16: 3557-3563.

Huang, S., Mills, L., Mian, B., Tellez, C., McCarty, M., Yang, X.D., Gudas, J.M., and Bar-Eli, M. 2002. Fully humanized neutralizing antibodies to interleukin-8 (ABX-IL8) inhibit angiogenesis, tumor growth, and metastasis of human melanoma. Am. J. Pathol. 161: 125-134.

Huber, W.E., Price, E.R., Widlund, H.R., Du, J., Davis, I.J., Wegner, M., and Fisher, D.E. 2003. A tissue-restricted cAMP transcriptional response: SOX10 modulates $\alpha$-melanocytestimulating hormone-triggered expression of microphthalmia-associated transcription factor in melanocytes. J. Biol. Chem. 278: 45224-45230.

Hussussian, C.J., Struewing, J.P., Goldstein, A.M., Higgins, P.A., Ally, D.S., Sheahan, M.D., Clark Jr., W.H., Tucker, M.A., and Dracopoli, N.C. 1994. Germline p16 mutations in familial melanoma. Nat. Genet. 8: 15-21.

Ilmonen, S., Hernberg, M., Pyrhonen, S., Tarkkanen, J., and Asko-Seljavaara, S. 2005. Ki-67, Bcl-2 and p53 expression in primary and metastatic melanoma. Melanoma Res. 15: 375381.

Isabel Zhu, Y. and Fitzpatrick, J.E. 2006. Expression of c-kit (CD117) in Spitz nevus and malignant melanoma. J. Cutan. Pathol. 33: 33-37.

Ito, A., Koma, Y., Watabe, K., Jippo, T., Wakayama, T., Iseki, S., and Kitamura, Y. 2004. Contribution of the SgIGSF adhesion molecule to survival of cultured mast cells in vivo. Biochem. Biophys. Res. Commun. 319: 200-206.

Jackson, S., Harland, M., Turner, F., Taylor, C., Chambers, P.A., Randerson-Moor, J., Swerdlow, A.J., dos Santos Silva, I., Beswick, S., Bishop, D.T., et al. 2005. No evidence for BRAF as a melanoma/nevus susceptibility gene. Cancer Epidemiol. Biomarkers Prev. 14: 913-918.

Jafari, M., Papp, T., Kirchner, S., Diener, U., Henschler, D., Burg, G., and Schiffmann, D. 1995. Analysis of ras mutations in human melanocytic lesions: Activation of the ras gene seems to be associated with the nodular type of human malignant melanoma. J. Cancer Res. Clin. Oncol. 121: 23-30.

Jallal, B. 2006. Targeted therapeutics in melanoma: Changing the front end of drug development. Keystone symposia. Advances in the understanding and treatment of melanoma. Abstract no. 011: 26.

Jeffers, M., Schmidt, L., Nakaigawa, N., Webb, C.P., Weirich, G., Kishida, T., Zbar, B., and Vande Woude, G.F. 1997. Activating mutations for the met tyrosine kinase receptor in human cancer. Proc. Natl. Acad. Sci. 94: 11445-11450.

Jiao, Z., Mollaaghababa, R., Pavan, W.J., Antonellis, A., Green,
E.D., and Hornyak, T.J. 2004. Direct interaction of Sox10 with the promoter of murine Dopachrome Tautomerase (Dct) and synergistic activation of Dct expression with Mitf. Pigment Cell Res. 17: 352-362.

Johnstone, R.W., Ruefli, A.A., and Lowe, S.W. 2002. Apoptosis: A link between cancer genetics and chemotherapy. Cell 108: 153-164.

Kadekaro, A.L., Kanto, H., Kavanagh, R., and Abdel-Malek, Z.A. 2003. Significance of the melanocortin 1 receptor in regulating human melanocyte pigmentation, proliferation, and survival. Ann. N. Y. Acad. Sci. 994: 359-365.

Kamal, A., Boehm, M.F., and Burrows, F.J. 2004. Therapeutic and diagnostic implications of Hsp90 activation. Trends Mol. Med. 10: 283-290.

Kamb, A., Gruis, N.A., Weaver-Feldhaus, J., Liu, Q., Harshman, K., Tavtigian, S.V., Stockert, E., Day III, R.S., Johnson, B.E., and Skolnick, M.H. 1994a. A cell cycle regulator potentially involved in genesis of many tumor types. Science 264: 436440.

Kamb, A., Shattuck-Eidens, D., Eeles, R., Liu, Q., Gruis, N.A., Ding, W., Hussey, C., Tran, T., Miki, Y., Weaver-Feldhaus, J., et al. 1994b. Analysis of the p16 gene (CDKN2) as a candidate for the chromosome 9p melanoma susceptibility locus. Nat. Genet. 8: 23-26.

Kamijo, T., Weber, J.D., Zambetti, G., Zindy, F., Roussel, M.F., and Sherr, C.J. 1998. Functional and physical interactions of the ARF tumor suppressor with p53 and Mdm2. Proc. Nat1. Acad. Sci. 95: 8292-8297.

Kannan, K., Sharpless, N.E., Xu, J., O'Hagan, R.C., Bosenberg, M., and Chin, L. 2003. Components of the $\mathrm{Rb}$ pathway are critical targets of UV mutagenesis in a murine melanoma model. Proc. Natl. Acad. Sci. 100: 1221-1225.

Karasarides, M., Chiloeches, A., Hayward, R., Niculescu-Duvaz, D., Scanlon, I., Friedlos, F., Ogilvie, L., Hedley, D., Martin, J., Marshall, C.J., et al. 2004. B-RAF is a therapeutic target in melanoma. Oncogene 23: 6292-6298.

Kelemen, L., James, M., Spurdle, A., Campbell, I., ChangClaude, J., Peel, D., Anton-Culver, H., Berchuck, A., Schildkraut, J., Whittemore, A., et al. 2005. BRAF polymorphisms and the risk of ovarian cancer of low malignant potential. Gynecol. Oncol. 97: 807-812.

Kennedy, C., ter Huurne, J., Berkhout, M., Gruis, N., Bastiaens, M., Bergman, W., Willemze, R., and Bavinck, J.N. 2001. Melanocortin 1 receptor (MC1R) gene variants are associated with an increased risk for cutaneous melanoma which is largely independent of skin type and hair color. J. Invest. Dermatol. 117: 294-300.

Khaled, M., Larribere, L., Bille, K., Ortonne, J.P., Ballotti, R., and Bertolotto, C. 2003. Microphthalmia associated transcription factor is a target of the phosphatidylinositol-3-kinase pathway. J. Invest. Dermatol. 121: 831-836.

Kharas, M.G. and Fruman, D.A. 2005. ABL oncogenes and phosphoinositide 3-kinase: Mechanism of activation and downstream effectors. Cancer Res. 65: 2047-2053.

Kim, M., Gans, J.D., Nogueira, C., Wang, A., Paik, J.-H., Feng, B., Brennan, C., Hahn, W.C., Cordon-Cardo, C., Wagner, S.N., et al. 2006. Comparative oncogenomics identifies NEDD9 as a melanoma metastasis gene. Cell 125: 12691281.

Kirkwood, J.M., Strawderman, M.H., Ernstoff, M.S., Smith, T.J., Borden, E.C., and Blum, R.H. 1996. Interferon alfa-2b adjuvant therapy of high-risk resected cutaneous melanoma: The Eastern Cooperative Oncology Group Trial EST 1684. J. Clin. Oncol. 14: 7-17.

Kirkwood, J.M., Ibrahim, J.G., Sosman, J.A., Sondak, V.K., Agarwala, S.S., Ernstoff, M.S., and Rao, U. 2001. High-dose inter- 
feron alfa-2b significantly prolongs relapse-free and overall survival compared with the GM2-KLH/QS-21 vaccine in patients with resected stage IIB-III melanoma: Results of intergroup trial E1694/S9512/C509801. I. Clin. Oncol. 19: 2370-2380.

Kong-Beltran, M., Seshagiri, S., Zha, J., Zhu, W., Bhawe, K., Mendoza, N., Holcomb, T., Pujara, K., Stinson, J., Fu, L., et al. 2006. Somatic mutations lead to an oncogenic deletion of met in lung cancer. Cancer Res. 66: 283-289.

Koprowski, H., Herlyn, M., Balaban, G., Parmiter, A., Ross, A., and Nowell, P. 1985. Expression of the receptor for epidermal growth factor correlates with increased dosage of chromosome 7 in malignant melanoma. Somat. Cell Mol. Genet. 11: 297-302.

Krimpenfort, P., Quon, K.C., Mooi, W.J., Loonstra, A., and Berns, A. 2001. Loss of p16Ink4a confers susceptibility to metastatic melanoma in mice. Nature 413: 83-86.

Kristiansen, O.P., Larsen, Z.M., and Pociot, F. 2000. CTLA-4 in autoimmune diseases-A general susceptibility gene to autoimmunity? Genes Immun. 1: 170-184.

Kuiper, R.P., Schepens, M., Thijssen, J., van Asseldonk, M., van den Berg, E., Bridge, J., Schuuring, E., Schoenmakers, E.F., and van Kessel, A.G. 2003. Upregulation of the transcription factor TFEB in $\mathrm{t}(6 ; 11)(\mathrm{p} 21 ; \mathrm{q} 13)$-positive renal cell carcinomas due to promoter substitution. Hum. Mol. Genet. 12: 1661-1669.

Kumar, R., Sauroja, I., Punnonen, K., Jansen, C., and Hemminki, K. 1998. Selective deletion of exon $1 \beta$ of the p19ARF gene in metastatic melanoma cell lines. Genes Chromosomes Cancer 23: 273-277.

Kumar, R., Smeds, J., Berggren, P., Straume, O., Rozell, B.L., Akslen, L.A., and Hemminki, K. 2001. A single nucleotide polymorphism in the 3 'untranslated region of the CDKN2A gene is common in sporadic primary melanomas but mutations in the CDKN2B, CDKN2C, CDK4 and p53 genes are rare. Int. J. Cancer 95: 388-393.

Kumar, R., Angelini, S., Snellman, E., and Hemminki, K. 2004. BRAF mutations are common somatic events in melanocytic nevi. J. Invest. Dermatol. 122: 342-348.

Kunisada, T., Lu, S.Z., Yoshida, H., Nishikawa, S., Mizoguchi, M., Hayashi, S., Tyrrell, L., Williams, D.A., Wang, X., and Longley, B.J. 1998. Murine cutaneous mastocytosis and epidermal melanocytosis induced by keratinocyte expression of transgenic stem cell factor. J. Exp. Med. 187: 1565-1573.

Ladanyi, M., Lui, M.Y., Antonescu, C.R., Krause-Boehm, A., Meindl, A., Argani, P., Healey, J.H., Ueda, T., Yoshikawa, H., Meloni-Ehrig, A., et al. 2001. The $\operatorname{der}(17) \mathrm{t}(\mathrm{X} ; 17)(\mathrm{p} 11 ; \mathrm{q} 25)$ of human alveolar soft part sarcoma fuses the TFE3 transcription factor gene to ASPL, a novel gene at 17q25. Oncogene 20: $48-57$.

Lamason, R.L., Mohideen, M.A., Mest, J.R., Wong, A.C., Norton, H.L., Aros, M.C., Jurynec, M.J., Mao, X., Humphreville, V.R., Humbert, J.E., et al. 2005. SLC24A5, a putative cation exchanger, affects pigmentation in zebrafish and humans. Science 310: 1782-1786.

Lang, D., Lu, M.M., Huang, L., Engleka, K.A., Zhang, M., Chu, E.Y., Lipner, S., Skoultchi, A., Millar, S.E., and Epstein, J.A. 2005. Pax3 functions at a nodal point in melanocyte stem cell differentiation. Nature 433: 884-887.

Laud, K., Kannengiesser, C., Avril, M.F., Chompret, A., StoppaLyonnet, D., Desjardins, L., Eychene, A., Demenais, F., Lenoir, G.M., and Bressac-de Paillerets, B. 2003. BRAF as a melanoma susceptibility candidate gene? Cancer Res. 63: 3061-3065.

Lazar-Molnar, E., Hegyesi, H., Toth, S., and Falus, A. 2000. Autocrine and paracrine regulation by cytokines and growth factors in melanoma. Cytokine 12: 547-554.

Leach, D.R., Krummel, M.F., and Allison, J.P. 1996. Enhancement of antitumor immunity by CTLA-4 blockade. Science 271: 1734-1736.

Lee, M., Goodall, J., Verastegui, C., Ballotti, R., and Goding, C.R. 2000. Direct regulation of the Microphthalmia promoter by Sox10 links Waardenburg-Shah syndrome (WS4)associated hypopigmentation and deafness to WS2. J. Biol. Chem. 275: 37978-37983.

Legha, S.S., Ring, S., Eton, O., Bedikian, A., Buzaid, A.C., Plager, C., and Papadopoulos, N. 1998. Development of a biochemotherapy regimen with concurrent administration of cisplatin, vinblastine, dacarbazine, interferon alfa, and interleukin-2 for patients with metastatic melanoma. J. Clin. Oncol. 16: $1752-1759$.

Leiter, U., Schmid, R.M., Kaskel, P., Peter, R.U., and Krahn, G. 2000. Antiapoptotic bcl-2 and bcl-xL in advanced malignant melanoma. Arch. Dermatol. Res. 292: 225-232.

Li, G., Schaider, H., Satyamoorthy, K., Hanakawa, Y., Hashimoto, K., and Herlyn, M. 2001. Downregulation of E-cadherin and Desmoglein 1 by autocrine hepatocyte growth factor during melanoma development. Oncogene 20: 81258135.

Libra, M., Malaponte, G., Navolanic, P.M., Gangemi, P., Bevelacqua, V., Proietti, L., Bruni, B., Stivala, F., Mazzarino, M.C., Travali, S., et al. 2005. Analysis of BRAF mutation in primary and metastatic melanoma. Cell Cycle 4: 1382-1384.

Liu, L., Dilworth, D., Gao, L., Monzon, J., Summers, A., Lassam, N., and Hogg, D. 1999. Mutation of the CDKN2A 5' UTR creates an aberrant initiation codon and predisposes to melanoma. Nat. Genet. 21: 128-132.

Llauger, L., He, H., Kim, J., Aguirre, J., Rosen, N., Peters, U., Davies, P., and Chiosis, G. 2005. Evaluation of 8-arylsulfanyl, 8-arylsulfoxyl, and 8-arylsulfonyl adenine derivatives as inhibitors of the heat shock protein 90. J. Med. Chem. 48: 2892-2905.

Loercher, A.E., Tank, E.M., Delston, R.B., and Harbour, J.W. 2005. MITF links differentiation with cell cycle arrest in melanocytes by transcriptional activation of INK4A. J. Cell Biol. 168: 35-40.

Lorusso, P.M., Krishnamurthi, S., Rinehart, J.R., Nabell, L., Croghan, G., Varterasian, M., Sadis, S.S., Menon, S.S., Leopold, J., and Meyer, M.B. 2005. A phase 1-2 clinical study of a second generation oral MEK inhibitor, PD 0325901 in patients with advanced cancer. ASCO Annual Meeting. Abstract no. 3011

Luchin, A., Suchting, S., Merson, T., Rosol, T.J., Hume, D.A., Cassady, A.I., and Ostrowski, M.C. 2001. Genetic and physical interactions between Microphthalmia transcription factor and PU.1 are necessary for osteoclast gene expression and differentiation. J. Biol. Chem. 276: 36703-36710.

Ludwig, A., Rehberg, S., and Wegner, M. 2004. Melanocyte-specific expression of dopachrome tautomerase is dependent on synergistic gene activation by the Sox 10 and Mitf transcription factors. FEBS Lett. 556: 236-244.

Lynch, T.J., Bell, D.W., Sordella, R., Gurubhagavatula, S., Okimoto, R.A., Brannigan, B.W., Harris, P.L., Haserlat, S.M., Supko, J.G., Haluska, F.G., et al. 2004. Activating mutations in the epidermal growth factor receptor underlying responsiveness of non-small-cell lung cancer to gefitinib. N. Engl. J. Med. 350: 2129-2139.

Ma, X., Ziel-van der Made, A.C., Autar, B., van der Korput, H.A., Vermeij, M., van Duijn, P., Cleutjens, K.B., de Krijger, R., Krimpenfort, P., Berns, A., et al. 2005. Targeted biallelic inactivation of Pten in the mouse prostate leads to prostate cancer accompanied by increased epithelial cell proliferation 
but not by reduced apoptosis. Cancer Res. 65: 5730-5739.

Mackenzie, M.A., Jordan, S.A., Budd, P.S., and Jackson, I.J. 1997. Activation of the receptor tyrosine kinase Kit is required for the proliferation of melanoblasts in the mouse embryo. Dev. Biol. 192: 99-107.

Maher, E.A., Furnari, F.B., Bachoo, R.M., Rowitch, D.H., Louis, D.N., Cavenee, W.K., and DePinho, R.A. 2001. Malignant glioma: Genetics and biology of a grave matter. Genes \& Dev. 15: 1311-1333.

Maldonado, J.L., Fridlyand, J., Patel, H., Jain, A.N., Busam, K., Kageshita, T., Ono, T., Albertson, D.G., Pinkel, D., and Bastian, B.C. 2003. Determinants of BRAF mutations in primary melanomas. J. Nat1. Cancer Inst. 95: 1878-1890.

Mansky, K.C., Sankar, U., Han, J., and Ostrowski, M.C. 2002. Microphthalmia transcription factor is a target of the p38 MAPK pathway in response to receptor activator of NF-к B ligand signaling. J. Biol. Chem. 277: 11077-11083.

Marcucci, G., Stock, W., Dai, G., Klisovic, R.B., Liu, S., Klisovic, M.I., Blum, W., Kefauver, C., Sher, D.A., Green, M., et al. 2005. Phase I study of oblimersen sodium, an antisense to Bcl-2, in untreated older patients with acute myeloid leukemia: Pharmacokinetics, pharmacodynamics, and clinical activity. J. Clin. Oncol. 23: 3404-3411.

Margolin, K.A., Longmate, J., Baratta, T., Synold, T., Weber, J., Gajewski, T., Quirt, I., Christensen, S., and Doroshow, J.H. 2004. CCI-779 in metastatic melanoma: A phase II trial of the California Cancer Consortium. ASCO Annual Meeting. Abstract no. 7523.

Martinez-Morales, J.R., Dolez, V., Rodrigo, I., Zaccarini, R., Leconte, L., Bovolenta, P., and Saule, S. 2003. OTX2 activates the molecular network underlying retina pigment epithelium differentiation. J. Biol. Chem. 278: 21721-21731.

McGill, G.G., Horstmann, M., Widlund, H.R., Du, J., Motyckova, G., Nishimura, E.K., Lin, Y.L., Ramaswamy, S., Avery, W., Ding, H.F., et al. 2002. Bcl2 regulation by the melanocyte master regulator Mitf modulates lineage survival and melanoma cell viability. Cell 109: 707-718.

McGill, G.G., Haq, R., Nishimura, E.K., and Fisher, D.E. 2006. c-Met expression is regulated by Mitf in the melanocyte lineage. J. Biol. Chem. 281: 10365-10373.

Meier, F., Schittek, B., Busch, S., Garbe, C., Smalley, K., Satyamoorthy, K., Li, G., and Herlyn, M. 2005. The RAS/RAF/ MEK/ERK and PI3K/AKT signaling pathways present molecular targets for the effective treatment of advanced melanoma. Front. Biosci. 10: 2986-3001.

Meierjohann, S., Wende, E., Kraiss, A., Wellbrock, C., and Schartl, M. 2006. The oncogenic epidermal growth factor receptor variant Xiphophorus melanoma receptor kinase induces motility in melanocytes by modulation of focal adhesions. Cancer Res. 66: 3145-3152.

Merlino, G. 2005. Cancer biology: The weakest link? Nature 436: 33-35.

Michaloglou, C., Vredeveld, L.C., Soengas, M.S., Denoyelle, C., Kuilman, T., van der Horst, C.M., Majoor, D.M., Shay, J.W., Mooi, W.J., and Peeper, D.S. 2005. BRAFE600-associated senescence-like cell cycle arrest of human naevi. Nature 436: 720-724.

Middleton, M.R., Grob, J.J., Aaronson, N., Fierlbeck, G., Tilgen, W., Seiter, S., Gore, M., Aamdal, S., Cebon, J., Coates, A., et al. 2000. Randomized phase III study of temozolomide versus dacarbazine in the treatment of patients with advanced metastatic malignant melanoma. J. Clin. Oncol. 18: 158166.

Mikhail, M., Velazquez, E., Shapiro, R., Berman, R., Pavlick, A., Sorhaindo, L., Spira, J., Mir, C., Panageas, K.S., Polsky, D., et al. 2005. PTEN expression in melanoma: Relationship with patient survival, Bcl-2 expression, and proliferation. Clin. Cancer Res. 11: 5153-5157.

Miller, A.J., Du, J., Rowan, S., Hershey, C.L., Widlund, H.R., and Fisher, D.E. 2004. Transcriptional regulation of the melanoma prognostic marker melastatin (TRPM1) by MITF in melanocytes and melanoma. Cancer Res. 64: 509-516.

Miller, A.J., Levy, C., Davis, I.J., Razin, E., and Fisher, D.E. 2005. Sumoylation of MITF and its related family members TFE3 and TFEB. J. Biol. Chem. 280: 146-155.

Mills, L., Tellez, C., Huang, S., Baker, C., McCarty, M., Green, L., Gudas, J.M., Feng, X., and Bar-Eli, M. 2002. Fully human antibodies to MCAM/MUC18 inhibit tumor growth and metastasis of human melanoma. Cancer Res. 62: 5106-5114.

Molven, A., Grimstvedt, M.B., Steine, S.J., Harland, M., Avril, M.F., Hayward, N.K., and Akslen, L.A. 2005. A large Norwegian family with inherited malignant melanoma, multiple atypical nevi, and CDK4 mutation. Genes Chromosomes Cancer 44: 10-18.

Montone, K.T., van Belle, P., Elenitsas, R., and Elder, D.E. 1997. Proto-oncogene c-kit expression in malignant melanoma: Protein loss with tumor progression. Mod. Pathol. 10: 939944.

Morii, E., Oboki, K., Kataoka, T.R., Igarashi, K., and Kitamura, Y. 2002. Interaction and cooperation of mi transcription factor (MITF) and myc-associated zinc-finger protein-related factor (MAZR) for transcription of mouse mast cell protease 6 gene. J. Biol. Chem. 277: 8566-8571.

Morii, E., Oboki, K., Ishihara, K., Jippo, T., Hirano, T., and Kitamura, Y. 2004. Roles of MITF for development of mast cells in mice: Effects on both precursors and tissue environments. Blood 104: 1656-1661.

Murakami, H. and Arnheiter, H. 2005. Sumoylation modulates transcriptional activity of MITF in a promoter-specific manner. Pigment Cell Res. 18: 265-277.

Murakami, M., Ikeda, T., Saito, T., Ogawa, K., Nishino, Y., Nakaya, K., and Funaba, M. 2006. Transcriptional regulation of plasminogen activator inhibitor-1 by transforming growth factor- $\beta$, activin A and microphthalmia-associated transcription factor. Cell. Signal. 18: 256-265.

Muthusamy, V., Hobbs, C., Nogueira, C., Cordon-Cardo, C., McKee, P.H., Chin, L., and Bosenberg, M.W. 2006. Amplification of CDK4 and MDM2 in malignant melanoma. Genes Chromosomes Cancer 45: 447-454.

Nakahara, M., Isozaki, K., Hirota, S., Miyagawa, J., HaseSawada, N., Taniguchi, M., Nishida, T., Kanayama, S., Kitamura, Y., Shinomura, Y., et al. 1998. A novel gain-of-function mutation of c-kit gene in gastrointestinal stromal tumors. Gastroenterology 115: 1090-1095.

Namiki, T., Yanagawa, S., Izumo, T., Ishikawa, M., Tachibana, M., Kawakami, Y., Yokozeki, H., Nishioka, K., and Kaneko, Y. 2005. Genomic alterations in primary cutaneous melanomas detected by metaphase comparative genomic hybridization with laser capture or manual microdissection: $6 \mathrm{p}$ gains may predict poor outcome. Cancer Genet. Cytogenet. 157: $1-11$.

Natali, P.G., Nicotra, M.R., Di Renzo, M.F., Prat, M., Bigotti, A., Cavaliere, R., and Comoglio, P.M. 1993. Expression of the c-Met/HGF receptor in human melanocytic neoplasms: Demonstration of the relationship to malignant melanoma tumour progression. Br. J. Cancer 68: 746-750.

Naylor, M.F., Crowson, N., Kuwahara, R., Teague, K., Garcia, C., Mackinnis, C., Haque, R., Odom, C., Jankey, C., and Cornelison, R.L. 2003. Treatment of lentigo maligna with topical imiquimod. Br. J. Dermatol. (Suppl. 66) 149: 66-70.

Niihori, T., Aoki, Y., Narumi, Y., Neri, G., Cave, H., Verloes, A., Okamoto, N., Hennekam, R.C., Gillessen-Kaesbach, G., 
Wieczorek, D., et al. 2006. Germline KRAS and BRAF mutations in cardio-facio-cutaneous syndrome. Nat. Genet. 38: 294-296.

Nishimura, E.K., Jordan, S.A., Oshima, H., Yoshida, H., Osawa, M., Moriyama, M., Jackson, I.J., Barrandon, Y., Miyachi, Y., and Nishikawa, S. 2002. Dominant role of the niche in melanocyte stem-cell fate determination. Nature 416: 854-860.

Nishimura, E.K., Granter, S.R., and Fisher, D.E. 2005. Mechanisms of hair graying: Incomplete melanocyte stem cell maintenance in the niche. Science 307: 720-724.

Nobori, T., Miura, K., Wu, D.J., Lois, A., Takabayashi, K., and Carson, D.A. 1994. Deletions of the cyclin-dependent kinase-4 inhibitor gene in multiple human cancers. Nature 368: 753-756.

Noel, B. and Kunzle, N. 2005. Image in clinical medicine. Lentigo maligna. N. Engl. J. Med. 353: 2176.

Noonan, F.P., Recio, J.A., Takayama, H., Duray, P., Anver, M.R., Rush, W.L., De Fabo, E.C., and Merlino, G. 2001. Neonatal sunburn and melanoma in mice. Nature 413: 271-272.

O’Brien, S.M., Cunningham, C.C., Golenkov, A.K., Turkina, A.G., Novick, S.C., and Rai, K.R. 2005. Phase I to II multicenter study of oblimersen sodium, a Bcl-2 antisense oligonucleotide, in patients with advanced chronic lymphocytic leukemia. J. Clin. Oncol. 23: 7697-7702.

Ogihara, H., Kanno, T., Morii, E., Kim, D.K., Lee, Y.M., Sato, M., Kim, W.Y., Nomura, S., Ito, Y., and Kitamura, Y. 1999. Synergy of PEBP2/CBF with mi transcription factor (MITF) for transactivation of mouse mast cell protease 6 gene. Oncogene 18: 4632-4639.

O'Hagan, R.C., Brennan, C.W., Strahs, A., Zhang, X., Kannan, K., Donovan, M., Cauwels, C., Sharpless, N.E., Wong, W.H., and Chin, L. 2003. Array comparative genome hybridization for tumor classification and gene discovery in mouse models of malignant melanoma. Cancer Res. 63: 5352-5356.

Onken, M.D., Worley, L.A., Ehlers, J.P., and Harbour, J.W. 2004. Gene expression profiling in uveal melanoma reveals two molecular classes and predicts metastatic death. Cancer Res. 64: 7205-7209.

Otsuka, T., Takayama, H., Sharp, R., Celli, G., LaRochelle, W.J., Bottaro, D.P., Ellmore, N., Vieira, W., Owens, J.W., Anver, M., et al. 1998. c-Met autocrine activation induces development of malignant melanoma and acquisition of the metastatic phenotype. Cancer Res. 58: 5157-5167.

Paez, J.G., Janne, P.A., Lee, J.C., Tracy, S., Greulich, H., Gabriel, S., Herman, P., Kaye, F.J., Lindeman, N., Boggon, T.J., et al. 2004. EGFR mutations in lung cancer: Correlation with clinical response to gefitinib therapy. Science 304: $1497-1500$.

Palmer, J.S., Duffy, D.L., Box, N.F., Aitken, J.F., O'Gorman, L.E., Green, A.C., Hayward, N.K., Martin, N.G., and Sturm, R.A. 2000. Melanocortin-1 receptor polymorphisms and risk of melanoma: Is the association explained solely by pigmentation phenotype? Am. J. Hum. Genet. 66: 176-186.

Panka, D.J., Wang, W., Atkins, M.B., and Mier, J.W. 2006. The Raf inhibitor BAY 43-9006 (Sorafenib) induces caspase-independent apoptosis in melanoma cells. Cancer Res. 66: 16111619.

Papp, T., Pemsel, H., Zimmermann, R., Bastrop, R., Weiss, D.G., and Schiffmann, D. 1999. Mutational analysis of the $\mathrm{N}$-ras, p53, p16INK4a, CDK4, and MC1R genes in human congenital melanocytic naevi. J. Med. Genet. 36: 610-614.

Partington, G.A., Fuller, K., Chambers, T.J., and Pondel, M. 2004. Mitf-PU.1 interactions with the tartrate-resistant acid phosphatase gene promoter during osteoclast differentiation. Bone 34: 237-245.

Pasare, C. and Medzhitov, R. 2003. Toll-like receptors: Balanc- ing host resistance with immune tolerance. Curr. Opin. Immunol. 15: 677-682.

Patton, E.E., Widlund, H.R., Kutok, J.L., Kopani, K.R., Amatruda, J.F., Murphey, R.D., Berghmans, S., Mayhall, E.A., Traver, D., Fletcher, C.D., et al. 2005. BRAF mutations are sufficient to promote nevi formation and cooperate with p53 in the genesis of melanoma. Curr. Biol. 15: 249-254.

Paumelle, R., Tulasne, D., Kherrouche, Z., Plaza, S., Leroy, C., Reveneau, S., Vandenbunder, B., and Fafeur, V. 2002. Hepatocyte growth factor/scatter factor activates the ETS1 transcription factor by a RAS-RAF-MEK-ERK signaling pathway. Oncogene 21: 2309-2319.

Plettenberg, A., Ballaun, C., Pammer, J., Mildner, M., Strunk, D., Weninger, W., and Tschachler, E. 1995. Human melanocytes and melanoma cells constitutively express the Bcl-2 proto-oncogene in situ and in cell culture. Am. J. Pathol. 146: 651-659.

Podsypanina, K., Ellenson, L.H., Nemes, A., Gu, J., Tamura, M., Yamada, K.M., Cordon-Cardo, C., Catoretti, G., Fisher, P.E., and Parsons, R. 1999. Mutation of Pten/Mmacl in mice causes neoplasia in multiple organ systems. Proc. Natl. Acad. Sci. 96: 1563-1568.

Pollock, P.M., Walker, G.J., Glendening, J.M., Que Noy, T., Bloch, N.C., Fountain, J.W., and Hayward, N.K. 2002. PTEN inactivation is rare in melanoma tumours but occurs frequently in melanoma cell lines. Melanoma Res. 12: 565-575.

Pollock, P.M., Harper, U.L., Hansen, K.S., Yudt, L.M., Stark, M., Robbins, C.M., Moses, T.Y., Hostetter, G., Wagner, U., Kakareka, J., et al. 2003. High frequency of BRAF mutations in nevi. Nat. Genet. 33: 19-20.

Pomerantz, J., Schreiber-Agus, N., Liegeois, N.J., Silverman, A., Alland, L., Chin, L., Potes, J., Chen, K., Orlow, I., Lee, H.W., et al. 1998. The Ink4a tumor suppressor gene product, p19Arf, interacts with MDM2 and neutralizes MDM2's inhibition of p53. Cell 92: 713-723.

Potterf, S.B., Furumura, M., Dunn, K.J., Arnheiter, H., and Pavan, W.J. 2000. Transcription factor hierarchy in Waardenburg syndrome: Regulation of MITF expression by SOX10 and PAX3. Hum. Genet. 107: 1-6.

Price, E.R. and Fisher, D.E. 2001. Sensorineural deafness and pigmentation genes: Melanocytes and the Mitf transcriptional network. Neuron 30: 15-18.

Price, E.R., Ding, H.F., Badalian, T., Bhattacharya, S., Takemoto, C., Yao, T.P., Hemesath, T.J., and Fisher, D.E. 1998a. Lineage-specific signaling in melanocytes. C-kit stimulation recruits p300/CBP to microphthalmia. J. Biol. Chem. 273: 17983-17986.

Price, E.R., Horstmann, M.A., Wells, A.G., Weilbaecher, K.N., Takemoto, C.M., Landis, M.W., and Fisher, D.E. 1998 b. $\alpha$-Melanocyte-stimulating hormone signaling regulates expression of microphthalmia, a gene deficient in Waardenburg syndrome. J. Biol. Chem. 273: 33042-33047.

Quelle, D.E., Zindy, F., Ashmun, R.A., and Sherr, C.J. 1995. Alternative reading frames of the INK4a tumor suppressor gene encode two unrelated proteins capable of inducing cell cycle arrest. Cell 83: 993-1000.

Rajagopalan, H., Bardelli, A., Lengauer, C., Kinzler, K.W., Vogelstein, B., and Velculescu, V.E. 2002. Tumorigenesis: RAF/ RAS oncogenes and mismatch-repair status. Nature 418: 934.

Ramanathan, R.K., Trump, D.L., Eiseman, J.L., Belani, C.P., Agarwala, S.S., Zuhowski, E.G., Lan, J., Potter, D.M., Ivy, S.P., Ramalingam, S., et al. 2005. Phase I pharmacokineticpharmacodynamic study of 17-(allylamino)-17-demethoxygeldanamycin (17AAG, NSC 330507), a novel inhibitor of heat shock protein 90 , in patients with refractory advanced 
cancers. Clin. Cancer Res. 11: 3385-3391.

Randerson-Moor, J.A., Harland, M., Williams, S., CuthbertHeavens, D., Sheridan, E., Aveyard, J., Sibley, K., Whitaker, L., Knowles, M., Bishop, J.N., et al. 2001. A germline deletion of p14(ARF) but not CDKN2A in a melanoma-neural system tumour syndrome family. Hum. Mol. Genet. 10: 5562.

Recio, J.A., Noonan, F.P., Takayama, H., Anver, M.R., Duray, P., Rush, W.L., Lindner, G., De Fabo, E.C., DePinho, R.A., and Merlino, G. 2002. Ink4a/arf deficiency promotes ultraviolet radiation-induced melanomagenesis. Cancer Res. 62: 6724-6730.

Richards, J.M., Mehta, N., Ramming, K., and Skosey, P. 1992. Sequential chemoimmunotherapy in the treatment of metastatic melanoma. J. Clin. Oncol. 10: 1338-1343.

Rimm, D.L., Caca, K., Hu, G., Harrison, F.B., and Fearon, E.R. 1999. Frequent nuclear/cytoplasmic localization of $\beta$-catenin without exon 3 mutations in malignant melanoma. Am. J. Pathol. 154: 325-329.

Rimoldi, D., Salvi, S., Lienard, D., Lejeune, F.J., Speiser, D., Zografos, L., and Cerottini, J.C. 2003. Lack of BRAF mutations in uveal melanoma. Cancer Res. 63: 5712-5715.

Rinehart, J., Adjei, A.A., Lorusso, P.M., Waterhouse, D., Hecht, J.R., Natale, R.B., Hamid, O., Varterasian, M., Asbury, P., Kaldjian, E.P., et al. 2004. Multicenter phase II study of the oral MEK inhibitor, CI-1040, in patients with advanced nonsmall-cell lung, breast, colon, and pancreatic cancer. J. Clin. Oncol. 22: 4456-4462.

Rizos, H., Puig, S., Badenas, C., Malvehy, J., Darmanian, A.P., Jimenez, L., Mila, M., and Kefford, R.F. 2001. A melanomaassociated germline mutation in exon $1 \beta$ inactivates p14ARF. Oncogene 20: 5543-5547.

Robertson, G.P. 2005. Functional and therapeutic significance of Akt deregulation in malignant melanoma. Cancer Metastasis Rev. 24: 273-285.

Robertson, G.P., Furnari, F.B., Miele, M.E., Glendening, M.J., Welch, D.R., Fountain, J.W., Lugo, T.G., Huang, H.J., and Cavenee, W.K. 1998. In vitro loss of heterozygosity targets the PTEN/MMACl gene in melanoma. Proc. Natl. Acad. Sci. 95: 9418-9423.

Rodriguez-Viciana, P., Tetsu, O., Tidyman, W.E., Estep, A.L., Conger, B.A., Cruz, M.S., McCormick, F., and Rauen, K.A. 2006. Germline mutations in genes within the MAPK pathway cause cardio-facio-cutaneous syndrome. Science 311: $1287-1290$.

Ross, P., Hall, L., and Haff, L.A. 2000. Quantitative approach to single-nucleotide polymorphism analysis using MALDITOF mass spectrometry. Biotechniques 29: 620-629.

Ruas, M. and Peters, G. 1998. The p16INK4a/CDKN2A tumor suppressor and its relatives. Biochim. Biophys. Acta 1378: F115-F177.

Rubinfeld, B., Robbins, P., El-Gamil, M., Albert, I., Porfiri, E., and Polakis, P. 1997. Stabilization of $\beta$-catenin by genetic defects in melanoma cell lines. Science 275: 1790-1792.

Rusciano, D., Lorenzoni, P., and Burger, M.M. 1995. Expression of constitutively activated hepatocyte growth factor/scatter factor receptor (c-met) in B16 melanoma cells selected for enhanced liver colonization. Oncogene 11: 1979-1987.

Saldanha, G., Purnell, D., Fletcher, A., Potter, L., Gillies, A., and Pringle, J.H. 2004. High BRAF mutation frequency does not characterize all melanocytic tumor types. Int. J. Cancer 111: 705-710.

Sanchez-Martin, M., Rodriguez-Garcia, A., Perez-Losada, J., Sagrera, A., Read, A.P., and Sanchez-Garcia, I. 2002. SLUG (SNAI2) deletions in patients with Waardenburg disease. Hum. Mol. Genet. 11: 3231-3236.
Sanchez-Martin, M., Perez-Losada, J., Rodriguez-Garcia, A., Gonzalez-Sanchez, B., Korf, B.R., Kuster, W., Moss, C., Spritz, R.A., and Sanchez-Garcia, I. 2003. Deletion of the SLUG (SNAI2) gene results in human piebaldism. Am. J. Med. Genet. 122A: 125-132.

Sanders, B.M., Jay, M., Draper, G.J., and Roberts, E.M. 1989. Non-ocular cancer in relatives of retinoblastoma patients. Br. J. Cancer 60: 358-365.

Sanderson, K., Scotland, R., Lee, P., Liu, D., Groshen, S., Snively, J., Sian, S., Nichol, G., Davis, T., Keler, T., et al. 2005. Autoimmunity in a phase I trial of a fully human anticytotoxic T-lymphocyte antigen- 4 monoclonal antibody with multiple melanoma peptides and Montanide ISA 51 for patients with resected stages III and IV melanoma. J. Clin. Oncol. 23: 741-750.

Sato, M., Morii, E., Takebayashi-Suzuki, K., Yasui, N., Ochi, T., Kitamura, Y., and Nomura, S. 1999. Microphthalmia-associated transcription factor interacts with PU.1 and c-Fos: Determination of their subcellular localization. Biochem. Biophys. Res. Commun. 254: 384-387.

Schmidt, L., Duh, F.M., Chen, F., Kishida, T., Glenn, G., Choyke, P., Scherer, S.W., Zhuang, Z., Lubensky, I., Dean, M., et al. 1997. Germline and somatic mutations in the tyrosine kinase domain of the MET proto-oncogene in papillary renal carcinomas. Nat. Genet. 16: 68-73.

Schon, M., Bong, A.B., Drewniok, C., Herz, J., Geilen, C.C., Reifenberger, J., Benninghoff, B., Slade, H.B., Gollnick, H., and Schon, M.P. 2003. Tumor-selective induction of apoptosis and the small-molecule immune response modifier imiquimod. J. Natl. Cancer Inst. 95: 1138-1149.

Schon, M.P., Wienrich, B.G., Drewniok, C., Bong, A.B., Eberle, J., Geilen, C.C., Gollnick, H., and Schon, M. 2004. Death receptor-independent apoptosis in malignant melanoma induced by the small-molecule immune response modifier imiquimod. J. Invest. Dermatol. 122: 1266-1276.

Sebolt-Leopold, J.S. and Herrera, R. 2004. Targeting the mitogen-activated protein kinase cascade to treat cancer. Nat. Rev. Cancer 4: 937-947.

Segal, N.H., Pavlidis, P., Noble, W.S., Antonescu, C.R., Viale, A., Wesley, U.V., Busam, K., Gallardo, H., DeSantis, D., Brennan, M.F., et al. 2003. Classification of clear-cell sarcoma as a subtype of melanoma by genomic profiling. J. Clin. Oncol. 21: 1775-1781.

Selzer, E., Schlagbauer-Wadl, H., Okamoto, I., Pehamberger, H., Potter, R., and Jansen, B. 1998. Expression of Bcl-2 family members in human melanocytes, in melanoma metastases and in melanoma cell lines. Melanoma Res. 8: 197-203.

Serrano, M., Hannon, G.J., and Beach, D. 1993. A new regulatory motif in cell-cycle control causing specific inhibition of cyclin D/CDK4. Nature 366: 704-707.

Serrano, M., Lee, H., Chin, L., Cordon-Cardo, C., Beach, D., and DePinho, R.A. 1996. Role of the INK4a locus in tumor suppression and cell mortality. Cell 85: 27-37.

Shapiro, G.I. 2004. Preclinical and clinical development of the cyclin-dependent kinase inhibitor flavopiridol. Clin. Cancer Res. 10: 4270s-4275s.

Sharov, A., Tobin, D.J., Sharova, T.Y., Atoyan, R., and Botchkarev, V.A. 2005. Changes in different melanocyte populations during hair follicle involution (catagen). I. Invest. Dermatol. 125: 1259-1267.

Sharpless, N.E. 2004. Ink4a/Arf links senescence and aging. Exp. Gerontol. 39: 1751-1759.

Sharpless, N.E. and DePinho, R.A. 2004. Telomeres, stem cells, senescence, and cancer. J. Clin. Invest. 113: 160-168.

637. 
Sharpless, N.E., Bardeesy, N., Lee, K.H., Carrasco, D., Castrillon, D.H., Aguirre, A.J., Wu, E.A., Horner, J.W., and DePinho, R.A. 2001. Loss of p16Ink4a with retention of p19Arf predisposes mice to tumorigenesis. Nature 413: 86-91.

Sharpless, N.E., Alson, S., Chan, S., Silver, D.P., Castrillon, D.H., and DePinho, R.A. 2002. p16INK4a and p53 deficiency cooperate in tumorigenesis. Cancer Res. 62: 2761-2765.

Sharpless, N.E., Kannan, K., Xu, J., Bosenberg, M.W., and Chin, L. 2003. Both products of the mouse Ink4a/Arf locus suppress melanoma formation in vivo. Oncogene 22: 50555059.

Shen, S.S., Zhang, P.S., Eton, O., and Prieto, V.G. 2003. Analysis of protein tyrosine kinase expression in melanocytic lesions by tissue array. J. Cutan. Pathol. 30: 539-547.

Shinozaki, M., Fujimoto, A., Morton, D.L., and Hoon, D.S. 2004. Incidence of BRAF oncogene mutation and clinical relevance for primary cutaneous melanomas. Clin. Cancer Res. 10: 1753-1757.

Sibilia, M., Fleischmann, A., Behrens, A., Stingl, L., Carroll, J., Watt, F.M., Schlessinger, J., and Wagner, E.F. 2000. The EGF receptor provides an essential survival signal for SOS- dependent skin tumor development. Cell 102: 211-220.

Sidhar, S.K., Clark, J., Gill, S., Hamoudi, R., Crew, A.J., Gwilliam, R., Ross, M., Linehan, W.M., Birdsall, S., Shipley, J., et al. 1996. The $\mathrm{t}\left(\mathrm{X}_{;} 1\right)(\mathrm{p} 11.2 ; \mathrm{q} 21.2)$ translocation in papillary renal cell carcinoma fuses a novel gene PRCC to the TFE3 transcription factor gene. Hum. Mol. Genet. 5: 13331338 .

Sihto, H., Puputti, M., Pulli, L., Tynninen, O., Koskinen, W., Aaltonen, L.M., Tanner, M., Bohling, T., Visakorpi, T., Butzow, R., et al. 2005. Epidermal growth factor receptor domain II, IV, and kinase domain mutations in human solid tumors. J. Mol. Med. 83: 976-983.

Silvers, W.K. 1979. The coat color of mice: A model for mammalian gene action and interaction. Springer-Verlag, New York.

Skvara, H., Thallinger, C., Wacheck, V., Monia, B.P., Pehamberger, H., Jansen, B., and Selzer, E. 2005. Mcl-1 blocks radiation-induced apoptosis and inhibits clonogenic cell death. Anticancer Res. 25: 2697-2703.

Slipicevic, A., Holm, R., Nguyen, M.T., Bohler, P.J., Davidson, B., and Florenes, V.A. 2005. Expression of activated Akt and PTEN in malignant melanomas: Relationship with clinical outcome. Am. J. Clin. Pathol. 124: 528-536.

Smith, R., Healy, E., Siddiqui, S., Flanagan, N., Steijlen, P.M. Rosdahl, I., Jacques, J.P., Rogers, S., Turner, R., Jackson, I.J., et al. 1998. Melanocortin 1 receptor variants in an Irish population. J. Invest. Dermatol. 111: 119-122.

Smith, A.G., Box, N.F., Marks, L.H., Chen, W., Smit, D.J., Wyeth, J.R., Huttley, G.A., Easteal, S., and Sturm, R.A. 2001. The human melanocortin-1 receptor locus: Analysis of transcription unit, locus polymorphism and haplotype evolution. Gene 281: 81-94.

Smolen, G.A., Sordella, R., Muir, B., Mohapatra, G., Barmettler, A., Archibald, H., Kim, W.J., Okimoto, R.A., Bell, D.W., Sgroi, D.C., et al. 2006. Amplification of MET may identify a subset of cancers with extreme sensitivity to the selective tyrosine kinase inhibitor PHA-665752. Proc. Natl. Acad. Sci. 103: 2316-2321.

So, H., Rho, J., Jeong, D., Park, R., Fisher, D.E., Ostrowski, M.C., Choi, Y., and Kim, N. 2003. Microphthalmia transcription factor and PU.1 synergistically induce the leukocyte receptor osteoclast-associated receptor gene expression. J. Biol. Chem. 278: 24209-24216.

Soengas, M.S. and Lowe, S.W. 2003. Apoptosis and melanoma chemoresistance. Oncogene 22: 3138-3151.
Solit, D.B., Garraway, L.A., Pratilas, C.A., Sawai, A., Getz, G., Basso, A., Ye, Q., Lobo, J.M., She, Y., Osman, I., et al. 2006. BRAF mutation predicts sensitivity to MEK inhibition. $\mathrm{Na}$ ture 439: 358-362.

Sondak, V.K. and Sosman, J.A. 2003. Results of clinical trials with an allogenic melanoma tumor cell lysate vaccine: Melacine. Semin. Cancer Biol. 13: 409-415.

Sotillo, R., Garcia, J.F., Ortega, S., Martin, J., Dubus, P., Barbacid, M., and Malumbres, M. 2001. Invasive melanoma in Cdk4-targeted mice. Proc. Natl. Acad. Sci. 98: 13312-13317.

Soufir, N., Avril, M.F., Chompret, A., Demenais, F., Bombled, J., Spatz, A., Stoppa-Lyonnet, D., Benard, J., and Bressac-de Paillerets, B. 1998. Prevalence of p16 and CDK4 germline mutations in 48 melanoma-prone families in France. The French Familial Melanoma Study Group. Hum. Mol. Genet. 7: 209-216.

Speiser, D.E., Pittet, M.J., Rimoldi, D., Guillaume, P., Luescher, I.F., Lienard, D., Lejeune, F., Cerottini, J.C., and Romero, P. 2003. Evaluation of melanoma vaccines with molecularly defined antigens by ex vivo monitoring of tumor-specific $\mathrm{T}$ cells. Semin. Cancer Biol. 13: 461-472.

Stahl, J.M., Cheung, M., Sharma, A., Trivedi, N.R., Shanmugam, S., and Robertson, G.P. 2003. Loss of PTEN promotes tumor development in malignant melanoma. Cancer Res. 63: $2881-2890$.

Stahl, J.M., Sharma, A., Cheung, M., Zimmerman, M., Cheng, J.Q., Bosenberg, M.W., Kester, M., Sandirasegarane, L., and Robertson, G.P. 2004. Deregulated Akt3 activity promotes development of malignant melanoma. Cancer Res. 64: 70027010.

Stambolic, V., Suzuki, A., de la Pompa, J.L., Brothers, G.M., Mirtsos, C., Sasaki, T., Ruland, J., Penninger, J.M., Siderovski, D.P., and Mak, T.W. 1998. Negative regulation of PKB/Akt-dependent cell survival by the tumor suppressor PTEN. Cell 95: 29-39.

Steel, K.P. 1995. Inherited hearing defects in mice. Annu. Rev. Genet. 29: 675-701.

Steingrimsson, E., Moore, K.J., Lamoreux, M.L., Ferre-D'Amare, A.R., Burley, S.K., Zimring, D.C., Skow, L.C., Hodgkinson, C.A., Arnheiter, H., Copeland, N.G., et al. 1994. Molecular basis of mouse microphthalmia (mi) mutations helps explain their developmental and phenotypic consequences. Nat. Genet. 8: 256-263.

Steingrimsson, E., Nii, A., Fisher, D.E., Ferre-D'Amare, A.R., McCormick, R.J., Russell, L.B., Burley, S.K., Ward, J.M., Jenkins, N.A., and Copeland, N.G. 1996. The semidominant $\mathrm{Mi}$ (b) mutation identifies a role for the HLH domain in DNA binding in addition to its role in protein dimerization. EMBO J. 15: 6280-6289.

Steingrimsson, E., Tessarollo, L., Pathak, B., Hou, L., Arnheiter, H., Copeland, N.G., and Jenkins, N.A. 2002. Mitf and Tfe3, two members of the Mitf-Tfe family of bHLH-Zip transcription factors, have important but functionally redundant roles in osteoclast development. Proc. Natl. Acad. Sci. 99: 4477-4482.

Stewart, A.L., Mhashilkar, A.M., Yang, X.H., Ekmekcioglu, S., Saito, Y., Sieger, K., Schrock, R., Onishi, E., Swanson, X., Mumm, J.B., et al. 2002. PI3 kinase blockade by Ad-PTEN inhibits invasion and induces apoptosis in RGP and metastatic melanoma cells. Mol. Med. 8: 451-461.

Stott, F.J., Bates, S., James, M.C., McConnell, B.B., Starborg, M., Brookes, S., Palmero, I., Ryan, K., Hara, E., Vousden, K.H., et al. 1998. The alternative product from the human CDKN2A locus, p14(ARF), participates in a regulatory feedback loop with p53 and MDM2. EMBO J. 17: 5001-5014.

Sturm, R.A. 2002. Skin colour and skin cancer-MC1R, the 
genetic link. Melanoma Res. 12: 405-416.

Takahashi, T., Tagami, T., Yamazaki, S., Uede, T., Shimizu, J., Sakaguchi, N., Mak, T.W., and Sakaguchi, S. 2000. Immunologic self-tolerance maintained by $\mathrm{CD} 25+\mathrm{CD} 4+$ regulatory $\mathrm{T}$ cells constitutively expressing cytotoxic $\mathrm{T}$ lymphocyte-associated antigen 4. J. Exp. Med. 192: 303-310.

Takata, M., Goto, Y., Ichii, N., Yamaura, M., Murata, H., Koga, H., Fujimoto, A., and Saida, T. 2005. Constitutive activation of the mitogen-activated protein kinase signaling pathway in acral melanomas. J. Invest. Dermatol. 125: 318-322.

Takayama, H., La Rochelle, W.J., Anver, M., Bockman, D.E., and Merlino, G. 1996. Scatter factor/hepatocyte growth factor as a regulator of skeletal muscle and neural crest development. Proc. Nat1. Acad. Sci. 93: 5866-5871.

Takeda, K., Takemoto, C., Kobayashi, I., Watanabe, A., Nobukuni, Y., Fisher, D.E., and Tachibana, M. 2000a. Ser298 of MITF, a mutation site in Waardenburg syndrome type 2, is a phosphorylation site with functional significance. Hum. Mol. Genet. 9: 125-132.

Takeda, K., Yasumoto, K., Takada, R., Takada, S., Watanabe, K., Udono, T., Saito, H., Takahashi, K., and Shibahara, S. 2000b. Induction of melanocyte-specific microphthalmia-associated transcription factor by Wnt-3a. J. Biol. Chem. 275: 14013-14016.

Takeda, K., Yokoyama, S., Aburatani, H., Masuda, T., Han, F., Yoshizawa, M., Yamaki, N., Yamamoto, H., Eguchi, N., Urade, Y., et al. 2006. Lipocalin-type prostaglandin D synthase as a melanocyte marker regulated by MITF. Biochem. Biophys. Res. Commun. 339: 1098-1106.

Talebi, T. and Weber, J.S. 2003. Peptide vaccine trials for melanoma: Preclinical background and clinical results. Semin. Cancer Biol. 13: 431-438.

Tang, Y., Kim, M., Carrasco, D., Kung, A.L., Chin, L., and Weissleder, R. 2005. In vivo assessment of RAS-dependent maintenance of tumor angiogenesis by real-time magnetic resonance imaging. Cancer Res. 65: 8324-8330.

Tetsu, O. and McCormick, F. 2003. Proliferation of cancer cells despite CDK2 inhibition. Cancer Cell 3: 233-245.

Tolcher, A.W., Chi, K., Kuhn, J., Gleave, M., Patnaik, A., Takimoto, C., Schwartz, G., Thompson, I., Berg, K., D'Aloisio, S., et al. 2005. A phase II, pharmacokinetic, and biological correlative study of oblimersen sodium and docetaxel in patients with hormone-refractory prostate cancer. Clin. Cancer Res. 11: 3854-3861.

Tron, V.A., Krajewski, S., Klein-Parker, H., Li, G., Ho, V.C., and Reed, J.C. 1995. Immunohistochemical analysis of Bcl-2 protein regulation in cutaneous melanoma. Am. J. Pathol. 146: 643-650.

Tsao, H., Benoit, E., Sober, A.J., Thiele, C., and Haluska, F.G. 1998. Novel mutations in the p16/CDKN2A binding region of the cyclin-dependent kinase-4 gene. Cancer Res. 58: 109113.

Tsao, H., Zhang, X., Kwitkiwski, K., Finkelstein, D.M., Sober, A.J., and Haluska, F.G. 2000. Low prevalence of germline CDKN2A and CDK4 mutations in patients with early-onset melanoma. Arch. Dermatol. 136: 1118-1122.

Tschentscher, F., Husing, J., Holter, T., Kruse, E., Dresen, I.G., Jockel, K.H., Anastassiou, G., Schilling, H., Bornfeld, N., Horsthemke, B., et al. 2003. Tumor classification based on gene expression profiling shows that uveal melanomas with and without monosomy 3 represent two distinct entities. Cancer Res. 63: 2578-2584.

Udart, M., Utikal, J., Krahn, G.M., and Peter, R.U. 2001. Chromosome 7 aneusomy. A marker for metastatic melanoma? Expression of the epidermal growth factor receptor gene and chromosome 7 aneusomy in nevi, primary malignant mela- nomas and metastases. Neoplasia 3: 245-254.

Uribe, P., Wistuba, I.I., and Gonzalez, S. 2003. BRAF mutation: A frequent event in benign, atypical, and malignant melanocytic lesions of the skin. Am. J. Dermatopathol. 25: 365-370.

Valverde, P., Healy, E., Jackson, I., Rees, J.L., and Thody, A.J. 1995. Variants of the melanocyte-stimulating hormone receptor gene are associated with red hair and fair skin in humans. Nat. Genet. 11: 328-330.

van den Oord, J.J., Vandeghinste, N., De Ley, M., and De WolfPeeters, C. 1994. Bcl-2 expression in human melanocytes and melanocytic tumors. Am. J. Pathol. 145: 294-300.

Vande Woude, G.F., Jeffers, M., Cortner, J., Alvord, G., Tsarfaty, I., and Resau, J. 1997. Met-HGF/SF: Tumorigenesis, invasion and metastasis. Ciba Found. Symp. 212: 119-154.

van Elsas, A., Zerp, S.F., van der Flier, S., Kruse, K.M., Aarnoudse, C., Hayward, N.K., Ruiter, D.J., and Schrier, P.I. 1996. Relevance of ultraviolet-induced N-ras oncogene point mutations in development of primary human cutaneous melanoma. Am. J. Pathol. 149: 883-893.

van Elsas, A., Hurwitz, A.A., and Allison, J.P. 1999. Combination immunotherapy of B16 melanoma using anti-cytotoxic $\mathrm{T}$ lymphocyte-associated antigen 4 (CTLA-4) and granulocyte/macrophage colony-stimulating factor (GM-CSF)-producing vaccines induces rejection of subcutaneous and metastatic tumors accompanied by autoimmune depigmentation. J. Exp. Med. 190: 355-366.

Van Raamsdonk, C.D., Fitch, K.R., Fuchs, H., de Angelis, M.H., and Barsh, G.S. 2004. Effects of G-protein mutations on skin color. Nat. Genet. 36: 961-968.

Verastegui, C., Bille, K., Ortonne, J.P., and Ballotti, R. 2000. Regulation of the microphthalmia-associated transcription factor gene by the Waardenburg syndrome type 4 gene, SOX10. J. Biol. Chem. 275: 30757-30760.

Vetrini, F., Auricchio, A., Du, J., Angeletti, B., Fisher, D.E., Ballabio, A., and Marigo, V. 2004. The microphthalmia transcription factor (Mitf) controls expression of the ocular albinism type 1 gene: Link between melanin synthesis and melanosome biogenesis. Mol. Cell. Biol. 24: 6550-6559.

Vlaykova, T., Talve, L., Hahka-Kemppinen, M., Hernberg, M., Muhonen, T., Collan, Y., and Pyrhonen, S. 2002. Immunohistochemically detectable bcl-2 expression in metastatic melanoma: Association with survival and treatment response. Oncology 62: 259-268.

von Willebrand, M., Kohler, K., Alanko, T., Laiho, M., and Saksela, O. 2005. FGF-2 blocks TGF- $\beta 1$-mediated suppression of Bcl-2 in normal melanocytes. Exp. Dermatol. 14: 202-208.

Wada, T. and Penninger, J.M. 2004. Mitogen-activated protein kinases in apoptosis regulation. Oncogene 23: 2838-2849.

Watanabe, A., Takeda, K., Ploplis, B., and Tachibana, M. 1998. Epistatic relationship between Waardenburg syndrome genes MITF and PAX3. Nat. Genet. 18: 283-286.

Weber, A., Hengge, U.R., Urbanik, D., Markwart, A., Mirmohammadsaegh, A., Reichel, M.B., Wittekind, C., Wiedemann, P., and Tannapfel, A. 2003. Absence of mutations of the BRAF gene and constitutive activation of extracellularregulated kinase in malignant melanomas of the uvea. Lab. Invest. 83: 1771-1776.

Weeraratna, A.T., Jiang, Y., Hostetter, G., Rosenblatt, K., Duray, P., Bittner, M., and Trent, J.M. 2002. Wnt5a signaling directly affects cell motility and invasion of metastatic melanoma. Cancer Cell 1: 279-288.

Wellbrock, C. and Marais, R. 2005. Elevated expression of MITF counteracts B-RAF-stimulated melanocyte and melanoma cell proliferation. J. Cell Biol. 170: 703-708.

Wellbrock, C., Ogilvie, L., Hedley, D., Karasarides, M., Martin, J., Niculescu-Duvaz, D., Springer, C.J., and Marais, R. 2004. 
V599EB-RAF is an oncogene in melanocytes. Cancer Res. 64: 2338-2342.

Weterman, M.A., Wilbrink, M., and Geurts van Kessel, A. 1996. Fusion of the transcription factor TFE3 gene to a novel gene, $\mathrm{PRCC}$, in $\mathrm{t}(\mathrm{X} ; 1)(\mathrm{p} 11 ; \mathrm{q} 21)$-positive papillary renal cell carcinomas. Proc. Natl. Acad. Sci. 93: 15294-15298.

Widlund, H.R., Horstmann, M.A., Price, E.R., Cui, J., Lessnick, S.L., Wu, M., He, X., and Fisher, D.E. 2002. $\beta$-Catenin-induced melanoma growth requires the downstream target $\mathrm{Mi}$ crophthalmia-associated transcription factor. J. Cell Biol. 158: $1079-1087$

Willmore-Payne, C., Holden, J.A., Tripp, S., and Layfield, L.J. 2005. Human malignant melanoma: Detection of BRAF- and c-kit-activating mutations by high-resolution amplicon melting analysis. Hum. Pathol. 36: 486-493.

Willmore-Payne, C., Holden, J.A., Hirschowitz, S., and Layfield, L.J. 2006. BRAF and c-kit gene copy number in mutationpositive malignant melanoma. Hum. Pathol. 37: 520-527.

Wiltshire, R.N., Duray, P., Bittner, M.L., Visakorpi, T., Meltzer, P.S., Tuthill, R.J., Liotta, L.A., and Trent, J.M. 1995. Direct visualization of the clonal progression of primary cutaneous melanoma: Application of tissue microdissection and comparative genomic hybridization. Cancer Res. 55: 3954-3957.

Winnemoeller, D., Wellbrock, C., and Schartl, M. 2005. Activating mutations in the extracellular domain of the melanoma inducing receptor Xmrk are tumorigenic in vivo. Int. J. Cancer 117: 723-729.

Wittbrodt, J., Lammers, R., Malitschek, B., Ullrich, A., and Schartl, M. 1992. The Xmrk receptor tyrosine kinase is activated in Xiphophorus malignant melanoma. EMBO J. 11: 4239-4246.

Wolchok, J.D. and Livingston, P.O. 2001. Vaccines for melanoma: Translating basic immunology into new therapies. Lancet Oncol. 2: 205-211.

Wolfel, T., Hauer, M., Schneider, J., Serrano, M., Wolfel, C., Klehmann-Hieb, E., De Plaen, E., Hankeln, T., Meyer zum Buschenfelde, K.H., and Beach, D. 1995. A p16INK4a-insensitive CDK4 mutant targeted by cytolytic T lymphocytes in a human melanoma. Science 269: 1281-1284.

Workman, P. 2004. Altered states: Selectively drugging the Hsp90 cancer chaperone. Trends Mol. Med. 10: 47-51.

Wu, M., Hemesath, T.J., Takemoto, C.M., Horstmann, M.A., Wells, A.G., Price, E.R., Fisher, D.Z., and Fisher, D.E. 2000. c-Kit triggers dual phosphorylations, which couple activation and degradation of the essential melanocyte factor Mi. Genes \& Dev. 14: 301-312.

Wu, H., Goel, V., and Haluska, F.G. 2003. PTEN signaling pathways in melanoma. Oncogene 22: 3113-3122.

Wu, W.S., Heinrichs, S., Xu, D., Garrison, S.P., Zambetti, G.P., Adams, J.M., and Look, A.T. 2005. Slug antagonizes p53mediated apoptosis of hematopoietic progenitors by repressing puma. Cell 123: 641-653.

Wullschleger, S., Loewith, R., and Hall, M.N. 2006. TOR signaling in growth and metabolism. Cell 124: 471-484.

Xing, M. 2005. The T1799A BRAF mutation is not a germline mutation in familial nonmedullary thyroid cancer. Clin. Endocrinol. (Oxf.) 63: 263-266.

Xu, W., Gong, L., Haddad, M.M., Bischof, O., Campisi, J., Yeh, E.T., and Medrano, E.E. 2000. Regulation of microphthalmia-associated transcription factor MITF protein levels by association with the ubiquitin-conjugating enzyme hUBC9. Exp. Cell Res. 255: 135-143.

Xu, G., Zhang, W., Bertram, P., Zheng, X.F., and McLeod, H. 2004. Pharmacogenomic profiling of the PI3K/PTEN-AKTmTOR pathway in common human tumors. Int. J. Oncol. 24: $893-900$.
Yang, G., Rajadurai, A., and Tsao, H. 2005. Recurrent patterns of dual $\mathrm{RB}$ and p53 pathway inactivation in melanoma. J. Invest. Dermatol. 125: 1242-1251.

Yasumoto, K., Yokoyama, K., Shibata, K., Tomita, Y., and Shibahara, S. 1994. Microphthalmia-associated transcription factor as a regulator for melanocyte-specific transcription of the human tyrosinase gene. Mol. Cell. Biol. 14: 8058-8070.

Yasumoto, K., Takeda, K., Saito, H., Watanabe, K., Takahashi, K., and Shibahara, S. 2002. Microphthalmia-associated transcription factor interacts with LEF-1, a mediator of Wnt signaling. EMBO J. 21: 2703-2714.

Yazdi, A.S., Palmedo, G., Flaig, M.J., Puchta, U., Reckwerth, A., Rutten, A., Mentzel, T., Hugel, H., Hantschke, M., SchmidWendtner, M.H., et al. 2003. Mutations of the BRAF gene in benign and malignant melanocytic lesions. J. Invest. Dermatol. 121: 1160-1162.

Yoeli-Lerner, M., Yiu, G.K., Rabinovitz, I., Erhardt, P., Jauliac, S., and Toker, A. 2005. Akt blocks breast cancer cell motility and invasion through the transcription factor NFAT. Mol. Cell 20: 539-550.

You, M.J., Castrillon, D.H., Bastian, B.C., O'Hagan, R.C., Bosenberg, M.W., Parsons, R., Chin, L., and DePinho, R.A. 2002. Genetic analysis of Pten and Ink4a/Arf interactions in the suppression of tumorigenesis in mice. Proc. Natl. Acad. Sci. 99: 1455-1460.

Young, J., Barker, M.A., Simms, L.A., Walsh, M.D., Biden, K.G., Buchanan, D., Buttenshaw, R., Whitehall, V.L., Arnold, S., Jackson, L., et al. 2005. Evidence for BRAF mutation and variable levels of microsatellite instability in a syndrome of familial colorectal cancer. Clin. Gastroenterol. Hepatol. 3: 254-263.

Zeitouni, N.C., Dawson, K., and Cheney, R.T. 2005. Treatment of cutaneous metastatic melanoma with imiquimod $5 \%$ cream and the pulsed-dye laser. Br. J. Dermatol. 152: $376-$ 377.

Zhai, S., Yaar, M., Doyle, S.M., and Gilchrest, B.A. 1996. Nerve grow th factor rescues pigment cells from ultraviolet-induced apoptosis by upregulating BCL-2 levels. Exp. Cell Res. 224: 335-343.

Zhang, Y., Xiong, Y., and Yarbrough, W.G. 1998. ARF promotes MDM2 degradation and stabilizes p53: ARF-INK4a locus deletion impairs both the $\mathrm{Rb}$ and $\mathrm{p} 53$ tumor suppression pathways. Cell 92: 725-734.

Zhang, X.D., Borrow, J.M., Zhang, X.Y., Nguyen, T., and Hersey, P. 2003. Activation of ERK $1 / 2$ protects melanoma cells from TRAIL-induced apoptosis by inhibiting Smac/DIABLO release from mitochondria. Oncogene 22: 2869-2881.

Zhiqi, S., Soltani, M.H., Bhat, K.M., Sangha, N., Fang, D., Hunter, J.J., and Setaluri, V. 2004. Human melastatin 1 (TRPM1) is regulated by MITF and produces multiple polypeptide isoforms in melanocytes and melanoma. Melanoma Res. 14: 509-516.

Zhuang, L., Lee, C.S., Scolyer, R.A., McCarthy, S.W., Palmer, A.A., Zhang, X.D., Thompson, J.F., Bron, L.P., and Hersey, P. 2005. Activation of the extracellular signal regulated kinase (ERK) pathway in human melanoma. J. Clin. Pathol. 58: 1163-1169.

Zuo, L., Weger, J., Yang, Q., Goldstein, A.M., Tucker, M.A., Walker, G.J., Hayward, N.K., and Dracopoli, N.C. 1996. Germ-

line mutations in the p16INK4a binding domain of CDK4 in familial melanoma. Nat. Genet. 12: 97-99. 


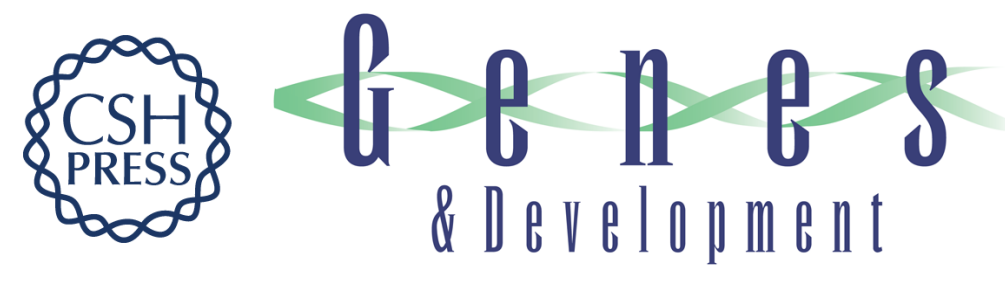

\section{Malignant melanoma: genetics and therapeutics in the genomic era}

Lynda Chin, Levi A. Garraway and David E. Fisher

Genes Dev. 2006, 20:

Access the most recent version at doi:10.1101/gad.1437206

References This article cites 377 articles, 143 of which can be accessed free at: http://genesdev.cshlp.org/content/20/16/2149.full.html\#ref-list-1

License

Email Alerting Receive free email alerts when new articles cite this article - sign up in the box at the top Service right corner of the article or click here.

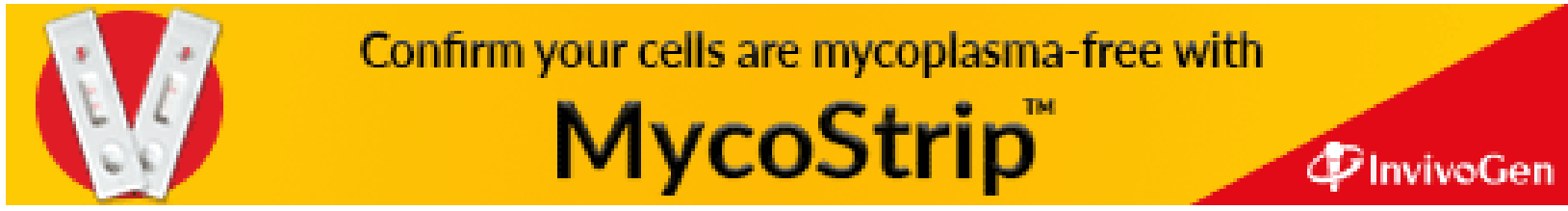

